\title{
Common Agricultural Policy and Local Economy and Development in the Region of Eastern Macedonia - Thrace (Greece)
}

\author{
Th. Markopoulos
}

Department of Oenology and Beverage Technology, Eastern Macedonia and Thrace Institute of Technology, Drama, Greece

Received 24 March 2019; Accepted 6 May 2019

\begin{abstract}
The current article details the impact of the Common Agricultural Policy (CAP), particularly the impact of each CAP reform on agricultural production and the rural economy in the region of Eastern Macedonia-Thrace (EMT), Greece, done via an econometric approach employing Factor Analysis techniques and Structural Equation Model. Detailed qualitative and quantitative data were obtained through structured questionnaires completed during in-depth interviews of the scientific staff working in regional agriculture and were subsequently used to build a Structural Equation Model. This scientific work was undertaken twice, each time following successive CAP reforms, in order to evaluate immediate impact, not only on the Local Economy, but the continuing regional Local Development. Following the comparison of the two successive reforms SEMs, a series of sectoral comparisons of the two reforms was undertaken to clarify the differences between the two specific reforms.It is concluded that the 2003 reform has had a negative impact on the local EMT economy compared to the 2014 reform, which appears to have contributed more favourably to the local economy and regional development, with Land Value-Purchase, Land Value-Hire, Product processing, Labour hands (harvesting, standardization, packaging etc) and Purchase of inputs (pesticides, fertilizers, supplies, etc.) being the local economy sectors that have responded positively to the second reform.
\end{abstract}

Keywords: CAP, Local Economy, Local Development, Land Value-Purchase, Land Value-Hire, Product processing, Labour hands, Purchase of inputs, Eastern Macedonia - Thrace, Factor Analysis, Structural Equation Modelling

\section{Introduction}

The Common Agricultural Policy (CAP) constitutes the common European policy that consumes most of the European Union (EU) budgetary resources. However, the EU's agricultural policy is not a static one but is dynamically policy under the influence of the EU's treaties and decisions. Therefore, a thorough study of this European Union policy and its impact on all sectors as well as at all levels is important.

The dynamically evolving nature of the CAP makes a simultaneous study of at least two European agriculture reforms to assess the correlation between between each reform and to draw conclusions about the changes occurring, effects on both the agriculture and the wider economy. In this context, the current scientific study attempts to capture the relationship between the effects of two reformed and evolving CAP, and the state of the local economy, not by recording one or more elements, e.g. production, sales, earnings, EU support (subsidies), etc., but through the rounded views of those scientists involved in the agricultural production and who scientifically cover all aspects of agricultural production, including consultation to farmers in modern contemporary farming that are affected by the CAP reforms.

The East Macedonia-Thrace (also known as "Anatoliki Macedonia-Thraki") is one of 13 regions in Greece. It is the

*E-mail addres thamarkopoulos@yahoo.gr ISSN: $1791-2377$ @ 2019 Eastern Macedonia and Thrace Institute of Technology. All rights reserved. doi:10.25103/jestr.122.25 most remote continental region of the country, being located in the North-eastern point of Greek territory and borders with Bulgaria (an EU member state) and Turkey. The agriculture sector is an important part of the regional economy. Important products (mainly from the western side of the region) include fresh fruits and vegetables, a high proportion of which (grapes, kiwi, asparagus and so on) is standardized, certified and exported with significant benefits to the local and national economy. The central and eastern parts of the Region are dominated by cereals, cotton and other field crops. The local economy is de facto affected to a significant degree by the specific applicable CAP and its amendments. (The detailed description of the Region is given in the next chapter).

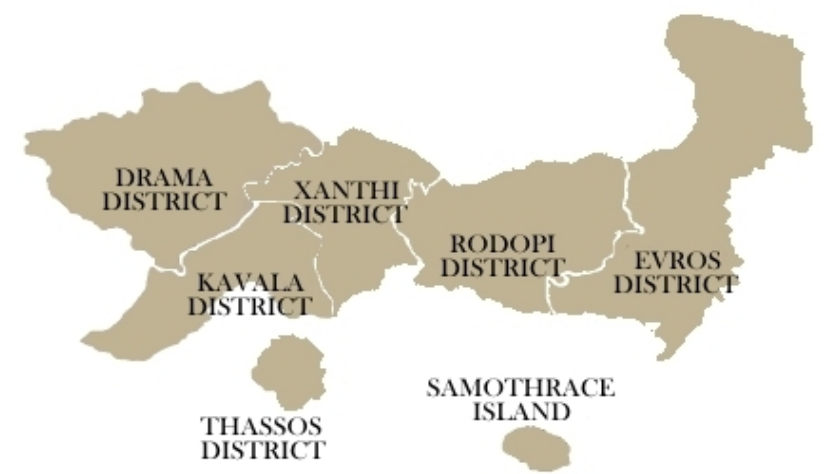

Fig. 1. The map of the East Macedonia-Thrace 


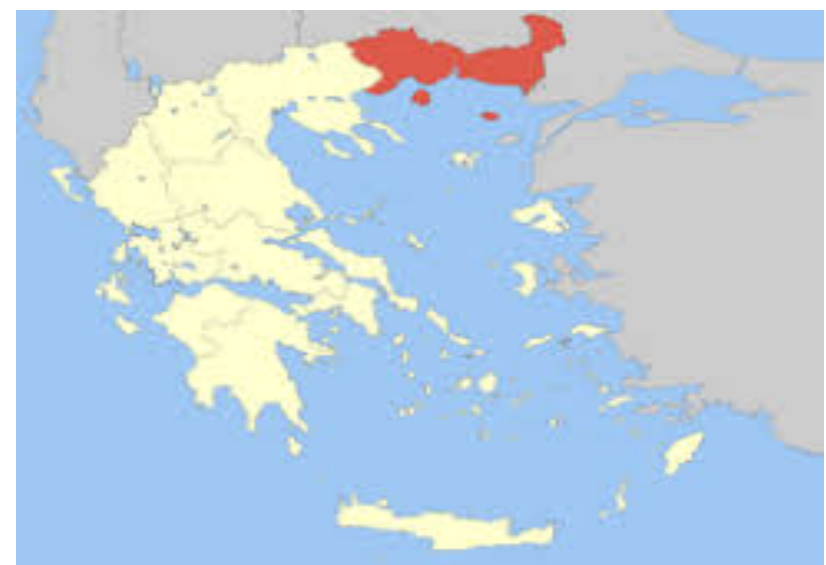

Fig. 2. The East Macedonia-Thrace and its position in Greek territory

CAP was introduced by the EU to improve the quality of life of a constantly-changing society that is still influenced by many different factors changing over time, depending on seasonal requirements [1]. Within this framework, CAP is influenced by the very needs of society and regular attempts to diversify or improve its priorities with the EU decisions in order to more effectively achieve its objectives [2].

If we want to give an acceptable but practical definition of the CAP then we can state that based on an EU-funded information campaign website in Cyprus, that "The Common Agricultural Policy (CAP) is the integrated agricultural policy of the Member States - EU members in order to help European farmers meet the needs of 500 million European citizens. The main objective of the CAP is to ensure a stable and safe food supply at affordable prices for consumers while ensuring a fair standard of living for farmers. The CAP includes a set of laws and regulations about agriculture, livestock farming and the movement of agricultural products, regulating price stability, product choice and quality, land use and employment in the agricultural sector." [3]. Also, from the same source, the objectives of CAP, as a matter of urgency and popularity, include:

- "Food sufficiency and safety;

- Price stability in agricultural products;

- Sustainable rural economy; and

- Respect for the environment and the sustainable use of natural resources".

It is commonly accepted by the EU that agriculture constitutes a special sector of the European economy differing from other sectors. In fact, the differences focus on the specific characteristics of agricultural production, in particular, with regard to food production and food security. In a relevant E.U. edition (2012) the following peculiarities of agriculture that differentiate it from other sectors of the economy, are noted (in the following Table 1)

Table 1. Particular features of agriculture that differentiate it from other sectors of the economy.

\section{Natural}

- Dependence on the environment

- Seasonality of many activities

- Production dangers

\section{Structural}

- Large number of producers/large numbers of small farms

- Geographical dispersal of production units
- Low mobility of production factors

- Human Resources

3. Economics

- Low productivity of the production factors

- Conditions that are close to the perfect competition

- Small elasticity

Thus, the CAP, in its successive, evolving forms, materializes unquestionably and decisively, both in the agricultural sector of all the European regions as wells as in the wider rural sector. However, as the agricultural and farming sectors constitute an important part of the local economy, the consequences of CAP are spreading to the local economy as well. It is also accepted that the strongest impacts are exercised on the so-called "rural" areas, i.e. in those areas where the agricultural and farming contribute higher percentages to the local economy. A CAP-based review has highlighted its consequences on local economy in Greece [4]. Indeed, in today's era, characterized by a longstanding economic crisis plaguing Greece, the role of agriculture has extra special importance and value. Accordingly, it has been suggested by scientists that "agriculture is a powerful tool of rural development in the current economic crisis although its significance for the economy has severely downgraded since agriculture's contribution to GDP has substantially reduced and agriculture's employment reached the lowest levels. Even though, decisions which drive efforts towards reviving rural areas, via agricultural activities sometimes are either totally suspended or undermined and this causes devastated effects upon the rural economy, finally" [5].

In any case, before examining the CAP's impact on the economy and the development of the Greek and European regions, the review and illustration of an approach of the historical path of the CAP is particularly important, since the last 60 years has seen many amendments to CAP by the EU, but the goals it pursues have also been radically modified under the weight of a series of determinant factors.

The first form of the Agricultural Policy was institutionalized with the Treaty of Rome in 1957, in a postwar era with strong nutritional deficiencies, but also with uncertainty in the rural sector of the then "European Economic Community". CAP's aim was the increase of agricultural production to meet the particularly high demand for agricultural products, both at a European and international level. Within this pretext, intensive farming was given a boost, providing the appropriate incentives to maximize production while ensuring high prices and a stable standard of living for producers [6]. In 1958 the CAP guidelines were put forward at the "Stresa Conference", while the beginning of its effective implementation dates back to 1962 .

By striking a balance between agricultural product supply and demand, new challenges and needs emerged, both at the European and international level. Since the early 1980s, a disruption of this supply and demand balance began with an increase in production at levels that could not be absorbed. During the course of CAP implementation, a technical upheaval was created in the markets, and as a result both consumers and farmers began criticizing this policy of intensive cultivation [7].

The intensification of the agricultural production also imposed a burden on the environment, as it formed an uncontrollable increase in inputs, without an effective control of product quality, with parallel effects on soil and 
groundwater (Beopoulos, 1996). Thus, since the beginning of the 1990s, an activation of consumers' environmental consciousness emerged and pushed for a radical overhaul of CAP that would also include basic environmental parameters in the pursuit of a rural policy, as the rational use of natural resources indeed started to constitute a desirable process of sustainable agriculture [8]. At the same time, various European nutritional scandals increased consumers anxiety on food safety and safe working conditions, as well as animal welfare.

In addition, over the years, a need emerged to adapt the EU agricultural policy to the principles of the General Agreement on Tariffs and Trade (GATT) and the World Trade Organization (WTO), thus at the beginning of 2000 and 2003 creating the conditions for new CAP reform. This treaty was assisted by both the suffocating demands of the markets for quality agricultural products [9], but also by many non-government environmental organizations, which indirectly imposed more environmentally-friendly methods of production.

It is worth mentioning that already, as of 1992, MacSharry, as the Commissioner for Agriculture, had attempted a first major reform of CAP, marking the fall in agricultural product support prices and the introduction of accompanying measures, which mainly concerned environmental protection and product quality [10]. Additionally, with this reform came the implementation of the EEC 2092/91 Regulation and the introduction of a significant number of agro-environment and other subsidized programmes (e.g. early retirement, organic farming / stockbreeding, reforestation) which had an impact, not only on agriculture, but also more widely on society and the local economy.

In 2000, the European Commission published the socalled "White Paper" in order to protect the health of the EU citizens from the consumption of agricultural products. Its goal was food safety through the safe production, storage, movement and disposal of agricultural products to consumers [11]. At the same time, the concept of "from the farm to the fork" was introduced, as well as the term "traceability" which, through the (EC) 178/2002 Regulation, becomes mandatory throughout the whole supply chain of agricultural products [12].

"The Action Program - Agenda 2000" is an extension and deepening of the 1992 MacSharry reform [13]. The European Commission's objective began to highlight, with increased importance, the assurance of the coherence of EU policies, as they now had to converge with the conflicting objectives including the enlargement of the EU and the integration of the new EU Member States, without increasing the budget, ensuring, inter alia, the continuity of the EU's rural policy.

Following previous reforms, CAP was called upon to play an important and more multifaceted role. Thus, with its latest reforms, CAP is now significantly strengthening the production of quality agricultural products with environmental sensitivity, discouraging agriculture that does not comply with the established codes of good agricultural practice included in the Multiple Compliance framework established in 2003.

The European Commission once again reformed CAP in 2003 following the proposal of the then Commissioner for Agriculture, F. Fischler, taking on one hand the enlargement of the EU into account, and on the other hand, taking into account the negotiations with the World Trade Organization (WTO), and the agreements for agricultural products in the
Doha and Uruguay rounds. This was the strongest and most radical reform of the $\mathrm{CAP}$ to date, with main objective remaining the environmental orientation of agriculture through the production of quality and safe products, since there had been strong pressure both from environmental organizations and consumer institutes. Thus, within a framework of improved regulation, the main principles adopted were:

- The decoupling of the Community subsidies from production. Subsidies are now calculated on the basis of the historical criteria for the reference period;

- The abidance of the Multiple Compliance by the agricultural holdings as a mandatory condition for the payment of aid (Reg. 1782/03);

- The retribution of rights;

- The implementation of Traceability and Integrated Management Systems (Reg. 1783/03);

- The provided options available to each Member State for the partial or full implementation of some measures;

- The Common Market Organizations (CMOs) and the provision of aid to Producer Organizations;

- The communication and informing of producers and consumers, etc.

A dominant element in this CAP reform is indeed the socalled "decoupling" of EU subsidies from production, a fact that had a significant impact not only on the types of cultivated crops but also on the mode of production as well as on the behavior and decision-making of producers, in general. In the end, both the effectiveness as well as the "extent" of these CAP measures were differentiated from state to state, taking into account the possibility for member states to form the precise implementation of some measures, such as the percentage of decoupling [14] within certain limits. However, at a general level, these reforms were estimated to have had a positive effect on the support of the rural income while at the same time reducing the negative impact of the agricultural activity on the environment [15].

The so-called "Health Check" of the CAP in 2009, reinforced the 2003 reform measures, by modernizing the control procedures, while it launched a further reduction in the expenditure for market support mechanisms to $10 \%$ which took place gradually by 2008 .

The European Commission instituted the so-called "Quality Package" in December 2010, in order to help producers to highlight the specific characteristics of their products and the comparative advantages of their production processes, thus ensuring better consumer information[16].

The agricultural policy which was adopted at that time and was implemented with the most recent reform of 2014 and with effect until 2020 is strongly linked to the EU's financial perspectives, with clear references to resource reduction, stabilization of cohesion-oriented expenditure in favor of the poorest new members and increasing resources for Research, Development and Innovation. The objectives of the current CAP are to strengthen competitiveness and sustainable agriculture, the adoption of good agricultural practices and the safekeeping of agriculture and employment in the region, particularly in disadvantaged areas. The structure of the new CAP 2014-2020 with the two pillars remained the same as the previous one.

It should be noted that the first pillar concerns the whole of the European Union and includes the annual EU-funded subsidies that are paid to all farmers in order to meet the 
major challenges that the European agriculture has to face. Direct payments have been designed to be the dominant measure of the CAP as well as a safety valve for the farmers' income to avoid intensifying or abandoning agriculture, in line with the texts accompanying this CAP reform. Income subsidies continue to be linked to Cross-Compliance in order to ensure the quality but also the protection of the environment and of natural resources. Accordingly, additional subsidy is provided for the production of quality products, produced with environmentally-friendly production processes (e.g. organic products or integrated management products). In order to address the reduced competitiveness and uneven distribution, particular attention is given to mountainous and disadvantaged areas, but also to the viability of small and medium-sized agricultural holdings, which have a significant contribution to employment.

The second pillar is co-funded by the communal and national budgets and in some cases by the farmers themselves. This Pillar has been designed to enhance the regional rural development by promoting the necessary structural changes that allow for a more flexible and higher added-value transition to a rural economy. It also launches its positive contribution to the environment and green growth, while allowing better targeting for a sustainable agriculture, incorporating new knowledge and technological innovations. An important element of the second pillar is that it provides the important advantage to the member state to be able to specify its political priorities. In addition, one of the objectives of CAP, according to the current conditions, is the organization of the agricultural markets, in order to ensure an adequate level of supply to the market with quality and safe food, and an adequate income for the producer [10].

With the introduction of the second pillar, the rural development of regions was further boosted; also the social and environmental objectives of the CAP were strengthened, as the pillar measures are also geared towards the market, marketing, competitiveness and the quality of agricultural products [17]. The effort was reinforced by the introduction of the Cross-Compliance as a condition for payment. All this grid of changes introduced in the CAP caused a rapid change and, as it has also been pointed out, it should be added that reform and the CAP formulation affect the behaviour of farmers [18].

It is worth mentioning that, in this way, the EU security of commodity products is a strategic choice of the new CAP. The supply chain for agro-food products has been for many years, a key link to the sustainability not only of the agriculture but of the economy as a whole [19]. The smooth operation of the whole agro-food chain from the farmer to the consumer also aims to provide a guarantee for keeping thousands of jobs in a competitive and unstable environment. This is supported by the Community initiatives such as the promotion of local products, the promotion of contract farming, the traceability of products, and the creation of local markets for the auctioning of agricultural products.

In addition, the EU's current 2014-2020 Agricultural Policy is called upon to address not only the effects of the accession of the new Member States but also the current economic crisis and climate change in order to adapt policies to the new data that have rapidly developed. The CAP is also directly linked to the new "Europe 2020" strategy for growth and jobs, adapting the objectives of the Treaty of Lisbon to the new conditions. It also provides for the reduction of differences between the producers by reducing or increasing, where appropriate, the entitlements established by the previous CAP, while also seeking to reduce the different levels of EU subsidies granted per hectare between the Member States and, in particular, those of the younger members more than the oldest EU Member States.

More specific scientific studies have shown both the impact of the CAP on the other sectors of the local economy as well as the importance of some crops that farmers ultimately choose or not to cultivate. Such is the characteristic example of tobacco and related scientific study, which inter alia states that: "The importance of some crop sectors can be better cast in a broader framework to account for intersectoral effects in local economy. In this respect, employment, income, and output multipliers were estimated to demonstrate the dynamics of the agricultural sector at the regional and national levels. A serious example is the impact of totally eliminating of the controversial crop of tobacco cultivation was computed. Results clearly demonstrate the significance of the tobacco sector and its interrelation with the rest of the economic sectors." [20]. In particular, in this scientific study, it was calculated for the Eastern Macedonia-Thrace Region, that a reduction of $11.9 \%$ in employment, $11.9 \%$ in household income generated, and $9.5 \%$ in total regional output would occur if tobacco cultivation were to cease.

The implementation of CAP and the reforms that took place since its inception caused a number of important effects on most of the crops, on the way of cultivation and production and on the use of the needed inputs. These effects, furthermore, extended to a wider range of subjects, such as transportation and product trade, producer investments and strongly affected all the other sectors of the local economy and of course the development of each area. Scientific studies [4] looked at the outcome of CAP at agriculture or widely at local economy totally, in rural areas; Table 2, which follows below, shows an outline of the assessments regarding the impacts on the main crops of the Region of Eastern Macedonia-Thrace since this radical reform of CAP in 2003, according to the views of the scientific staff working in the region's agriculture. It should be noted that these views are not far from the actual changes in the crops which were recorded on the fields of land. It is also worth mentioning that five (5) years after the current reform of the CAP is applied, a corresponding table will be attempted anew.

\section{Literature Review}

\subsection{Scientific research and conclusions on the CAP and} its implications"

As mentioned in the introduction, this specific scientific study deals with a series of issues that aims to deepen the long-term consequences of CAP on the local economy and the evolving development of the Region of Eastern Macedonia-Thrace through CAP's two recent reforms (2003 and 2014). A scientific methodology is used to study the changes caused by the implementation of the current twice reformed CAP on the local economy and local development, whilst making use of the data available in the international bibliography. 
Table 2. Consequences on specific crops or categories of crops, from the 2003 CAP reform, according to the views of the scientific staff working in agriculture in the Region of Eastern Macedonia - Thrace.

\begin{tabular}{|c|c|c|c|c|c|}
\hline . & $\begin{array}{l}\text { High decrease of } \\
\text { cultivated areas }\end{array}$ & $\begin{array}{c}\text { Decrease of } \\
\text { cultivated areas }\end{array}$ & $\begin{array}{c}\text { Steady cultivated } \\
\text { areas }\end{array}$ & $\begin{array}{c}\text { Increase of } \\
\text { cultivated areas }\end{array}$ & $\begin{array}{l}\text { High increase of } \\
\text { cultivated areas }\end{array}$ \\
\hline Table grapes & & & & & \\
\hline Wine vineyards & & & & & \\
\hline Olive trees & & & & $=$ & \\
\hline Orchards & & & & & \\
\hline Asparagus & & & & & \\
\hline $\begin{array}{l}\text { Bostan (watermelons, } \\
\text { etc.) }\end{array}$ & & & & & \\
\hline Potatoes & & 1 & & & \\
\hline Beans & & & $\square$ & & \\
\hline Other legumes & & & & & \\
\hline Vegetables & & & & & \\
\hline Ornamental plants & & & & & \\
\hline Tobacco & $\square$ & & & & \\
\hline Cotton & & & & & \\
\hline Sugar beet & $\square$ & & & & \\
\hline Industrial Tomato & $\square$ & & & & \\
\hline Sunflower & & & & & \\
\hline Hemp & & & & & $=$ \\
\hline Corn & & & & & \\
\hline Soy & & & С & & \\
\hline Rice & & & & & \\
\hline Durum Wheat & & & & & \\
\hline Bread (or Soft) Wheat & & & & & \\
\hline Barley & & & $\square$ & & \\
\hline Alfalfa and clovers & & & & & \\
\hline $\begin{array}{l}\text { Aromatic } \\
\text { Plants }\end{array}$ & & & & & \\
\hline
\end{tabular}

Source: [21]

The impact of CAP implementation and its reforms on farming and the wider agricultural sector is important in the international bibliography. However, references related to the impact on the local economy of a region or the course of its development, are significantly limited. In particular, it becomes obvious that there is no detailed inventory of the reformed impacts and consequences of the CAP on the various sectors of economic activity, in the Region of Eastern Macedonia-Thrace. In this context, it is important to quote the bibliographic scientific references, which are mainly related to the recent CAP reforms that have direct or indirect effects, both on the agricultural and rural sectors, as well as the local economy and the development of the regions.

2.2 Concerning the 2003 reform and other related issues of the CAP 
As stated in the introduction, the 2003 CAP reform was a profound, radical change - a reformation that replaced a well-established practice of providing support to agriculture that had been in place for decades and at the same time formed the basis for the next 2014 reform, which is in effect and is currently being used. Thus, since then, the decoupling of the EU subsidies from production has been introduced as Single Farm Payment (SFP) Scheme. The SFP has introduced the payment of the decoupled single farm support, based on the 'reference period', which has shaped the amount and value of allowances. This specific reform, set, at the same time, the creation of the commitments of the Cross-Compliance, which also includes on the one hand, the environmental aspect of the CAP and on the other hand, initiated the transfer of funds from Pillar 1 to Pillar 2 through the so-called diversification. The reform of CAP that took place in 2003 and went into force in 2004, leaving room for national choices by the Member States that have in this way defined the implementation of the CAP format in each country [22], [23]. This radical change also affected the finance of farmers and their way of working, resulting in clear changes in the local financial development of each rural area [21], [24]. Additionally, the 2003 CAP review has been shown to affect the production practices of major crops such as cereals [24].

Another important point of change of the reform, which should be mentioned, is the decision that the decoupling of subsidies from production did not have a uniform power for all products, as for certain products, such as cotton and rice, a partial link of subsidies to production was maintained [25]. In any case, it should here be noted here that the specific change that the EU brought into CAP caused even stronger effects in agriculture and beyond in Greece, since the country, in the context of the possibilities provided in order to made national choices, chose the full decoupling of production subsidy. Thus, the associated EU subsidies in Greece were limited to a few crops with the most typical examples being cotton and rice. So, through this reform, the fully-decoupled new regime of the decoupled Single Farm Payment (SFP) scheme was introduced.

In the context of these changes, it has been claimed that the reduction of the importance of agriculture in the economy of many rural areas in the EU has led to a "postproductivist" era as it was called, where the rural economy is now being driven by non-agricultural and consumption needs (Slee, 2005). Slee argued that factors such as greater wealth and mobility have increased the tendency for nonproduction based on land use and that, furthermore, these are the factors which are the predominant drivers for economic change. Therefore, it was estimated that the acknowledgement of these factors could lead to a more innovative approach of development. However, Burton and Wilson (2006) formed a different opinion, as they argued that despite the emphasis on the change of agriculture, farmers themselves continue to rely on production [22]. As a result, moves towards a "post-productive" behaviour are, at least in the short and long term, supported by strong productive identities, and therefore, despite the changes towards the direction of post-productivism at a local and national level, they do not take place in the so-called lower classes. Thus, data from South-East England [26] had confirmed that the decision-making process of many farmers is based on production and that involvement with the policy revision measures only occurs when they do not contravene with the primary objective. It was argued earlier that this different character of agricultural households in their ability to adapt to and adopt the changing agrarian policies (Shucksmith and Herrmann, 2002) has implications as far as the implementation of rural development and of the wider development of the region is concerned. The diversity of the various regions, from an agricultural point of view, both within and between the EU Member States implies that despite the common problems that exist, there is need for flexibility in the policy to allow for more specific support, which depends on the special productive and social needs and conditions of the region.

At the same time, with the challenges posed back then by the implementation of the CAP, it was argued that this shifting of emphasis also requires a change in the way rural development initiatives are being evaluated. Hodge and Midmore (2006) argued that rural development had already undergone a fundamental change since those years, with profound implications on the assessment of the policy[27]. Rizov studied the impacts of prosperity from CAP, which, as argued, evolved from a policy of support of the agricultural product to an integrated rural development and the use of the environment [28], [29]. Rizov concluded that the redistribution of CAP subsidies could have significant consequences on communal rural development and household welfare, but that this impact depends on household technology, which contribute to growth at their existing levels in the contribution and shaping of the form of EU development

It was estimated by scientists that the wider rural area labour market was able to take over all the excess labour force from agriculture and thus was in the position to meet the demand for wage labour in the agricultural sector [30].

Earlier on, under the so called "Agenda 2000" review programme, the mid-term review of the 2000-2006 period had already been decided. So, in July 2002 the then EU Agriculture Commissioner, Franz Fischler, presented the text "Mid-term review of the Common Agricultural Policy". The objectives of the (then) new reform were those set out at the European Council in Berlin in 1999 and, respectively, in Gothenburg, Sweden in 2001 [25]. The primary objective was to establish a competitive agriculture and at the same time a good standard of living, as well as income stability for those employed in the agricultural sector, with whatever this implies for society and the economy. An important goal was also the adoption of environmentally-friendly production methods in order to produce quality products for consumers [25]. Yet another EU objective was the existence of the diversity of the agricultural activities alongside the respect for the natural environment and the support of agricultural societies. It is important that the aforementioned EU objective does not concern a simple agricultural policy but essentially it also includes a clear division of responsibility for the application and implementation of the policy between the European Commission and the Member States [25]. Furthermore, the EU, in addition to pushing the CAP in order to make it more of a benefit policy, also recommended a more integrated development of the rural sector [25]. Finally, the EU text which was adopted by the Council in June 2003 had the title "Long-term political outlook for a sustainable agriculture" and set out the main axes for the new and different CAP. It is worth mentioning that the achievement of an increase in wealth and cohesion within the EU, without any prospect of an increase in the EU's agricultural policy budget appearing anywhere is included as an objective (http://www.europa.eu).

The first change had to do with the switch from product support scheme to the producer support scheme (Cunha, 
2004). In particular, the subsidies received by the producer in order to produce his products would now be paid to him as a single payment without the EU's agricultural policy taking into account the fact of production or products [31]. It is of extreme importance the introduction of the decoupling from production with a view to balance better the producers' incomes through the single decoupled subsidy per agricultural holding, and ultimately avoiding the overproduction of surpluses so that, through decoupling, there is a balance of supply and demand, whilst maintaining farmer incomes. In this context, it was estimated that the farmer could decide which crop he would prefer to cultivate without risking the loss of the EU subsidy, which he would still continue to receive in order to secure his income [26]. The decoupling of subsidies from the productive process, with its radical character, affected not only the way and levels of agricultural production, but also the local economy and society. The abolition of the connection between subsidies and production, was expected to make EU farmers more competitive, more market and consumer-oriented and provide the necessary income stability in rural areas [32]. Ultimately, however, it is questionable whether this has actually been achieved [4], [21].

An additional significant change was introduced and is valid until today and is directly related to the previous point, is that of Cross-Compliance, as it determines the environmental measures which must be followed as a condition for the beneficiary to receive the amount of EU subsidies ratio [26]. The producer is required to comply with all animal welfare standards, adhere to the rules on food safety and quality and produce by respecting land and soil components. All these prerequisites are described as CrossCompliance and it is clear that in the case the producer does not follow the rules, the EU imposes on him financial cuts or the full deduction of subsidy [26], [33]. The rules and criteria that the farmer must now adhere to in order to obtain direct payments are laid down by Regulation 73/2009. Council Regulation 73/2009 while there are other regulations and directives specifying the measures per category (environment, animal welfare, etc.).

In addition, in 2003, it was decided to gradually phase out the direct payments by $3-5 \%$ per year by 2012 , with the exception of producers whose direct EU subsidy received does not exceed $€ 5,000$. The reduction in direct payments to large agricultural holdings was called diversification. The amounts that would be saved were designed to be transported by $80 \%$ to the Member States from which they were obtained, while the remaining amount would be available to other Member States on the basis of particular criteria such as the agricultural land, labour force in the agricultural sector, per capita gross domestic product, etc [25].

At the same time, the EU created a financial discipline mechanism to ensure that the amount corresponding to agricultural spending in the Community budget will not be exceeded in the future [32]. It is therefore important that the changes of the two recent reforms have a positive impact on the EU budget, as on the one hand, the expenditure on direct payments was consolidated so as to avoid an increase in the burden of the budget, while on the other hand, a part of the expenditure was already transferred from the first pillar (production support) to the second (rural development) [25]. Here, it should be mentioned that $1.27 \%$ of GDP was set as the budget limit for rural spending [34]. It is also important that with these decisions, the EU harmonized its policy with the World Trade Organization [35], [36].
The current CAP, with this specific reform (but, in fact, and with the next reform of 2014), attempted to boost and provide incentives for rural development, by helping to maintain dynamic agricultural communities so that they can in their turn create employment opportunities, as it was scientifically pointed out four years after the implementation of this CAP reform [33].

Even before the implementation of the specific form of $\mathrm{CAP}$, in the context of work on the evaluation of the Agenda 2000 reform, for each of the 15 Member States of the European Union, significant research was carried out by the Center for Rural Economy, University of Newcastle Upon Tyne [37]. The researchers took into account the agricultural and non-agricultural feedback consequences, and the bilateral links with the rest of the world. The framework of the model incorporated precise representations of the CAP's interventions and the surrounding Uruguay WTO reforms, but did not take into account the enlargement of the European Union. An analysis of the Comprehensive General Equilibrium (CGE) of the CAP reform was carried out by using the "Global Trade Analysis Project" (GTAP). The simulations examined both the Agenda 2000 reforms and the full commitments of the Uruguay Round. The main findings of their analysis, at a European Union level, showed that the grain sector was going to face a reduction of production due to the reduction of subsidy prices and the increase of the cessation of the farming area. It is worth noting that in some sectors, such as cereals and animal products, a negative element of support emerged from the support of the products used as inputs in these sectors. In the livestock product sectors, the European breeders would buy their grain-based fodder at much higher prices than the international ones. The cattle sector would face a reduction in production, with the exception of Greece, Ireland and Denmark, where there was a possibility of a small to moderate increase in production. Generally speaking, the raw milk sector would show an increase in production due to the increase in quotas. The reduction in supportive subsidies was expected to reduce consumer prices for most of the goods of the Member States. Greece was predicted to experience the largest deflationary impact (-5.6\%). Concerning the overall economic prosperity, 14 of the 15 Member States had predicted that they would have a net financial benefit from the reforms, with Spain being the only loser within these estimates. In line with the projected sectoral consequences on the rural income, the arable crop producers in most Member States were expected to be the losers, along with dairy farmers. However, the stockbreeders including those of France and Greece was argued that would be the biggest winners. At EU level, the agricultural households were predicted to have a loss of income as a result of the reforms. The main losers would be in France, Spain and the United Kingdom, but there were small profits which were predicted for the agricultural income of households in Finland, Ireland, Sweden and Austria.

A spatial and dynamic model "AgriPolis" was used to simulate and analyze the effects of Agenda 2000, a revision policy for the regional structural changes in Germany [30], [38]. The model was calibrated on the basis of typical agricultural holdings in the region. For the organization of spatial data, a Geographic Information System (GIS) has been developed. The main results showed that the policies of Agenda 2000, prior to the 2003 reform, seemed to act as an incentive for small agricultural holdings in order to withdraw from the sector and lead larger farms to produce at the lowest cost and to the actualization of scale economies. 
Land prices were estimated to show a dramatic decrease due to decoupling as each farm would spend less on renting land and sought alternative uses of supplementary labour and capital, thus increasing the potential for structural changes. A theoretical Dutch model [39] also examined the Agenda2000 Agrarian Development Regulations and the shifting of attention from the agricultural production to wider rural development, which included altogether the agricultural holdings and the residents who were also outside of the agricultural holdings.

Many scientific papers details the consequences of CAP reform, in a number of areas, such as productivity, sustainability of agriculture, and the expected improvement in competitiveness, even before the formal implementation of CAP reform, which actually started in 2004, due to the radical changes that were included in it. In this context, members of the scientific community claimed, even before the start of the radical implementation of the 2003 reform and the start of a period which last up to today, that full decoupling could lead to a general decline in agricultural activity [40], while these estimates included also the view that the attempted increase in competitiveness involved the risk that many agricultural trade operations (commodities) would become less profitable. At the same time, the reduction in the support provided to the CAP would be significant for important sectors of the agri-food sector, such as cereals [41]. The 2003 reform (as well as later on the one of 2014) had consequences on the whole production process, the farmer behaviour, the choices that farmers adopt, and also on the way they cultivate [18]. It was also estimated that with the introduction of decoupled support, farmers were now faced with an extra increased instability concerning the rural income which they managed to produce [42]. For example, in the case of Scotland [41] it was pointed out that the significant reduction which was foreseen raises questions about the farmers' response and adjustment, under the circumstances which were caused by the specific CAP reform.

In response to the request made in 2003 by the Agriculture Council for a possible policy reform and also to assess the contribution of CAP and the Rural Development Regulation to rural employment (with particular reference to young people and women) a pan-European study entitled "Study on Employment in Agricultural Areas" (SERA) was launched after CAP reform [43]. Fifteen case studies analyzed the state of agriculture in terms of employment and development. Nine of these studies concerned areas in the EU (out of the then 15 members) while a further objective was put forward to examine the consequences of the 2003 CAP reform. Nine of these case studies reflected a wide range of natural conditions, socio-economic characteristics, agricultural holding structures and also size of agricultural holding. The historical downward trend (uniform reduction of $2 \%$ per year) in rural employment was consistent in most study area. The local economy and the labour market conditions, including the structural changes, were generally considered to be the most important determining factors of change arising from CAP reform. Moreover, there was no evidence to prove that the northerner regions of the case studies lost at a slightly faster pace in the field of work, and that the so-called 'pull factors' compared to the rural economy were affected by the rate of exit. Five of the studies were largely characterized by part-time work in agriculture, while the remainder showed a larger average size of the agricultural holdings and high rates of full-time farmer employment. Regarding the impact of the CAP reform, the SERA authors expected that the implementation options chosen by the other Member States to have a profound effect on farming and employment systems, with the greatest changes being expected in areas where full decoupling had been adopted from the beginning. However, it was considered to be too early to try measure the possible consequences of the reforms during the SERA study.

Sckokai and Moro studied before the implementation of the reform, the impact of the consequences on the so-called "cross-culture" cultivation [44]. The results of their study have shown that, since then, the interactions may be important not only for relative price/subsidies, but also for the relative expected fluctuation of production/covariance. For example, while all the cereals rains in their sample had the same proportional reduction in intervention prices and the same increase in area subsidies, the cultivation of durum wheat was becoming all the more attractive to farmers who detested the risk. In conclusion, a series of recurring issues was ascertained in all areas of the study concerning the changes expected due to the 2003 CAP reform, such as the intensification of the farming systems had been predicted through a variety of changes, including the lower farmer prices, the reduced applied fertilizers, the reduced unit work, etc. The process was estimated to be able to cause a significant reduction in employment in the processing sector and in the supply to industries and not to agriculture itself. However, in the case of part-time occupations, which were held by farmers or members of their families, the chaining consequences could have led to a whirl of changes.

In the case of the work undertaken by the Food and Agricultural Policy Research Institute (FAPRI) in Ireland, the 2003 reform impact was examined both in the European Union as a whole, as well as in Irish agriculture. The study predicted that reduction in production levels was likely to have an impact on agricultural employment of these sectors too.

Lobley and Butler conducted a study in Devon (UK) to assess the possible impact of the 2003 CAP reforms on regional agriculture [45]. Apart from developing economic models, they held a farmer's discussion group (representing a wide range of ages, types and sizes of agricultural holdings) to assess opinions on the 2003 reforms. The consequences to Devon's dairy farms were predicted to be negative. However, while the consequences of the modulation of subsidy payments and subsidy per agricultural holding were considered significant, the exploitation of the milk price was considered the key determinant of the future of dairy production in Devon. Overall, the CAP reform and its impact on the revenue generated, was expected to trigger further restructuring of agriculture in this region, with a delay before the full results be experienced.

Ballas et al. developed a socio-economic model to assess the consequences of the policies on rural development and on the plans for Ireland [46]. This model contained geographic information and allowed a regional or local approach to the analysis of the policy. This model, which was called "SMILE" was both static and dynamic, creating the population base and capturing the characteristics of the individuals so as to contribute to the dynamic model. In this survey, the researchers applied the model in order to assess the consequences of the recent CAP reforms on the priority rural areas identified in Ireland's National Spatial Planning Strategy (NSS) and concluded that reforms were likely to reinforce the economic stability of the regions where unemployment was low and those where relatively high numbers of young farmers engaged in dairy products and 
herbivores. Those who were involved in dairy products and maintained grazing animals were recognized as a potentially powerful group after decoupling, and those able to adapt their systems to maximize market yields were predicted to have a good performance. The traditional rural areas of grazing livestock in West and Northern Ireland, where there are high concentrations of cattle were expected to do badly in the context of the CAP reform. These regions also had high unemployment rates and the NSS characterized them as remote, weak and already in need of additional investment.

Various studies examined the consequences of both the Agenda 2000 and the aspects of the 2003 reforms in terms of Austrian labour force demand [15], [47]-[49]. By using the Positive Agricultural Sector Modelling "PASMA", they estimated the production, labour and income through the responses for each of the production units under consideration. The model was calibrated for the history of crop and livestock activities using the Positive Mathematical Programming (PMP). The main results from the different scenarios examined were the following:

- Reference scenario: the welfare of the agricultural holdings (sum of farm surplus for agricultural and forestry activities, direct payments and transfers) slightly increases in the baseline scenario compared to the Agenda 2000 scenario. Also, an increased market of livestock production inflows came about compared to other scenarios, higher cattle production, while income opportunities were not fully exploited,

- Full decoupling: assessed as the lower welfare of farms. The revenue of the product shows a significant reduction. Saving cost of inputs and a more or less unchanged flow of payments will form a better situation for farmers. Also, a possible reduction in agricultural expenditure was estimated and, in addition, the non-full utilization of the competitiveness of farms.

Overall, it was argued that agriculture was to be expected to become more extensive but not necessarily in each region. It was also claimed that there would be more pressure for structural adjustments. This is indeed counterproductive to rural employment but goes hand in hand with the increase of competitiveness. In addition, it has been suggested that there will be a reduction in labour demand due to the shift in production patterns.

Another study, examined the results of the distribution of the CAP tools to the rural income of the agricultural holdings in Austria [15]. The "tools" studied were direct subsidies (Pillar I) and the rural development programs (Pillar II), the latter being differentiated in terms of payments for disadvantaged areas and agri-environment programmes. The analysis using the "SAS" software for Austrian farms found out that on average the market income increased with direct payments and agri-environmental payments from $€ 7,000$ and in the disadvantaged areas with subsidies of $€ 3,000$ each. The disadvantaged subsidy payments had only a small effect on inequality, while the other two types of subsidies (direct and agri-environmental) increased the absolute inequality between FADN farms, as they were proportionate to the size of the farms. A study in Finland evaluated the rural sector in relation to the economic, social and ecological indicators that four different scenarios used, which were simulated with a mathematical model at the time of the implementation of the reformed
CAP [50]. The model allowed the indicators used to change over time and discuss the implications for Finland through the following scenarios:

- A baseline scenario after the reform of the Agenda 2000,

- A scenario of the 2003 partial decoupling reform,

- An integrated rural and environmental policy, and

- The liberalization with full decoupling of payments and subsidies of the regions.

A model called "DREMFIA" was used to work on four Finnish prefectures, which were divided into smaller areas. The "DREMFIA" is a positive model of mathematical programming. All the major production lines were included, and some expenses were allowed for transportation. There were no links with other sectors of the Finnish economy. The economic factors such as inflation, elasticity and consumption were defined to represent the general trends in the economy. The main categories of indicators were the total number of the different livestock units by 2020, the cultivated land and other land uses by 2020, the remaining of the nitrogen and phosphorus, the income and profitability, and, finally, the working hours and income per hour worked. Drastic results were found in all the scenarios for cattle and dairy production, which were not surprising, given the current supportive situation. Less dramatic results were found for the production of pigs and poultry where there was less intervention or production quota. A complete decoupling from subsidies was estimated to be likely to lead to an increase in the omissions and a decrease in the cultivated areas, mainly in the northern and eastern regions. The disconnection and application of the Cross-Compliance slow down land abandonment while there is a trend towards a cessation of cultivation. Also, the decoupling was, in the long run, estimated to reduce the less profitable production. It was predicted that the production efficiency would increase with the decoupling resulting in higher income per hour of work. The highest incomes were found in the scenario of the integrated rural and environmental policy. The partial disconnection and price reductions would have positive consequences on the environment if the production intensity and volume were reduced. The complete decoupling was likely to lead to a downward spiral in the long run and to the regional concentration that would not bring any extra environmental benefits. The model which was used for Finland did not use a social accounting framework and therefore could not take into account the interconnections between the rural and national economy. All four scenarios were estimated to lead to a downward escalation of agriculture, but the model could not predict the flow of resources (labour and capital) in other sectors of the economy. Nevertheless, it was predicted that a certain substitution had to take place, such as "the reduction of the agricultural income and the reduction of the working hours in the rural sector, which seem to have been directed towards the fact that the role of agriculture as a rural backbone would gradually disappear."

The Swedish Institute of Food and Rural Economy had undertaken three studies concerning the CARERA study [51]-[53]. While none of these studies directly concerned the Agenda 2000 or the CAP reforms, they provided useful information on the success or failure of rural development programmes in Sweden. The first study aimed to evaluate the government's support for rural projects which were implemented in the regions during the previous policy period. The aim of this study was to determine which 
variables affected successful job creation and which variables did not. Over the period of 1995-1999, some 3,000 projects were supported in Sweden, many of which achieved their objectives or produced long-term effects on employment. Many projects had features including events, workshops and education. The focus of the SLI [51] study was on projects with clear objectives for the invigoration of new business and the criterion of success was employment, which would remain even after the project was completed. The other report was a mandatory assessment of the support investment towards food and the target areas of the program were the rationalization of packaging, conservation, recycling and investment in new techniques. The evaluation of the EU policy considered it mandatory in order for questions to be asked. Qualitative research, as well as the econometric overall assessment was the followed approach. The inquiries were answered by 90 companies except for the 400 applicants. The best consequences of support were reported by the small businesses with fewer than 10 employees. These reported a positive impact on employment, while the results from larger companies were more neutral. The small businesses were also more dependent on co-financing, while the larger businesses also implemented their plans without support. According to the businesses, the production capacity and improvements in hygiene were among the biggest effects observed. The econometric evaluation was aimed at investigating changes in productivity and the use of inputs. The subsidized food production areas were compared with sectors which did not receive any support. The data from Sweden's statistical office were used to determine the production operations and the relations of demand for inputs. The regression did not show any increase in productivity and no increase in demand for entry agents. This, however, was not related to the size of the support. The reasons for these neutral effects were that:

- The investments in hygiene and animal welfare, which did not change the productivity and use of inputs in the short term;

- The fact that a big part of the support went to large companies and large producer cooperatives that made high levels of investment, regardless of subsidies. The third study (SLI, 2004b) examined the relationship between rural development, agriculture and the region's income. This study did not directly analyse a rural development plan but rather discussed the consequences of the rural development programmes on specific sectors such as agriculture and their consequences on the regional economic development. The conclusion was that the rural policy, which focused on agriculture, hunting and fishing, would be detrimental to the regions in terms of economic growth. Plans to support agriculture could have a wide impact on rural development.

However, a study of 1,144 organic holdings in the United Kingdom and the Republic of Ireland [54] predicted that if $20 \%$ of the farms in the two countries were to become organic, there would be an increase in job positions in agriculture, which would range between $6 \%$ and $19 \%$. The sample which was studied accounted for $23 \%$ of all organic farms and this meant jobs by region, significantly lower in organic holdings and farm jobs per farm than national averages.

A comprehensive study, using three different models to evaluate the interactions between agriculture and the environment at regional level in Denmark [55]. Three scenarios were identified, a baseline, a release scenario and an environmental one. The baseline followed the continuing trend, the release scenario removed all barriers from the trade and all support, and the environmental scenario simulated an enforcement of stricter environmental restrictions on livestock production. Three different models were used in the analysis. A national macroeconomic model called "AAGE" was used to identify the economic variables such as the production values, net exports, inputs, prices, consumption and investment at a national level. An agricultural model called "ESMERALDA" was used to determine the distribution of agricultural production among the regions based on the simulations obtained with AAGE. This model provided simulations for the agricultural and livestock production, income and employment. The results from these models were then used in a third model, the "LINE" model, which is a general balance of a local economic model. The national macroeconomic outcomes were therefore used for the regional analysis, with the difference that the agricultural sector was specifically shaped in the regional ESMERALDA model. The agricultural model covered 15 types of agricultural production and 11 types of production and demand for seven variable inputs. It determined the economic behaviour of about 2,000 representative units. By using data from the agricultural model and the macroeconomic model, the LINE model then found equilibrium solutions in regional commodity markets for each basic commodity, by using firm/stable price assumptions. The "LINE" model, being a general equilibrium model, was calibrated using the SAM-K matrix of social accounting for the municipalities of Denmark, showed the flow of the resources such as working in other areas and increasing economic activities anywhere else. However, this impact differed between the regions, with rural communities suffering from the decline in profitability due to a greater emphasis on the sector of agriculture, while urban areas were not affected by the liberalization.

Other studies in Finland examined the factors that influenced the farmers' decisions to retire. Pietola et al. examined the impact of the policy concerning the timescale and the type of exit from agriculture in Finland [56]. The conclusion was that if the CAP reforms reduced the producer prices, in countries such as Finland with high costs and low population density it would be difficult to maintain an adequate level of entry for young people into agriculture and for young farmers to remain in rural areas. In addition, a study by Vare examined the effect of marital retirement [57]. The study found out that while rural couples made uniform decisions to retire, farmers did not take a uniform decision to retire with their spouses working under other pension schemes. The factors described above affected the joint retirement decision, but it was found out that the implementation of early retirement schemes and the succession of agricultural holdings occurred more often in crops with two entrepreneurs than with one entrepreneur [56].

In the sector of the agricultural holdings structures, quantitative analyses, which were published two years after the implementation of the reformed CAP, showed estimates of a reduction in the area of cereals (about 5\%) and oilseeds (around 3\%), an increase in fodder plants and reduction of cattle [58]. At the same time, it is reported that durum wheat is under harsh pressure in some countries. However, other scientific research, even before the start of the implementation of the reformed CAP, showed a large 
reduction in internal grain prices, as a result of the comparison of the scenarios [59]. This assessment has not been confirmed, as it should be noted that the very texts of the EU assessment for the CAP (http://www.europa.eu) predicted a limited reduction in cereals as a result of the decoupled support, an increase in energy crops, especially of the oilseeds, but also a reduction in livestock farming (cattle and sheep breeding).

One of the findings in the bibliographic review of the authors was in Häring et al. and Abildtrup et al., 2006 [60], [61], the estimation that non-agricultural activities, such as agrotourism, were more often found at organic holdings. However, this could not compensate for the lower returns during the assessment of the consequences on employment. Another earlier study by Offerman and Nieberg showed that $10-15 \%$ of the cases had higher usage of work for organic holdings compared to similar conventional farms [62]. However, this varied from country to country, in some cases showing less work at organic farms. A general balanced model, a result by Jacobsen, provided less employment in both agriculture as well as processing after the conversion of conventional into organic farming[26], [55].

Gohin questioned the validity of the consequences of the available studies for the 2003 reforms, which showed a substantial reduction in beef production and lower reductions in arable crop production [63]. It considered that the studies, which were based on the assumption that the Agenda 2000 reforms had already led to decoupled direct payments for arable crops, did not reflect the real situation. Leeuwen et al. (2011) studied the impact and consequences of Turkey's possible accession to the EU on the agricultural sectors in Turkey and the European Union [64]. The AGMEMOD, an econometric, dynamic, multi-spatial, multipurchasing, partially balanced, economic model of the EU agriculture at Member State level, was extended to a model for Turkey and then applied in order to acquire quantitative knowledge concerning the consequences of the potential accession of Turkey to the EU. In order to create a model for Turkey, as for any other candidate country, the application of the model equations required estimation parameters, or if an econometric estimation was not possible, the determination of the synthetic model parameters. In order to assess such a parameter model and develop a functional model in the field of Turkish agriculture, a database with time series data on Turkish agricultural production, market and price balances, macroeconomic variables and policy variables, had to be developed.

However, the farmers' reactions to the radical change of the CAP were not uniform, due to the different conditions in the practice of agriculture, while the expected effects of the decoupling of the support had not been confirmed in some cases due to a limited adjustment of a number of agricultural holdings and their loyalty to the previously applied models as reported by Lobley and Butler in 2010[45]. In addition, other scientists suggested that the study of the changes in farmer behaviour was considered to be limited since, as mentioned, it is about a radical change without previous experience as far as its implementation is concerned [65].

To the question raised in the two regions in France [66], with the CAP support being interrupted, a significant proportion of farmers planned to cease the practice of agriculture. This trend appears more pronounced in the mountainous and disadvantaged areas. In Ireland, the decoupled support continues to affect production. However, its impact is less compared to the related production subsidies [65].
Not all areas in Spain were affected to the same extent[67]; following on from the decoupling of the subsidy, significant reduction in crops with high irrigation requirements, (e.g. cotton, beet and maize), and an important increase in crops with low irrigation requirements, such as those of winter cereals, sunflower and olives, was observed [68]. It was also reported that the introduction of the decoupling has influenced the use of inputs and also the irrigation on sugar beet and cotton, bringing the form of practiced cultivation closer to a somewhat more sustainable practice (in the sense of environmentally friendly). Gracia et al. (2008), reported from an early point, the reduction in cereals due to the Single Farm Subsidy (SFP) implementation and the reduction of the subsidies they receive, as a potential possibility[69].

In Italy, the widening of the gap between cost and yield, as well as the consequences on durum wheat farming were pointed out [70]. Also, the view that this reduction had a negative impact was recorded too, causing a reduction in the profits of commercial grain businesses or even their exit from the market.

On the other hand, the interest in the cultivation of the plants from which biofuels are produced, increased. In Germany and France [23] there was a decrease in the fields of maize, cereals and fodder maize, which were covered by other crops. The change in trends caused by the CAP reform is the same in both countries, but it remains stronger in France.

Michalek et al, expressed an estimation about the income of the redistributed CAP impacts for farmers and land owners[71]. Firstly, Michalek et al. theoretically analyzed the level of the farmers and landowners' profits from the coupled and decoupled subsidies. Secondly, by using a unique level of agricultural data of the FADN table for the period 1995-2007, the researchers investigated the steady effects, choosing Heckman's bias and the GMM estimators to estimate the income of the redistributed effects of CAP subsidies. The results did not confirm the theoretical assumption that landowners benefited from the large share of CAP subsidies. According to their estimates, the farmers obtained between $60 \%$ and $95 \%, 80 \%$ to $178 \%$ and $86 \%$ to $90 \%$ of the total value of the coupled crop / animal, of the coupled and the decoupled subsidies respectively. The CAP subsidies only marginally capitalized the land rents. Their results showed that rental rates responded more to the structural variables and showed a strong dependence of time, a fact which showed the presence of rigidities in the EU rental markets, which limited the regulation of the land rents to the market signals and thus reduced the profits of the landowners from the implementation of the CAP. In another article, it was reported that land values and the degree of capitalization on land cost were not expected to decrease due to the CAP reform, while simultaneously maintaining the high land prices that may create an entry barrier for young farmers and, potentially, hamper the competitiveness of European agriculture [72].

Psaltopoulos et al., examined the agro-urban consequences of the CAP measures by using a hybrid social accounting matrix for the study of three areas of Crete[73]: Archanes (a rural town), Northern Kazantzakis (a neighbouring rural area), and Heraklion (the urban center of the region). The researchers concluded that the rural areas and particularly the most remote ones ("Northern Kazantzakis"), had economic benefits. Households were more dependent on inter-regional flows (mainly for employment) and had lower income and earning potential 
than urban households. The Archanes area received high levels of agricultural guarantees and rural development funding during the 1990s, particularly in terms of household employment and income, but these benefits also spread to Northern Kazantzakis and Heraklion. However, the different benefits came from different types of support, the CAP development measures looked more successful in the creation of employment implications in Archanes and the economic benefits in Heraklion, while farm subsidies generated income in all rural areas. They concluded, therefore, that the type of the subsidy in question should depend on the policy objectives and thus be specific to each particular area.

Lobley and Battler looked at the farmers' intentions following the implementation of the 2003 CAP reforms and identified the extent to which these plans have been affected by the introduction of the single payment scheme and assessed the consequences of possible structural changes e.g. changes in land, labour and capital development[45]. In conclusion, it was argued that the CAP reform unequally affected each agricultural holding and all the different situations in agriculture which are associated with the different types of reaction. The purchase of rights may have become a powerful driving force for the farmers' behaviour, but the 2003 reforms may have had the potential to be successful and to provide farmers with the freedom to cultivate without being dependent on the combination of subsidies. Based on the results presented in their research, only a minority of farmers were so well positioned and prepared to take advantage of the opportunities.

Giannakis and Efstratoglou analyzed the role of the extensive relationship with intensive farming systems in the Greek countryside in Trikala and evaluated the consequences of the land resource change on the intensive farming systems due to CAP reform [74]. The multiplying inputs-outputs analysis showed that the intensive rearing system in Trikala created the strongest vertical interconnections with other sectors of the economy. The income and employment multipliers were rather low for almost all farming production with intensive farming systems having the highest, due to their high direct consequences on income and the employment that they create. Among the non-agricultural sectors, commercial commodities and tourism appeared to create the longest and most delayed connections compared to the rest of the economy. The CAP reform and the implementation of the decoupled Single Subsidies introduced the reallocation of the land resources from intensive to extensive agricultural cultivation and initiated changes in rural areas. From the above analysis, it emerged that the net production from the redistribution of land was negative for the rural economy. However, the process of the redistribution of land, was revealed to be at an early stage and was expected to evolve.

Severini and Tantari (2012) looked at the role of agricultural income distribution among farmers after the decoupling of the direct payments[75]. Their analysis calculated the direct market subsidies which were allocated in the framework of market and income support policies and rural development policies. By using the "Gini" coefficient and its allocation, these researchers explored the impact of both types of payments on the rural income inequality among a large sample of agricultural holdings in Italy. The analysis was developed at a national level, taking into account, however, the three main regions of Italy and the three types of agriculture. The direct agricultural subsidies were very close but reduced the agricultural income inequality. Therefore, their reduction should have led to an increase in collection of agricultural income, in particular in some of the types of agriculture under consideration. The results showed that the CAP reform had reduced the role of the direct subsidies, helping to reduce the inequalities in agricultural income. This was not only due to the alteration of their relative importance, but mainly because of changes in their distribution patterns.

\subsection{Concerning the 2014 reform and other related issues of CAP}

Conclusions show us that the introduction of the greening measures in CAP does not lead to significant increase in environmental benefit, in general. Additionally, complying with the greening requirements does not put a significant additional economic burden on farmers, at the aggregate level. However, as the saying goes, "the devil is the detail". Consequently, it is important that the regional allocation of environmental and economic impacts is uneven. Additionally, the simulation results were able to identify regions with more significant environmental and/or economic impact, and farm types that are more exposed to greening impact [76].

In Sweden a study evaluated the impact of CAP agricultural subsidies on employment outside the agricultural sector. It has to be added that Sweden, with the decoupling reform applied in 2005, introduced a grassland support which caused a redistribution of payments among regions. Subsidies created private jobs at a cost of about $\$ 26,000$ per job, which is consistent with earlier estimates based on US data [77].

In the context of the conditions shaped by CAP, researchers in southern Italy propose as another version [78]; the adoption of a holistic sustainable system called "conservation-agriculture" in order to meet the environmental requirements and to cover the production needs. It is highlighted that this is a system "combining satisfaction of food needs and land preservation. As it is said it is a possible solution which combines a holistic production system consistent with a sustainable development model, designed to satisfy diverse "local" economies. The "conservation agriculture (CA" could be a part of this model, as it includes a set of best practices available to preserve agrarian soil and its biodiversity". The results of another scientific work in the northern side of Italy highlight the fact that the introduction of greening in a region with high density of monoculture has led to strong discontinuities in farmland allocation; such a result is relevant, if compared to a certain widespread opinion that considered greening rules quite ineffective at EU level according to the European Court of Auditors - 2017 [79].

With regards to the implementation of the CAP in Portugal for 30 years, it is concluded that while there are improvements concerning the environmental measures side, there could have been a more ambitious programme in this area. Furthermore, spatial asymmetries remain despite the existence of some signs of convergence in the agricultural sector. Moreover, it is characteristically mentioned that "production has changed with a reduction in arable cropping and an increase in pastures and livestock. Competitiveness has decreased, after the 1992 CAP reform" [80].

In another recent study it is mentioned that the " $C A P$ and the reforms and society's expectations of agriculture have resulted in a growing need for improved information on the electiveness of policy in achieving high-level objectives for 
more sustainable practice in agriculture. This is a high priority given its importance for consumers, public policy and private industry"[81]. This study, following this note, proceeds to an evaluation of the collection systems and data and the FADN.

In connection with the global economic crisis that occurred and persisted for many years in Greece, a significant scientific study states that:"It is important the scientific opinion that the agro-food sector serves as a highly powerful 'stabiliser' of the economy. The current USA and European crises clearly demonstrate this role as the agro-food sector is virtually the only sector that has succeeded in functioning normally under dismal economic conditions" [82]. Additionally, in another article it is said that "it is a common point that without the CAP's support, several farm activities would be reduced or even ceased, with devastating consequences on employment" [83].

Another scientific study stated that "the majority of responded farmers consider the state and political parties (of Greece) as being responsible for environmental problems". It is also argued that "This study examines the attitudes and perceptions of landowners regarding various options for rural development and the existence of alternative prospects for enhancing primary production, family income and, consequently, quality of life. The farmers argue that future regional development may depend on agriculture and livestock production. Furthermore, most of them wish to engage in alternative crops like truffle, pomegranate and dogwood and the reasons behind such a decision are the competitive profile of and increased demand for such products, along with state subsidies in order to deal with the decrease in their income" [84].

Another scientific study reveals the necessity to provide consultancy services from an organized center in a central area of Greece, so that all those involved in agroforestry production to be able to cope with challenges of agriculture and the framework created by the current CAP and the real conditions [85].

In the document entitled "Overall of CAP reform 2014 2020" (2013) the following is claimed about the current CAP, which is a result of the 2014 reform: "The new CAP maintains the two pillars, but increases the links between them, thus offering a more holistic and integrated approach to policy support. Specifically, it introduces a new architecture of direct payments; better targeted, more equitable and greener, an enhanced safety net and strengthened rural development. As a result, it is adapted to meet the challenges ahead by being more efficient and contributing to a more competitive and sustainable EU agriculture." While as its basic goals the following are being recorded: viable food production, sustainable management of natural resources and climate action and balanced territorial development. With regard to the CAP budget the following data are listed in the same text (Table 3, 4 \& 5,):

Table 3. MFF Ceiling 2014-2020 (in billion EUR)

\begin{tabular}{l|c|c}
\hline & $\begin{array}{c}\mathbf{2 0 1 4 - 2 0 2 0} \\
\text { Ceiling } \\
\text { (Current Prices) }\end{array}$ & $\begin{array}{c}\mathbf{2 0 1 4 - 2 0 2 0} \\
\text { Ceiling } \\
\text { (2011 Prices) }\end{array}$ \\
\hline Pillar 1 & 312,74 & 277,85 \\
Pillar 2 & 95,58 & 84,94 \\
Total CAP & 408,31 & 362,79 \\
\hline
\end{tabular}

(Source: DG Agriculture and Rural Development) [10]

The priorities of the current CAP are described concisely in the table below.
Table 4 Rural Development Priorities

1. Fostering knowledge transfer and innovation in agriculture, forestry, and rural areas

2 . Enhancing farm viability and competitiveness of all types of agriculture in all regions and promoting innovative farm technologies and sustainable management of forests

3. Promoting food chain organisation, including processing and marketing of agricultural products, animal welfare and risk management in agriculture

4. Restoring, preserving and enhancing ecosystems related to agriculture and forestry

5. Promoting resource efficiency and supporting the shift towards a low carbon and climate resilient economy in agriculture, food and forestry sectors

6. Promoting social inclusion, poverty reduction and economic development in rural areas

(Source: DG Agriculture and Rural Development, cited: Overall of CAP reform 2014 - 2020) [86]

In addition to setting priorities, the EU has expressed the view that for the first time, the linking and synergy between the two Pillars has been ensured in order to optimize the results. Characteristic is the table below:

Table 5. Actions targeted under both Pillars

\begin{tabular}{l|l|l}
\multicolumn{1}{c|}{ Pillar I } & \multicolumn{1}{|c}{ Targeted } & Action Pillar Ii* \\
& & $\begin{array}{l}\text { Agri-environment } \\
\text { climate Organic, } \\
\text { Natura 2000 } \\
\text { Business } \\
\text { development grants }\end{array}$ \\
\hline Green payment & Environment & $\begin{array}{l}\text { Higher investment } \\
\text { aid } \\
\text { Area payments }\end{array}$ \\
Top-up payment & $\begin{array}{l}\text { Areas } \\
\text { Natural } \\
\text { Constraints } \\
\text { Small Farmers }\end{array}$ & $\begin{array}{l}\text { Business Farmers } \\
\text { development grants }\end{array}$ \\
$\begin{array}{l}\text { Alternative } \\
\text { simplified } \\
\text { scheme } \\
\begin{array}{l}\text { Improved legal } \\
\text { framework }\end{array}\end{array}$ & $\begin{array}{l}\text { Producers } \\
\text { Cooperation }\end{array}$ & $\begin{array}{l}\text { Aid for setting up } \\
\text { producer groups } \\
\text { Cooperation and } \\
\text { short supply chain }\end{array}$ \\
\hline
\end{tabular}

*Only main measures that target the specific issue under Pillar 2 are mentioned.

(Source: DG Agriculture and Rural Development, cited: Overall of CAP reform 2014 - 2020).[86]

Crescenzi and Giua have tried in their study to examine the EU Cohesion Policy and explore how the EU policies for agriculture and rural development shape its influence on regional development[87]. The analysis of the regional development factors has shown that the EU regional policy has a positive and significant impact on the economic development in all regions. However, the impact of its results becomes more effective in most of the socioeconomically developed areas and is maximized when expenditure is complemented by rural development and CAP funds. The CAP top-down funding seems to be in a position to bring some benefits to the most disadvantaged regions. Conversely, only the most dynamic rural areas are in a position to make good use of the measures of the EU's rural 
bottom-up development policy. This suggests that policy makers in all EU sectors should continually seek the best combination of bottom-up and top-down measures to tackle structural disadvantages. The conclusions of the work refer to the need to achieve good co-ordination among those involved and to define the agenda of issues at a national level, issues which could favour on-the-spot coordination between different policies. On the contrary, at a local level, conflicts and contradictions between different agencies and offices could make it much more difficult to achieve a developmental effect for the benefit of the region.

As early as 2015 in a scientific study, consideration of the changes included in the reformed 2014 CAP and the clarity of the objectives included, and whether the objectives recorded in it have a significant reflection in reality through the financial measures contained in the CAPE[31]. CAP's environmental aspect is mentioned as a typical example, which being popular with the public according to scientists, refers to all the points but is not proportionately included to the extent that it should be in the measures that are financed by the actions, but also in the distribution of the budget. The research notes in its conclusions that while until recently the adaptation of the measures and the allocation of the CAP resources constituted points of disagreement and confrontation, henceforth the points used by the key factors that are decisively involved in the shaping of CAP can be characterized as controversial, and that there were points in the CAP configuration which operate in a competitive way. Overall, however, it is stated that the current reform of CAP does not slow down production, but seeks to achieve a political compromise between the different effects that have emerged following the European Parliament's involvement in the decision-making process on the CAP. Alons and Zwaan ascertain important differences between the reason and the arguments of those involved, and also point to both the lack of common ground between the EU and three of the most important member countries (Germany, France and the United Kingdom), as far as the uploading (negotiations) and the downloading (CAP implementation but also one of the Commission's noted controversies by the European Parliament on matters relating to the CAP) are concerned. This study refers to CAP in its form after 2014 [88].

The issue of further expansion of the EU concerning CAP issues is linked in scientific studies; Tankosic and Stojsavljevic state that the enlargement of the European Union with the accession of the countries of Eastern Europe (especially Romania and Bulgaria) and possibly of Western Balkans where agriculture is significantly represented in their national economies and which are lagging behind in all almost all aspects of the development of the "old" EU Member States, is an additional challenge for the EU agricultural policy makers[89]. The specific scientific study refers to Serbia, for which it emphasizes that the importance of the rural sector for the Serbian economy is great because Serbia's agriculture is relatively small as a country at a European level, but agriculture as a sector constitutes the major part of the requirements of the so-called acquis communautaire and is therefore of great importance to Serbia's path towards EU membership. The rural sector has to face as a result major reforms in order to resume the responsibilities of the country's prospects for a possible EU membership. In order for the country to start using funds from the European subsidies, Serbia must first create the necessary institutional framework and also management and control systems. Overall, the importance of the social role currently exercised by the European agricultural model through the production of public goods and services in favour of a new welfare model is being underlined. The presented studies investigate the impact on local communities' sustainability and well-being, which result from diversification and multifunctional practices, including also land-grabbing, highlighting the effective and efficient outcomes of various police officers.

The prospects offered by the new CAP for the achievement of a competitive redeployment of the European agricultural and rural systems, with emphasis on new prospects for the European holdings, agricultural supply chains and agricultural land of the CAP, have been the subject of the 51st "SIDEA" Conference. The conclusions from this effort are published in a study by Nazzaro and Marotta[90]. In the study, it is concluded that the 2014-2020 CAP reform aims to promote greater competitiveness, the efficient use of public goods, food security, environmental conservation and specific actions against climate change, social and territorial balance and a more open rural development. The economic crisis of recent years, globalization, the increasing pressure on natural resources, the increasing diversity of agriculture and rural areas in the new enlarged Europe, and the expectations of citizens about the environment, food safety and quality, health and prosperity, the countryside, biodiversity and climate change and the unequal distribution of resources are some of the major issues that this policy has encountered in a production context guided by the principles of justice and effectiveness. The policy ways are largely transformed in order to meet these challenges and to achieve specific objectives and are included in the two complementary pillars (direct payments and market measures, the former and rural development, the latter).

A scientific study, which took place in the Opole region (Poland) concluded that the development of the region and the improvement of the income of the agricultural holdings in the region plays an important role and inter alia, is connected to market prices of products, as well as the increase of productivity of the holdings and with their adaptation to the necessary innovations through the financial programmes provided, the awareness of the role played by agricultural production in the local development, which changes the perception of the problems that occur in the community, the beginning of pursuing business activities outside of agriculture, the improvement of the experience of farmers and of them being informed about the development potential of the area[91]. At the same time, the involvement of farmers in the management of their ecosystem services is described as important, investing under the regime of a developmental environment in the community. However, it is pointed out that the residents of the area and their business will depend on the quality of life in rural areas, ensuring the stability of the agricultural holdings in which CAP implementation and the quality of life that will be provided in the region play an important role. Finally, in the context of the scientific study, the scientists note that the diversity of rural areas in Europe requires further specialization of provided measures and mechanisms, since the study revealed weak support provided financially by the framework of the Rural Development Program, which may become an obstacle to the implementation of integrated territorial development. In the same study, the factors that determine the agricultural holdings' income on the basis of farmers' opinions are described and these are in turn: market prices, machinery and facilities' prices, prices of fertilizers and plant protection products, seed prices and increase in the 
price of products due to the possibility of storage at the agricultural holding, the cost of the subsidies, the amount of taxes, the amount of direct subsidies, the subsidies which derive in correlation with high production quality and subsidies resulting from participation in a Producers Group.

Research from Poland that studied the instability of Polish basic agricultural commodities prices under the CAP spectrum stated that the completion of the EU integration had a positive impact by restricting the instability of the Polish agricultural products[92]; under CAP influence, prices were initially reduced to EU-level prices, especially when it comes to cereals, while in the meantime the EU prices increased as a result between 2004 and 2007, in the specific country, the average prices of the agricultural products increased by $12 \%$. So finally, according to the scientists concerned, while the CAP focuses on the increase of efficiency, which increases the concentration and scale of production, and supports the process of developing a wider rural competition, its practices have contributed to stabilizing the prices of agricultural products.

The CAP problems are analyzed by Kuhmonen, using the methodology of system dynamics in charts of causal loops[93]. The categorization of 303 listed problems to be addressed in the future by CAP has led to 22 key problems under specific areas (social environment, spatial planning, politics, markets, agriculture). The problems constituted three subsystems with reinforcing causal loops of competitiveness, viability and heterogeneity. The complete system of CAP problems involved 114 causal links across all sectors. For example, it should be noted that, according to the study, the multidimensional sustainable development was identified as the most networked problem, free trade with different agricultural regulations was the most widespread problem, and competitiveness and income in agriculture was the most widespread dependent problem. In the conclusions of the study it is recorded that the negative impacts of climate change on food production capacity and food security are expected to deteriorate. The solutions to the CAP issues are said to be limited to a specific sectoral approach, either as spatial, agricultural, commercial or environmental problems, but as problems in a single network and a whole with impact on all sectors.

In a scientific paper by Rudloff and Bruntrup, the scientific view expressed is that, overall, the consequences on production and price of the current CAP are negligible[94]. These consequences are not determined by the overall size of the CAP budget, but by its design which is mostly neutral in production. Indeed, the view in this study is that even the complete abolition of the CAP will lead to a slight decrease in agricultural production.

\subsection{Further research concerning the CAP Pillars and other more specific issues}

With regard to Pillar II investments, these have been considered for more than 10 years to be useful in creating long-term agricultural stability in order to enable efficient part-time agricultural employment, high environmental value in agriculture, and investments in diversification and training[43]. In areas where such developments did not take place and the agricultural population was dependent on the high levels of direct payments, employment in agricultural holdings was more likely to be lost. The farmers' perceptions were that direct payments to agricultural holdings have a direct impact, while changes to Pillar II measures have more complex, long-term effects. Another study, which refers to the neighbouring region of Central Macedonia, records:
"Additionally, a key strategy proposed by other scientists, for the Region of Central Macedonia, is to alleviate unemployment through an increase in the Pillar II funds. The CAP's policy measures, besides creating jobs directly, keep alive several farming activities which, without their support, would probably cease with significant job losses in many regions» [83]. While in another study, it is mentioned that: "With more rural development funds, it is said that agriculture and its related sectors, will boost employment levels in the regional economy. The region's development strategies should focus on those sectors that benefit most considering all the specific characteristics, of the region, while the implementation of Pillar II measures has a positive impact on the regional economy".[95]

\subsection{Further research into the consequences of the CAP on employment issues and other specific issues}

Two Greek studies have examined CAP's impact on employment in rural areas. The first one, by Skuras et al., before the beginning of the 2003 reform (2003) implementation, examined the effects of capital subsidies on the creation of rural employment[96]. One of the main factors that appeared to affect the subsidy prices for small and medium-sized enterprises was their position in the peripheral regions which were lagging behind, where there was an increase in production and transport costs. The allocation of capital grants was also determined by a number of social welfare criteria, such as the impact on job creation, the adoption of new technology, and the substitution of imports. This study investigated the agricultural businesses that lagged behind in the Ionian and Aegean islands, which had benefited from subsidies from national programmes and those of the EU. A total of 83 businesses were questioned, and indicated an overall negative impact on employment, such as the capital subsidies which led to labour substitution with capital. This impact depended on whether the company produced a flexible or non-flexible price for the products, with an inflexible price for goods that had a negative impact. The capital subsidies were not used for the reduction of production costs, so thus, the product prices did not fall, and there were no benefits for exit or employment.

The second even earlier Greek study examined the CAP and its consequences on Greek agriculture, fisheries and employment in mountainous areas, and included an assessment of the major Greek economic sectors [97]. The findings were consistent with more recent study, proving that remote rural areas suffered greater consequences from $\mathrm{CAP}$ and its reforms. Baltas used an input-output methodology, an input-output environmental model, and a SAM methodology matrix with a questionnaire and secondary data for impact assessment and found out that the CAP agreement had multiple effects on the Greek Agriculture. The most significant impacts occurred in remote rural areas lagging behind, where new strategic systems had to be designed. These areas usually relied on their economic viability in the agricultural sector and so the transition was difficult. There was a significant non-trade relationship between the economic growth and the environmental degradation, which should also be taken into account in policy decisions.

In other scientific papers examining other EU Member States, it has been attempted to assess the potential impact on employment and on farmers' incomes under different policy scenarios and market conditions[98].

A reference should also be made to the pan-European study with the title "Study on Employment in Agricultural 
Areas", entitled "SERA" which was also mentioned in a previous section of this chapter [99].

A survey carried out in Germany by Fasterding and Rixen analyzed the employment opportunities and implications of the 2003 CAP reform on rural employment [98]. Predictions over a ten-year horizon included the following: A. Reduction of family employment (about $64 \%$ in 2012); B. Little increase in demand for labour, especially for crop production, but reduction in livestock production, where there is hardly any impact by the agricultural policies - \& C. Reduced labour demand, mainly due to the introduction of the decoupled direct payments ("Combimodel"), the differences of the areas, the differences between different types of agricultural holdings and lack of skilled labour supply.

With regard to the question of employment, scientific research has, among other things, shown and concluded that "policies aimed at fostering farm employment should focus on interventions that permanently change the individual propensity to work off the farm, e.g. focusing on education and development of personal skills" [100]. Previously Corsi and Salvioni, tried to assess the consequences on the sector of non-agricultural employment and its participation in the overall labour market for farmers, an issue also important in terms of the consequences of the rural development. For this effort they used an impact model "probit", thus controlling the unnoticed heterogeneity in the work of farmers. The results showed that the consequences of reform on the labour market in the non-agricultural sector were weak. According to this study, no variable directly related to the revision of the CAP was statistically significant.

In another Spanish study [101] under the framework of the Horizon 2020 programme, a joint approach to EU rural and regional policy was attempted, and concluded that a range of social and economic benefits for rural areas could be utilised that could be increased by the development of 'livestock farming' which tends to become more widespread because it relates to: (a) creation of employment opportunities for current and future risk teams; (b) diversification of agricultural products; (c) new agricultural and rural initiatives beyond the tourism sector that enhance multifunctionality and create added-value; (d) unification of sustainable ecological agriculture and support of the quality and proximity to the product transportation systems; (e) increased social services which are at risk in rural areas where resources are scarce and their needs are difficult to meet; (f) the arrival of new families in small villages that are attracted by new employment opportunities linked to the SFs and services tailored to their needs; (g) extension of the types of entities and initiatives combining rural and other more urban activities that require a natural environment of high quality; (h) the empowerment of risk groups and, inter alia (i) the potential for social integration and inclusion in employment, which may lead to a reduced probability of recurrence (e.g. former detainees) and greater selfconfidence for members of these groups. In the field of development, the study states that "social stock farming" provides a clear example of economic and social innovation closely linked to collective action and active, participatory and continuous interaction between individuals and available resources. These are seen as facilitating the establishment of cooperation and cooperation networks at local level that promote social cohesion and help to stabilize the population of a region, while at the same time increasing the sense of belonging to a community and encouraging cooperation.
In summary, it can be argued that the trend for part-time agricultural and part-time work outside the agricultural holdings is expected to continue, as many women and young people will continue to look for employment outside of agriculture.

\subsection{Indicative conclusions from the bibliographic survey on the up-to-date revisions of the CAP and its} implications

The previous relevant scientific literature showcased:

- The importance of CAP for both the agricultural and the wider agricultural sector as well as for the wider local economy and for the development of the regions of all EU districts,

- The complexity of the subject as diverse local conditions and circumstances enter into it, which interact with the CAP framework, like the market trends and the evolving consumer preferences - such as \&

- The imperative need to know and understand the CAP framework so that realistic assessments and choices can be made on the course of both the agricultural holdings and on the whole of the agricultural sector at regional and national level, so that the effects on the wider local or national economy and development will be affected accordingly.

general, conclusions that can be drawn from the scientific studies mentioned above, include, among others, the note that the recent reforms of CAP have resulted in the ongoing restructuring of agriculture in the EU Member States and a series of impacts on other sectors of the local economy in European and Greek regions and, consequently, the region under study: Eastern Macedonia-Thrace.

At this point we must cite briefly and indicatively, the main, long-lasting (since the country's accession to the EU) positive impacts of the CAP on the Greek agriculture, including:

- Noticeable support for the Greek products with prices higher than the international ones;

- Input of high financial resources, even in the form of social benefits since the 2003 reform;

- The strong positive impact of CAP in terms of income, exchange, financial as well as on the local development of regions and districts;

- Significant investments for development projects: (increase by $45 \%$ in irrigated land, doubling of first processing plants).

At the same time, the following can be considered as the main long-lasting negative effects of CAP on Greek agriculture (since the country's accession to the EU):

- Passive trade balance (mainly intra-Community),

- Reinforcement of monoculture and change of crop structure on agricultural holdings,

- Emphasis on direct income support rather than on longterm structural programs,

- An uneven distribution of resources in products and areas (e.g., flatlands and crops such as cotton, tobacco were favoured - before 2004), etc.,

- Restriction of the intensive nature of agriculture and drop in production levels, mainly after the implementation of the 2003 reform - similarly \& 
- Avoidance of cultivation activities, especially of the expensive ones and drop in quality product levels (after the implementation of the 2003 reform).

Of course, in each case it is obvious that in the overall assessment of CAP in Greece all these decades, the balance between positive and negative impacts, the positive effects clearly outweigh those that are negative.

\subsection{Brief reference to the forthcoming reform of the CAP and other relevant development issues}

From the conclusions included in the Journal of European Integration [102], which explores both the current situation and the developments in the CAP, through the use of interviews of experts closely involved in reforms, either as commentators (as they are called in this scientific study those who express their opinion by systematically monitoring the evolution of the EU agricultural policy from different positions) or as representatives of interest groups, as far as the future is concerned, it must mentioned that these interviews reveal a sharp conflict between the powerful interest groups and their examples for more room inside CAP. The current developments include e.g. the effort to integrate environmental issues into CAP which is promoted by so-called "ecologists" and the proposal for "sustainable intensification" which is promoted by groups of farmers.

As documented, the process has so far led to the existing multi-level CAP, while also created inherent tensions. Existing tensions include, among others:

(i) The effort and extent of integration of environmental issues within the CAP;

(ii) The proposal for the so-called "sustainable intensification";

(iii) The support for rural development and for small farmers;

(iv) The contradictory future strategies of the various stakeholders. As has been mentioned, the current CAP is a product of intense tension and confrontation between large farmers' organizations and environmental NGOs. Despite the fact that there is agreement between these key interest groups on the need to preserve the CAP, there are tensions about how to allocate the resources that accompany it [103].

Many also request further transfer of more money to the second pillar. Meanwhile, farmers' organizations continue to struggle to maintain the first pillar as income support and at the same time support the need for a more balanced second pillar.

The so-called commentators point out that more recently the growing demand for food has been used as a stronger argument for the continued focus of interest on food production. In this sense, there is a new conflict of opinion formed between, on the one hand multi-functionality, and sustainable intensification on the other hand, with emphasis on food production.

Future changes, according to this study, depend on the way with which interest groups manage to gain room in a tighter budget. The projected budget cuts due to the UK's exit from the EU (Brexit) may escalate the already tense relations between large farming organizations and environmentalists.

Regarding the future of Greek agriculture, under the weight of the reform that will follow, and more generally the forthcoming changes to CAP and consequently the wide impact it will have on the local economy and the development of the regions, one must note the increase of the national choices which appear, as well as the so-called "subsidiarity" that will allow in the future (to the extent that will be adopted) Member States to provide subsidiary national actions to its producers. Important texts for the next CAP reform are:

- The Commission Announcement 713 / 29.11.2017 COM (2017) 713 entitled "The future of food and agriculture";

- The Proposal COM (2018) 392 / 1.6.2018 "On the establishment of rules to support the strategic plans to be drawn up by the Member States under the CAP framework (CAP Strategic Plans) and to be funded by the European Agricultural Guarantee Fund (EAGF) and the European Agricultural Fund for Rural Development (EAFRD), and the abolishment of Regulation (EU) No $1305 / 2013$ of the European Parliament and of the Council and the Regulation (EU) No 1307/2013 of the European Parliament and of the Council.

A Commission press release of $1 / 6 / 2018$ on the objectives of the future CAP for the period 2021-2027 states that it will focus on nine general objectives which reflect the economic, environmental and social importance of the support policy:

1. A sustainable agricultural income and ensuring resilience throughout the EU in order to improve food security;

2. Strengthening of market orientation and increasing competitiveness, as well as greater focus on research, technology and digitization;

3. Improvement of the position of farmers in the value chain; 4. Contribution to climate change mitigation and adaptation also to sustainable energy;

5. Promotion of sustainable development and efficient management of natural resources such as water, soil and air; 6. Contribution to the protection of biodiversity, enhancement of ecosystem services and preservation of habitats and natural landscapes;

7. Attraction of young farmers and facilitation of business development in rural areas;

8. Promotion of employment, economic growth, social inclusion and local development in rural areas, including the bio-economy and sustainable forestry;

9. Improvement of the response of EU agriculture to the social requirements in terms of food and health, including among others safe, nutritious and sustainable food, as well as animal welfare.

While it is characteristically reported that: "the promotion of knowledge, innovation and digitization in the field of agriculture and rural areas constitutes a horizontal policy objective."

The main elements of the Commission's proposals for the modernization and simplification of the CAP which are mentioned in the same text are as follows:

1. New way of working: The Member States will be given greater flexibility as to how they use the financial subsidies allocated to them, thanks to which, they will have the ability to design specific tailored programs that respond more effectively to the concerns of their farmers and of their wider rural communities. The Member States will also be able to switch between direct subsidies and rural development, and 
vice versa, up to $15 \%$ of their allocated CAP funds in order to ensure that their priorities and measures are funded. Level playing field terms between states will be ensured through:

- Strategic plans covering the whole period, setting out the way in which each Member State intends to achieve the 9 economic, environmental and social objectives at EU level, by using both the direct subsidies and rural development. The Commission will approve each plan to ensure the coherence and protection of the common market,

- The Commission will closely monitor the performance and progress of each country towards achieving the agreed objectives

2. More equitable conditions through better targeting of support: The direct payments will continue to be an essential part of the policy and ensure stability and predictability for the farmers. Priority will be given to the support of small and medium-sized agricultural holdings, which account for the bulk of the agricultural sector, as well as aid for young farmers. The Commission remains committed to the goal for fairer distribution of the direct subsidies between the Member States through external convergence. In addition, the direct subsidies to farmers of more than 60,000 EUR will be reduced in staggered stages and a ceiling will be imposed on subsidies exceeding 100,000 EUR per agricultural holding ... The Member States should reserve at least $2 \%$ of their direct subsidies and specifically for the support of the establishment of young farmers. This measure will be complemented by financial subsidies for rural development and various measures which facilitate access to land and the transfer of land.

3. Greater ambitions concerning the environment and climate action: The EU-level targets which are currently proposed cover both climate change, natural resources, biodiversity, habitats and natural landscapes. Income support to farmers is already linked to the implementation of environmentally friendly and climate-friendly practices while the new CAP will require farmers to achieve more ambitious targets through mandatory measures and incentive measures:

- The direct subsidies will depend on enhanced environmental and climate requirements;

- Each Member State should offer ecological schemes to support farmers to go beyond mandatory requirements, which will be funded with part of their national direct subsidy funds;

- At least $30 \%$ of each national rural development fund will be specifically earmarked for environmental and climate measures;

- $40 \%$ of the total CAP budget is expected to contribute to climate action;

- In addition to the possibility of transferring $15 \%$ between the pillars, the Member States will also be able to transfer an additional 15\% from pillar 1 to pillar 2 for expenditure on climate and environmental measures (without national co-financing).

4. Greater use of knowledge and innovation: The modernized CAP will use all the latest technologies and innovations, thus helping both farmers and public administrations, in particular through:
- A specific budget of $€ 10$ billion from the "Horizon Europe" research program

- Encouragement of the Member States to use mass data and new technologies for audits and monitoring with a significant reduction in the need for on-the-spot checks;

- More intensive digitization of rural life, for example by expanding broadband access to rural areas, which will improve the quality of life in these areas and contribute to the competitiveness of European agricultural production."

(For more details a relevant table is given in the Annex)

It should also be added here that the forthcoming exit of the United Kingdom (Brexit) from the EU can have a decisive impact not only on the budget but also on the whole course of the EU as well as on the CAP. Beyond the budget, however, Brexit, together with the debate on the next CAP reform that will shape the course of the CAP and its effects from 2021, will result in a climate of uncertainty often codified in the wording that many of the farmers end up in an attitude that can be described as a "seeing and doing" attitude before making decisions. Such an attitude causes procrastination on issues such as, for example, investments for the rationalization of the agricultural systems or decision-making on leaving or remaining in agriculture, the introduction of innovations in the production and marketing of products and the possibility of adopting the so-called intelligent agriculture on each agricultural holding.

In any case, however, the intense fluctuations in international food prices, in the context of so-called globalization for the future, cannot be ignored or excluded as a possibility.

More generally, however, it is important that more organized and competitive agricultural holdings, especially those with limited amounts of liabilities to third parties are expected to adapt and survive more easily and continue to produce with greater comfort, adapting to the changing conditions of CAP.

\subsection{Region Description}

This study evaluates the impact of the implementation of CAP on the local economy and the development course of the Region of Eastern Macedonia-Thrace (also known as "Anatoliki Macedonia - Thraki" in Greek). In this region, agriculture is one of the main economic activities and accounts for a large share of regional GDP, employment and income. Geographically, the Region of East MacedoniaThrace (EMT) is located at the north-eastern edge of Greek territory. With an area of $14,157 \mathrm{~km}^{2}$, it covers $10.7 \%$ of the total area of the country and ranks 4 th in expanse and 6 th in population, among the 13 Regions of the country. It includes the Regional Units of Drama, Kavala, Thassos, Xanthi, Rodopi and Evros ${ }^{1}$.

The geographical location of the region has been in the past and for decades at a determinant developmental disadvantage, due to its distance from the metropolitan centers of Athens and Thessaloniki and its proximity to Turkey and Bulgaria. It is worth noting that for this long

\footnotetext{
${ }^{1}$ According to the previous administrative division of the country, the Region consisted of 5 prefectures (Drama, Evros, Kavala, Xanthi \& Rodopi). Today each Regional Unit (Law 3852/2010) corresponds to the homonymous prefecture. Apart from the Prefecture of Kavala, which includes the Regional Unity of Kavala and the Regional Unity of Thassos (the homonymous island).
} 
period of the many decades, the borders were boundaries with limited to minimal communication through them. Nowadays or to be precise for the last two decades and up until today, the borderland position of the region constitutes a powerful comparative advantage, as the Transylvanian National and Trans-European Networks of Transports and Energy Pipes are being transported through EMT and thousands of citizens, visitors as well as large quantities of goods cross the border. In addition, the region has other important entrances such as its airports and ports. The profile of the EMT region includes an interesting geomorphological terrain on which the existence of extensive plains with dynamic crops, the rich natural resources and the dominance of the agricultural sector on these lands and also on the local economy are imprinted. The terrain and the areas of the region gain particular developmental importance when combined with the strategic position of EMT, which is the physical space for the Greek economy to escape to the East and the North, the Balkan countries, the Western Black Sea zone and Turkey.

Regarding the demographic characteristics of the region, it should be recorder that according to ELSTAT's 2011 census, the population of the region rises to 613,607 , showing a slight decrease of $1 \%$ compared to the 2001 census. Of these, the Muslim Community of Xanthi and Rodopi numbers approximately 120,000 inhabitants, thus presenting a significant differentiation in the population composition of the region compared to the other regions of the country. The age distribution shows that $68 \%$ of the population are economically active, ranging from 15-64 years. The low birth rate, as in the rest of the country, is one of the alarming features of the EMT Region, as only $15 \%$ of the population is under 15 and $18 \%$ over 65 .

In general, it should be noted that unemployment in the EMT Region in 2010 amounted to $13.2 \%$. At the end of 2011 whilst the economic crisis, which has prevailed in the country for several years, was evolving, unemployment rate rose sharply, surpassing $20 \%$, even more than the country's average $(16.3 \%)$. Among the regions of the country, EMT continues to occupy the third place in unemployment, after the South Aegean and Western Macedonia. According to more recent estimates, unemployment in the EMT region continues to range at high levels in unemployment rates among young people, women and the long-term unemployed (http://www.statistics.gr). The sectoral composition of employment in the EMT region shows its great dependence on the primary sector, with $29 \%$ of the workers being employed in the primary sector, while in the secondary sector $17 \%$ is being employed and in the tertiary $57 \%$. The GDP per capita gross domestic product (GDP) of the region at current prices, was growing at a slower pace compared to the national average, to reach $€ 20,830$ in 2009 , while under the impact of the economic crisis it was reduced to $€ 14,945$, ranking the EMT in the last (13th) position, between the regions of the country.

Strong inequalities, however, also occur within the regional sections, based on the level and the diachronic variation of the indicators of the produced and the per capita product. The Evros and Kavala prefectures are also included with an equivalent participation in the regional product and the level of the per capita product, which collectively produce almost $55 \%$ of the total product of EMT and have a higher standard of living than the average of the region by 8 to $9 \%$. The Regional Units of Xanthi, Rodopi and Drama contribute cumulatively to $45 \%$ of the product of the EMT, while their living standards are below the average of the
Region by 5 to 10 percentage points. The lowest GDP is recorded in the Rodopi area with $€ 13,624$, down by approximately $17 \%$ compared to the highest GDP, $€ 15,398$ in the Regional Prefecture of Evros (http://www.statistics.gr).

Regarding the infrastructure of the EMT Region, Egnatia Odos, which connects the Middle East with the countries of Europe, crosses the EMT region, ensures easy, safe and fast transport of agricultural products to the metropolitan center of Thessaloniki and to the port of Igoumenitsa, thus forming the main international transport axis and the gateway to the Balkan and European countries. The completion of the vertical interconnection axes between Greece and Bulgaria (Alexandroupolis - Ormenio, Komotini - Nymphaia, Xanthi - Echinos, Drama - Exohi) will make the EMT Region even more of a center of promotion and development of the inter-Balkan economic, social and cultural cooperation. In addition, the vertical axis of Alexandroupolis - Ormenio connects Egnatia with the Trans - European axes of Alexandroupolis - Helsinki, while the completion of the vertical axes of Drama - Exohi, Komotini - Nymphaia, Xanthi - Echinos will connect Egnatia with the horizontal axis of Constantinople - Dresden and will give to the EMT region an even more important international role. The European motorway E61, which when completed will connect Sofia via the port of Kavala and Egnatia Odos via Serres and Drama, is expected to play an important developmental role in the region. The railway network that crosses the region cannot be considered to meet the modern needs since, apart from its old age and lack of upgrades, it follows a mountainous Mediterranean route without connecting with the ports (except for that of Alexandroupolis), the airports and without any point of contact with Egnatia Odos. The launch and implementation of the major project of the Egnatia railway in conjunction with the international railway project connecting Rousse to the Bulgaria-Romania border, the ports at Varna and Burgas in Bulgaria and the Greek ports of Alexandroupolis, Kavala and Thessaloniki will provide the region with a significant growth momentum. The agreement on this project has been signed but the timetable for the implementation is not known. Whereas, for years it has been interesting to see the under-study railway project of the commercial port of Kavala, "Philip II of Macedonia", with the railway network at Toxotes of Xanthi. The prefecture has two important ports; those of Alexandroupolis and Kavala. In fact, it should be noted that there is a port system in Kavala, which is more complex as there is a different passenger port in the city center (Port "Apostolos Pavlos"), which is also the only coastal connection of the islands of the North Aegean with northern Greece while the routes extend to the southern Aegean Sea. A different commercial port exists in the east of the city (Port "Philip II") and also different port facilities exist and serve the fish-wharf and the two largest industries in the area (fertilizer plant \& crude oil facilities, which is pumped into the deposits of the bay of Kavala) east of the city. Apart from the port of Alexandroupolis and the port system of Kavala, there are ports of lesser importance such as those at Porto Lagos in Xanthi, Keramoti, Limenas Thassos \& Prinos of Thassos, N. Peramos in the Prefecture of Kavala, the harbour of Kamariotissa in Samothrace in the Prefecture of Evros and a long series of fishing shelters in Makri of Evros, Maroneia and in Imerod of Rodopi, the seaside villages of Thassos etc. There are also two major international airports in the district, which connect the prefecture with Athens domestically, but also with many 
destinations abroad, mainly in the summer, with touristic charter flights, serving the tourist traffic.

There are also the major dams which are managed by PPC SA (also DEI in Greek) in the Nestos River as well as the dams under construction at Iasi in the Rodopi prefecture and Marmaras River in Kavala, while smaller water reservoirs exist in Maries of Thassos, in Folia of Pangaio and elsewhere. The Region also has significant water resources based on the development of irrigation networks from the 1960s to 1970 s with open pipelines such as in the area of the western plain of the Nestos River.

In the tourism sector it has to be mentioned that there has been a developmental mood in recent years, since domestic tourism has been reduced due to the economic crisis, hundreds of thousands of tourists from the Balkan countries but also from Russia and central and northern Europe come to the region in the summer months. It is worth noting that more than $80 \%$ of the tourist beds in the region are located on the island of Thasos.

The EMT region has significant natural resources, terrestrial, aquatic as well as subsoil. It is worth noting that important rivers of the country go through EMT, which are characterized as international, as most of them spring from the mountainous masses of the Rodopi Mountains within Bulgaria, such as the Evros River, which is also the border of Greece with Turkey, the tributaries of Arda and Erythropotamos, the Nestos River, the tributaries of Strymonas, Aggitis, Marmaras, etc. Apart from the rivers, the lake of Porto Lagos is worth mentioning, as are the lagoons in the Evros Delta, the colourful lake (also known as
"Alatza Giola") in the Nestos Municipality and the lagoons in the same municipality, within the Gulf of Kavala, where special harvested facilities exist for catching fish which are naturally squeezed into them in phases of their biological cycle. It is worth noting that all these water bodies, as well as the country's only riparian forest, located at the estuary of the Nestos River, are included in the EMT Wetland Park, as well as in the Natura 2000 network and are mostly protected by the Ramsar Treaty.

In the EMT Region there is also the only oil deposit in the "Prinos" Marine Region, which has been utilized since 1979. In the same sea area, there is also a natural gas depot, which has been depleted. Also, in the Prefectures of Drama \& Kavala (both in the mainland of the prefecture as well as on Thasos) there are quarries from which high-quality marble is mined, as well as in the area of the Pangaio Municipality where mining of shale takes place. Additionally, in the Evros Regional District there is a rich zeolite deposit, in the greater area of Orestiada.

EMT is perhaps the richest or one of the richest regions of the country with regard to geothermal energy as within its expanse there are significant geothermal fields, which have been identified in its territorial limits, but without the exploitation and utilization of many of those to an extent equivalent to the energy they can provide (Table 6). The exploitation of geothermal fields in EMT is particularly important in combination with geographical location of the region and the existing infrastructure (Egnatia Odos, airport) in order to promote the products produced [104].

Table 6. The geothermal fields of the EMT Region

\begin{tabular}{|c|c|c|c|c|c|}
\hline Geothermal Field & $\begin{array}{c}\text { Field size } \\
\left(\mathrm{km}^{2}\right)\end{array}$ & $\begin{array}{c}\text { Depth } \\
\text { (m) }\end{array}$ & $\begin{array}{c}\text { Maximum } \\
\text { supply } \\
\text { (t/h) }\end{array}$ & $\begin{array}{c}\text { Maximum } \\
\text { temperature } \\
\left({ }^{\circ} \mathrm{C}\right)\end{array}$ & Utilization capabilities \\
\hline Aristinon Evros & 30 & $150-450$ & 400 & 92 & $\begin{array}{l}\text { Greenhouses, Aquaculture, Spa } \\
\text { tourism }\end{array}$ \\
\hline Tixeron Evros & - & 400 & 500 & 38 & Greenhouses, Aquaculture \\
\hline Traianoupolis Evros & - & $50-150$ & 100 & 52 & Spa tourism \\
\hline $\begin{array}{l}\text { Samothraki island, } \\
\text { Evros }\end{array}$ & - & $40-120$ & 100 & 100 & Spa tourism \\
\hline Sapes Rodopi & 25 & 400 & 500 & 40 & Greenhouses, Aquaculture \\
\hline $\begin{array}{l}\text { Komotini } \quad \text { South, } \\
\text { Rodopi }\end{array}$ & 30 & 450 & - & 40 & Greenhouses \\
\hline Mitriko Rodopi & 7 & 500 & - & 40 & Greenhouses, Aquaculture \\
\hline Lagos Xanthi & - & 450 & 20 & 38 & Greenhouses, Aquaculture \\
\hline N. Kessani Xanthi & 25 & 400 & 500 & 40 & Greenhouses, Aquaculture \\
\hline Eratino Kavalas & 14 & $600-800$ & 300 & 70 & $\begin{array}{l}\text { Greenhouses, Aquaculture, Spa } \\
\text { tourism }\end{array}$ \\
\hline Eleftheron Kavalas & $\begin{array}{l}\text { Small } \\
\text { scalle }\end{array}$ & $150-200$ & 5 & 41 & Spa tourism \\
\hline Akropotamos Kavalas & 6.9 & $100-185$ & 415 & 90 & $\begin{array}{l}\text { Greenhouses, Aquaculture, Spa } \\
\text { tourism }\end{array}$ \\
\hline
\end{tabular}

Source: IGME - Directorate of Geothermal and Thermal Water (2007) \& IGME - Directorate of Geothermal and Thermal Waters "Geothermal Fields Surveillance Report" (2010) [105].

The primary sector constitutes, along with tourism, a key area of development for the EMT region. The primary sector is mainly based on the exploitation of farmland and pastures, combined with the water resources and the good climatic conditions. The primary sector covers $96 \%$ of the total area of the region. According to the data of the General Secretariat for Forests (2013), 35.2\% of the total area is covered by fields (agricultural land), $37.7 \%$ by forests, $15 \%$ by forest land, $8 \%$ by forest land grazing) and the remaining $2 \%$ of arid land (http://www.statistics.gr).
The primary sector contributes $8.7 \%$ (about three times the national one) to the total GDP of the EMT region and contributes a significant proportion of raw materials to the secondary sector (manufacturing). It participates with $42 \%$ of the region's exports, which however remain small, as only $14.6 \%$ of its total primary production is exported. Exports include mainly grapes, asparagus and kiwis from the areas of Kavala's Regional Unity and less from other areas.

Regarding the structure of agriculture, the basic crops of the region remain the annual field crops, with the main and 
traditional cultivation of cereals, covering about $47 \%$ of the agricultural land. The coupled subsidy of the cotton culture provided a boost to the preservation of crop areas, while at the same time the extremely intense reduction of tobacco and sugar beet was recorded. In contrast, oilseed rape has been on the rise in recent years. At the same time, the "guarantee" of contract farming has helped in the increase of soybean cultivation. More specifically, the total area of the cultivated agricultural land in EMT is approximately 5 million acres, or $34.77 \%$ of its total area. A $34.81 \%$ of the cultivated land (roughly the average for the country) is irrigated, which can be increased by better and more rational utilization and management of the available water resources. In EMT, arable crops account for about $80.41 \%$ of the cultivated land, with the second in tree crops, which occupy $4.31 \%$. Winter cereals utilize most of the non-irrigated areas of the region, as well as marginal land in mountain and disadvantaged areas. Hard wheat was previously adopted by a large number of agricultural holdings in such areas, due to the high area subsidy it received, based on older forms of CAP that have been in force for a long time. It must be pointed out, however, that especially in the western part of the region and especially in the prefecture of Kavala, intensive crops have been developed, which exploit high amounts of capital in the planting and their cultivation as well as work, while producing high quality products, which are standardized, certified and exported for the most part, bringing significant benefits to both the local economy and the national economy. Such crops are mainly table grapes, kiwi fruit, asparagus, vegetables, other vegetables, edible olives, olive oil, etc. Also, in the EMT region in the last decades, significant and quality wines are being produced, which are consumed either in Greece or abroad as well as other products.

In the last fifteen years, the modern farming methods in the region are increasing rapidly, such as integrated agriculture, which covers $15 \%$ of the corresponding area at national level, with over 65,000 ha (Table 7) (http://www.agrocert.gr) Organic agriculture, which accounts for about $10 \%$ of the annual organic production of the country, remains satisfactory (Table 8). A scientific work [106] has shown that the subsidy granted to carry out certification plays an important role in the adoption of this form of agriculture by farmers. Therefore, the CAP should probably identify alternative tools that will help to promote integrated agriculture.

Table 7. The main crops in which integrated agriculture is applied in the EMT Region

\begin{tabular}{l|l|l|r|r}
\hline No & Regional & Crop & $\begin{array}{l}\text { Cultivated } \\
\text { Area } \\
\text { (Stremmas) }\end{array}$ & $\begin{array}{l}\text { Number } \\
\text { of } \\
\text { Producers }\end{array}$ \\
\hline 1 & Drama & Cotton & 12.436 & 424 \\
2 & Drama & Potatoes & 3.748 & 70 \\
3 & Drama & Wheat & 8.482 & 524 \\
4 & Evros & Wheat & 120.581 & 2.799 \\
5 & Evros & Grapes & 212 & 31 \\
6 & Evros & Cotton & 2.200 & 394 \\
7 & Evros & Asparagus & 3.934 & 148 \\
8 & Kavala & Tobacco & 1.756 & 167 \\
9 & Kavala & Grapes & 1.262 & 51 \\
10 & Kavala & Wheat & 1.001 & 12 \\
11 & Kavala & Olive & 92.663 & 2.422 \\
& & trees & 1.132 & 251 \\
12 & Kavala & Kiwi & 3.170 & 153 \\
13 & Kavala & Asparagus & 11.556 & 251 \\
14 & Xanthi & Wheat & 16.182 & 2.831 \\
15 & Xanthi & Tobacco & 1.204 & 79 \\
16 & Xanthi & Kiwi & 13.914 & 154 \\
17 & Xanthi & Cotton & 546 & 16 \\
18 & Xanthi & Asparagus & 174.654 & 2.121 \\
19 & Rodopi & Cotton & 85.811 & 2.146 \\
20 & Rodopi & Wheat & 55.890 & 5.800 \\
21 & Rodopi & Tobacco &
\end{tabular}

Source: AGROCERT - Ministry of Rural Development and Food (2012), (http://www.agrocert.gr).

Table 8. The area (in acres) of the cultivated organic farming species in the EMT Region in 2012.

\begin{tabular}{l|l|l|l|l|l|l|l|l|l}
\hline $\begin{array}{l}\text { Regional } \\
\text { Unit }\end{array}$ & $\begin{array}{l}\text { Olive } \\
\text { trees }\end{array}$ & Alfalfa & Corn & Wheat & $\begin{array}{l}\text { Table } \\
\text { Grapes }\end{array}$ & $\begin{array}{l}\text { Wine } \\
\text { vineyards }\end{array}$ & $\begin{array}{l}\text { Almond } \\
\text { trees }\end{array}$ & Kiwi & Total \\
\hline Drama & 42 & 14248,27 & 1596,57 & 2700,8 & - & - & - & - & $18.587,64$ \\
Kavala & 489,25 & 577,53 & 126,85 & 229,1 & - & 233,4 & 75,5 & 56 & $1.787,63$ \\
Evros & 194,7 & 20520,18 & 795,3 & 2470,25 & 47,7 & 0,5 & 4,2 & & $24.032,83$ \\
Xanthi & 341,92 & 1502,2 & 184,1 & 213,5 & - & - & - & - & $2.241,72$ \\
Rodopi & 197,4 & 2217,9 & & 468,5 & - & - & - & - & $2.883,8$ \\
\hline
\end{tabular}

Source: Ministry of Rural Development and Food (2012) [8].

The role of stockbreeding is also very important for the development of the primary sector, as $20 \%$ of cattle and $10 \%$ of sheep and goats are located in the region. Unfortunately, the various animal viruses that have plagued the region in recent years, such as bluetongue, smallpox, brucellosis and nodular dermatitis have decimated many herds, endangering not only the survival of breeders but also of the production of "feta cheese" with obvious consequences of a national significance. In addition, a significant problem in stockbreeding is the determination of eligible grazing areas as identified by OPEKEPE" (the Greek "Payment and

\footnotetext{
${ }^{2}$ Due to the reorganization of the European Agricultural Guidance and Guarantee Fund (E.A.G.G.F.), OPEKEPE became the Paying Authority in Greece responsible for the following three funds: European
}

Control Agency for Guidance and Guarantee Community Aid") and has resulted in a significant reduction in the amount of the received subsidies received for the regional breeders since 2012 and the corresponding impact on the increase of the financial constraints and the difficulties of the breeders.

Beekeeping is an additional dynamic branch of the agricultural production. Because of its nomadic practice beekeepers exploit the great biodiversity and the abundance of native vegetation of beekeeping plants. There are 1,641 registered breeds, with 160,679 bee colonies and an annual

Agricultural Guarantee Fund (E.A.G.F.), European Agricultural Fund for Rural Development (E.A.F.R.D.), and European Fisheries Fund 05 
production which is estimated to be at 2,384 tons. The largest concentration of livestock is located in the prefecture of Kavala with more than 46,000 bees and especially on the island of Thasos, where due to the diversity of the region and the good beekeeping practices, high quality products are produced in branded and knowledgeable packages all over the country (chestnut honey, forest honey, honeycombs, candle, propolis, royal pulp and pollen). The most representative of these are the renowned and well-known pine tree as well as the special flower honey of the region.

Finally, the fisheries and aquaculture sectors are particularly dynamic and show growth in all Regional Units, most of which are in the Regional Unity of Kavala. Units of fish farming and shellfish farming are mainly found on the sea front and a smaller number in inland waters. In particular, the Thracian Sea is one of the richest catchment areas across the Mediterranean and the most productive fishing area in the whole country, thus making EMT one of the most important catchment and marketing areas of high quality. It should be noted that based on unofficial data, Kavala's Fish Wharf is the first in the sea catching trade while it is ranked in third place on a Pan-Hellenic basis based on the total turnover, which includes both imports and exports, as well as the products of the fish farms. Exports take place from Kavala's Fish Wharf, not only to neighbouring countries but also to other distant parts of the world such as Japan, the US and Canada.

Based on the above brief description, the importance of the agricultural and rural sectors in the economy and the developmental effort of EMT is obvious. This constitutes as a necessary and capable condition the application of the important consequences of CAP, which plays a catalytic role in the agricultural and rural sectors throughout the economic and development area of the region, which are potentially being launched either through the EU subsidies it provides or through the financial instruments and measures it provides both for the production and processing of products or the terms and conditions included in the CrossCompliance but also because of the inputs incorporated by the agricultural sector as well as the employment and income it generates, which are then diffused into the local economy as well as by exports. In this context, the relationship that potentially develops with tourism through wine tasting and the consumption of products by the visitors of the region during their stay in the area, as well as due to the transportation, etc., should also be mentioned.

Apart from the description of the area, which is based on the quoting of the statistics and other information related to it, it is worth mentioning some additional indicative, qualitative data which have been generated by research and concern the human resources of EMT that is active and produces in the agricultural sector. An assessment of the sources of information of the people dealing with CAPrelated agriculture issues is given in the first table (Table 9). The second table (Table 10) concerns an assessment of the interest of the region's producers in CAP and the developments related to it, and finally, the third table (Table 11) addresses the main problems identified as regards the inclusion of producers in financial measures of Pillar II and, in particular, the most common case concerning the measure relating to the implementation of investments in agricultural holdings. It should be pointed out that this image has emerged in the context of research [21] through questionnaires addressed to scientific staff working in the agricultural sector of the Region.
Table 9. Agricultural Producers' Information Sources of the EMT (through questionnaires by the scientific personnel working in the Region's agriculture). The evaluation ranges from $5=$ very large information provision, up to $1=$ no provision of information.

\begin{tabular}{l|c}
\hline $\begin{array}{l}\text { Stores of pesticides and supplies } \\
\text { Seminars and conferences of agronomic / } \\
\text { geotechnical organizations }\end{array}$ & 3,72 \\
Internet & 2,80 \\
Cooperative Organizations & 2,68 \\
The press & 2,47 \\
Producers' Organizations & 2,28 \\
Public Services \& Organizations & 2,26 \\
Agricultural Associations \& Confederations & 2,09 \\
Media (TV, radio) & 1,81 \\
Political parties & 1,76 \\
Local Authorities (Municipalities, etc.) & 1,50 \\
\hline
\end{tabular}

It turns out from the above table on the one hand, that the small, below the expectant provision of information from the public sector (Public Services \& Organizations as well as from the Local Authorities, Municipalities, etc.) and the identification as a main source of information of the outlet points of sale for the productive agricultural process (pesticides, fertilizers and other supplies). Also, at a low point, in terms of their assessment, are the collectives, which concern the rural world and include both the Cooperatives as well as the Agricultural Associations.

Table 10. Evaluation of the farmers' interest in CAP. (through questionnaires by the scientific staff working in the Region's agriculture).

\begin{tabular}{l|r}
\hline & \multicolumn{2}{|c}{ Percentage } \\
\hline $\begin{array}{l}\text { It covers in-depth the developments } \\
\text { regarding the CAP }\end{array}$ & 10,7 \\
It concerns only the amount of the \\
subsidies \\
$\begin{array}{l}\text { It does not exist. They are not } \\
\text { interested at all }\end{array}$ \\
TOTAL
\end{tabular}

The above table showcases a worrying finding because it indicates that only one in 10 farmers of the region is interested in the CAP developments, whereas the overwhelming majority's interest is limited to the payment and collection of EU subsidies. This fact leads us to the conclusion that, since farmers are not interested in this crucial issue, it entails that they cannot timely adapt to the new developments that arise and this becomes decisive for the region as CAP exerts a clear and significant influence not only on agriculture, but also on the local economy and the development of the region. 
Table 11. Ranking in terms of the importance of the problems identified in the implementation of the financial measures, as they were pointed out.

\begin{tabular}{l|c}
\hline $\begin{array}{l}\text { Main problems in the implementation of } \\
\text { Improvement Plans and other financing } \\
\text { measures }\end{array}$ & $\begin{array}{c}\text { Sum of } \\
\text { percentages } \\
\text { "I totally } \\
\text { agree" \& } \\
\text { "Agree" }\end{array}$ \\
\hline "excessive bureaucracy" & $96,3 \%$ \\
"tremendous time until approval" & $96,3 \%$ \\
$\begin{array}{l}\text { "unforeseen timetables, irregular notice } \\
\text { periods" }\end{array}$ & $87,5 \%$ \\
"insufficient funds" & $85,4 \%$ \\
"continuous changes to terms and & $84,4 \%$ \\
"interest and revaluations" use up "the & $78,7 \%$ \\
$\begin{array}{l}\text { amount of the subsidy until the final } \\
\text { approval" } \\
\text { "Inappropriate objectives of the financing } \\
\text { measures" }\end{array}$ & $54 \%$ \\
\hline
\end{tabular}

This table essentially describes the negative contribution of public administration to the implementation of the CAP Pillar II financial measures, as the first three answers, which are fully accepted, as well as the fifth answer, relate to the functioning of public administration and refer to excessive bureaucracy, lack of regular time-frames in order to prepare each interested and potentially eligible farmer, as well as excessive time for the adoption and final implementation of the proposals approved and included in the financial measures. This issue is also linked to the sixth answer as time delays involve a charge of interests on agricultural holdings and this is of particular importance as funding during the economic crisis is particularly limited. The answers show that $85 \%$ believe that the resources allocated to these measures are insufficient and should be higher. Finally, around $50 \%$ think that the objectives of the measures are inappropriate, a fact which may pose a question of re-approaching the eligible actions of the program, alongside with the necessity raised by $85 \%$, which seek more resources for these measures.

\subsection{Purpose}

The purpose of this scientific paper is to investigate the impact of the reformed CAP as it applies every time to the local economy of the regions of Eastern Macedonia-Thrace (Greece) and the development of the region. As it has also been pointed out, CAP is not a stable and unchanging European policy, but as described in the introduction and the literature review, it is periodically reviewed and adapted to changing EU objectives. Thus this study looks at the effects of two successive CAP reforms that were implemented; the first since 2004 and the second since 2014. The length of the years covered by the present study which concern the local economy provide the possibility of stating that this study relates to the impact of CAP and its reforms, as well as in the course of the development of the Region.

The scientific study gathers data which concern the whole region, which consists of five prefectures or six Regional Units today, through structured questionnaires, however, no sampling has been carried out to collect them, as the source of the data is the scientific staff working in agriculture and consists mainly of agronomists who are graduates of tertiary education, who cover the whole region and are mainly employed in all sectors of the agricultural production, but also provide all kinds of scientific advice concerning the whole of the production sector, marketing and including also for example, the submission of supporting documents concerning either IACS (Integrated Management and Control System for EU subsidies, the available financial instruments, the possibility of adopting a different production method, certification, etc.) and not only plant protection. It should be noted that those who provided the data are not the producers themselves, but the scientists involved, each of whom interacts and cooperates with hundreds of farmers, receiving from them the relevant stimuli, which is also processed based on his scientific background to form a comprehensive view, which we gathered with the use of the relevant research tools (questionnaires and interviews).

The purpose of this paper is not limited to the impact of CAP on the local economy and development as a whole, which is expressed by the comparison of two econometric equations, but aims at approaching also the individual sectors of the local economy, which are sometimes more affected and other times less from the implementation of each form of the CAP following each reform, which differentiates the reality both in its production and structure, as well as in the marketing and processing or subsequent manufacturing of the products. It is also noted that the scientific study accepts the scientific view, which was cited in previous chapters, which asserts that the CAP and its effects on agriculture resemble, with a conceived image of concentric circles, the other non-agricultural sectors of the local economy and local development. The study examines its implications on the entire local economy and development.

It should be added here that the region, as an administrative unit and as an area, constitutes a suitable space for such a research to be carried out, due its expanse, its population (agricultural and scientific), and also the volume and diversity of its products.

\section{Research Methodology}

The research methodology includes a survey based on interviews with a questionnaire in the region of Eastern Macedonia-Thrace. The specific questionnaire was formed after the earlier use of a questionnaire and the conduction of a qualitative survey that contributed to the formulation of the quantitative research questionnaire. The questionnaire was addressed to all the scientific potential of agriculture. The procedure was repeated after subsequent revisions of CAP, without the part dealing with the qualitative research of the questionnaire.

The questionnaire included four sections. The items in the first section addressed the general CAP consequences of Pillar I on the population of the region, from the point of view of the scientific staff working in agriculture. The next section recorded the environmental issues of CAP and the third section addressed the financial consequences of CAP. Thus, taking account the full content of the three units, which finally form the three latent variables, they are named as follows: "CAP - Pillar I", "CAP - Multiple Compliance" and "CAP - Pillar II". The last section of the questionnaire investigated consequences of CAP on the local economy and finally forms the forth latent variable, named "Local Economy". The answers were given in the form of the fivepoint Likert scale, where 1 stands for "Strongly Agree" and 
5 denotes "Strongly Disagree". The sample size was 140 participants at the first period and 93 at the second period of the CAP review, who are mainly agronomist scientists, who work in the region's private agriculture sector.

The validity of the questionnaire structure was tested via factor analysis since the specific questionnaire was used in previous research [24](Markopoulos PAPER). The purpose of the previous research was the identification of the items that have the most significant impact on CAP reform - Pillar I, environmental issues - Multiple Compliance, financial issues - Pillar II and the local economy. In this study, the same instrument was used in order to obtain the answers of the scientists under the new circumstances created by the new CAP review of 2014. For each one of the factors, reliability was also examined and tested with Cronbach's $a$ criterion. A value of Cronbach's $a$ greater than 0.6 indicates high reliability. The full table, including factor loadings is presented in Appendix A (Table A.2). More details on factors for the specific analysis can be found in Markopoulos et al[24].

The design of the entire research methodology of this scientific project initially included the formulation of the econometric equations, which form the four latent variables and then the formulation of the equation that connects them (CAP - Pillar I, CAP - Multiple Compliance, CAP - Pillar II and Local Economy) at each one of the two time periods, named "2004" (i.e. Local Economy - 2004) and "2014" (i.e. Local Economy - 2014) since those are the years of implementation of each CAP reform in agricultural production.

In addition, and besides the formulation of the structural equations of the years 2004 and 2014, a comparison of the SEM Models of the two CAP Reforms (2004 and 2014) follows. In addition to the comparison, it is also possible to assess whether the opinion of those that participated in the survey is positive (or less negative) for each part of the SEM equation in the two CAP reforms.

At the next part of the survey, the opinion of the participants, regarding the impact on each one of the 13 individual sectors of the local economy, was studied. These sectors were part of the quantitative questionnaire and were fully determined by the qualitative research that had originally taken place. Thus, apart from the overall view of the impact of CAP reforms on local development and the economy, the survey provides a specific view at the individual sectors of the local economy, by comparing the CAP - 2004 and the CAP - 2014 reforms. These comparisons showed that there are significant changes in opinions between the two periods.

The following figure outlines the course and steps for implementing this scientific work, as it is described above.

Structural Equation Modelling (SEM) was then used in order to fit the investigated model and to estimate its coefficients for the new period of the CAP review, i.e. 2014. This analysis is the appropriate method for processing in the case where the relationships lie between latent and observed variables and between latent variables simultaneously, in order to validate or reject the assumptions made by the researcher [107]. Moreover, as a part of the analysis, the full model will be re-estimated, with both the samples used and under the new conditions that the CAP review create in the local economy. For this purpose, the statistical package LISREL 9.2 (SSI, 2000) was used.

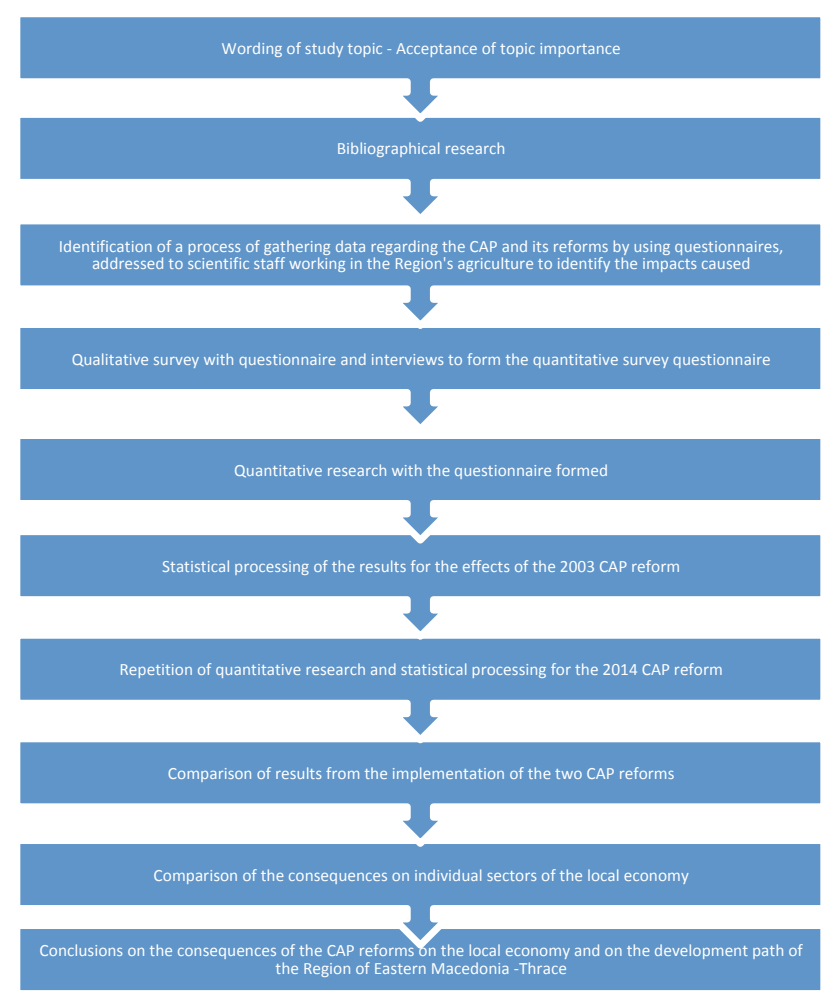

Fig 3. Steps to implement this scientific paper

In the model one variable from each group of observed variables that determine the latent variables had a factor loading fixed to the unit, or the variance of each latent variable must be fixed to one. The reason for imposing these constraints is the indeterminacy between the variance of a latent variable and the loadings of the observed variables on that latent variable. Utilizing either of these methods will eliminate the scale indeterminacy problem [107]. Moreover, this technique is necessary in multiple group analysis in order to put the latent variables in same scale in each group. This makes it possible to compare the variances of the latent variables in the two groups [108]. Thus, the variables that are set to have loadings equal to the unit are: "Product Production" (M1), "Application Accuracy" (M6), "Marketing Practices" (M13) and "Areas in dependence on Agriculture" (M45). The reason for this choice is that these variables identify to a great scale their respective factors, as is clear from the reliability analysis. The model shown in the following Figure 4 can be expressed by the following equations (Measurement model):

(CAP-Pillar I)

$+\lambda_{13}(\mathrm{M} 3)+\lambda_{14}(\mathrm{M} 4)+\lambda_{15}(\mathrm{M} 5)$

(CAP-Multiple Compliance)

$+\lambda_{23}(\mathrm{M} 8)+\lambda_{24}(\mathrm{M} 9)+\lambda_{25}(\mathrm{M} 10)$

(CAP-Pillar II)

$(\mathrm{M} 13)+\lambda_{33}(\mathrm{M} 14)+\lambda_{34}(\mathrm{M} 15)$

(Local Economy)

$(\mathrm{M} 46)+\lambda_{43}(\mathrm{M} 47)$

and the single equation, which is the structural model:

(Local Economy) $=\xi_{1}($ CAP-Pillar I $)+\xi_{2}$ (CAP-Multiple Compliance $)+\xi_{3}$ (CAP-Pillar II), 
where: $\lambda_{i j}, i=1,2,3,4, j=1, \ldots, 4$ and $\xi_{i}, i=1,2,3$ are the coefficients to be estimated.

Based on the results of the factor analysis, the full model under investigation, for both CAP reforms (2004 and 2014), is illustrated in the following Figure 4.

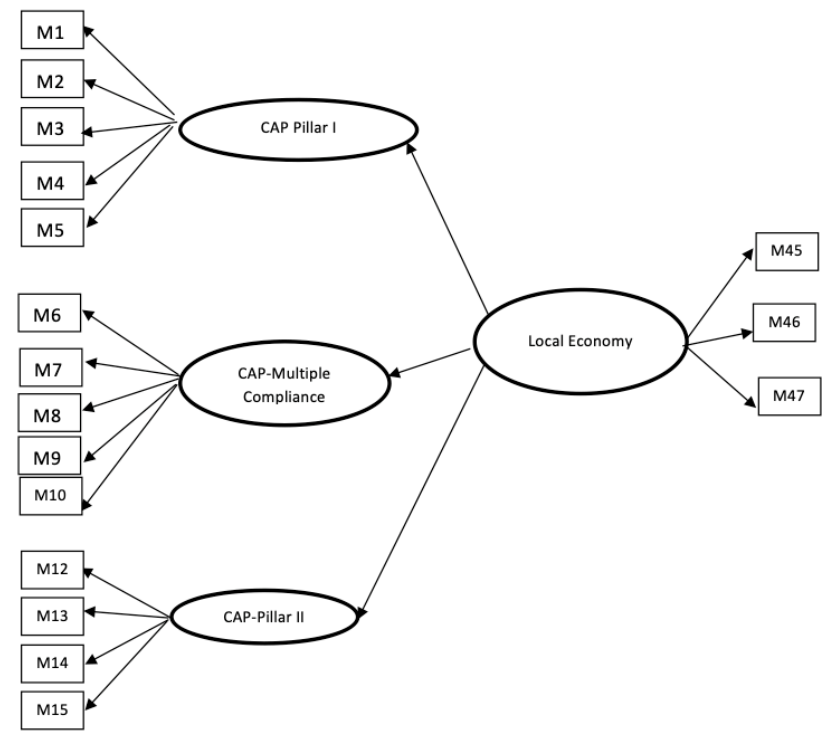

Fig. 4. Structural and measurement model of the research for both periods of CAP Reform.

\section{Results}

For the adjustment of the two models, the unweighted least squares (ULS) procedure was used, because of the ordinal scale of the items. Therefore, they cannot be treated as quantitative, since their number is small, and consequently, it cannot be regarded that they follow the normal distribution [107]. Table 12 shows the standardized factor loadings of the observed variables for each one of the latent variables of the two models. All the coefficients have a significant effect on the corresponding variables at the $5 \%$ significance level.

Table 12. Standardized Factor Loadings for the SEM model for the two periods of CAP reform (2004 and 2014). (In brackets the is the corresponding standard error of the estimates)

\begin{tabular}{c|c|c}
\hline Coefficient & $\begin{array}{c}\text { Estimators for 2004 } \\
\text { review }\end{array}$ & $\begin{array}{c}\text { Estimators for } \\
\text { 2014 review }\end{array}$ \\
\hline$\lambda_{11}$ & $-0.920(0.233)$ & $-0.821(0.125)$ \\
$\lambda_{12}$ & $-0.584(0.129)$ & $-0.541(0.104)$ \\
$\lambda_{13}$ & $-0.553(0.311)$ & $-0.452(0.314)$ \\
$\lambda_{14}$ & $-0.786(0.326)$ & $-0.811(0.285)$ \\
$\lambda_{15}$ & $0.629(0.219)$ & $0.741(0.203)$ \\
$\lambda_{21}$ & $0.725(0.218)$ & $0.796(0.204)$ \\
$\lambda_{22}$ & $-0.240(0.172)$ & $-0.321(0.162)$ \\
$\lambda_{23}$ & $-0.518(0.122)$ & $-0.574(0.129)$ \\
$\lambda_{24}$ & $-0.671(0.117)$ & $-0.526(0.185)$ \\
$\lambda_{25}$ & $0.398(0.243)$ & $0.253(0.198)$ \\
$\lambda_{31}$ & $0.312(0.017)$ & $0.423(0.102)$ \\
$\lambda_{32}$ & $-0.326(0.109)$ & $-0.296(0.124)$ \\
$\lambda_{33}$ & $-0.462(0.114)$ & $-0.485(0.021)$ \\
$\lambda_{34}$ & $0.421(0.016)$ & $0.502(0.085)$ \\
$\lambda_{41}$ & $0.506(0.013)$ & $0.571(0.039)$
\end{tabular}

\begin{tabular}{c|c|c}
\hline Coefficient & $\begin{array}{c}\text { Estimators for 2004 } \\
\text { review }\end{array}$ & $\begin{array}{c}\text { Estimators for } \\
\text { 2014 review }\end{array}$ \\
\hline$\lambda_{42}$ & $0.528(0.107)$ & $0.488(0.089)$ \\
$\lambda_{43}$ & $0.332(0.221)$ & $0.384(0.192)$ \\
\hline
\end{tabular}

Hence, the equations using the estimated standardized coefficients become:

\section{Measurement Equations: First Period (2004)}

$($ CAP- Pillar I) $=-0,920$ (Product production)-0,584 (Output Reduction)-0,553 (Differentiation) -0,786 (Human Resources)

$$
+0,629 \text { (Farms) }
$$

$($ CAP-Multiple Compliance $)=0,725$ (Application Accuracy)-0,240 (Financial Consequences)-0,518 (Impact)

$-0,671$ (Farm Income from winter cereals) $+0,398$ (Farm Income from summer cereals)

(CAP-Pillar II) $=0,312$ (Market Bodies)-0,326 (Marketing Practices)-0,462 (Marketing Problems)

$$
+0,421 \text { (Climate Impact) }
$$

(Local Economy) $=0,506$ (Areas in dependence on Agriculture) + 0,528 (Boarder Sectors)+0,332(Land Value)

\section{Structural Equation: First Period (2004)}

$($ Local Economy $)=-0,850($ CAP Pillar I $)-0,870($ CAPMultiple Compliance) + 0,704 (CAP-Pillar II)

\section{Measurement Equations: Second Period (2014)}

$($ CAP Pillar I) $=-0,821$ (Product production) $-0,541$ (Output Reduction)-0,452 (Differentiation)

(Farms)

$$
-0,811 \text { (Human Resources) }+0,741
$$

$($ CAP-Multiple Compliance $)=0,796$ (Application Accuracy) -0,321(Financial Consequences)-0,574 (Impact)

$$
-0,526 \text { (Farm Income from }
$$
winter cereals) $+0,253$ (Farm Income from summer cereals)

(CAP-Pillar II) $=0,423$ (Market Bodies) -0,296 (Marketing Practices)-0,485 (Marketing Problems)

$$
+0,502 \text { (Climate Impact) }
$$

(Local Economy) $=0,571$ (Areas in dependence on Agriculture) + 0,488 (Boarder Sectors)+0,384 (Land Value)

\section{Structural Equation: Second Period (2014)}

$($ Local Economy $)=-0,317($ CAP Pillar I) - 0,784 (CAPMultiple Compliance) + 0,911 (CAP-Pillar II)

In the Table 13, the two structural equations of the two periods are presented together. 
Table 13. The two Structural Equations for the two periods of CAP reform (2004 and 2014).

\begin{tabular}{|c|c|}
\hline 2004 & $\begin{array}{c}(\text { Local Economy })=-0,850(\text { CAP-Pillar I })- \\
-0,870(\text { CAP }- \text { Multiple } \\
\text { Compliance })+0,704 \text { (CAP - Pillar II })\end{array}$ \\
\hline 2014 & $\begin{array}{r}(\text { Local Economy })=-0,317 \text { (CAP Pillar I) }- \\
-0,784 \quad(\text { CAP }- \text { Multiple } \\
\text { Compliance })+0,911(\text { CAP }- \text { Pillar II })\end{array}$ \\
\hline
\end{tabular}

\section{Comparing the SEM Models of the two CAP reforms (2004 and 2014)}

LISREL assumes by default that the models are identically the same over groups, i.e. all the parameters and all the relationships are the same in each group and something that is happened in this case, as the previous factor analysis has shown. Thus, only differences between groups need to be specified. The most common application of multi group analysis is factorial invariance, which states that the factor loadings are the same in all groups. The specific assumption seems to be fulfilled in this case, as the previous Table 12 of the loadings of the groups is shown, but a statistical test must be held in order to make the assumption more accurate. The comparison of the overall fit of the two models, separately, show that both are very good, as indicated by the indexes presented in Table 14.

Table 14. Goodness of model fit for both periods

\begin{tabular}{ll|l|l|l}
\hline \multicolumn{1}{c|}{ Index } & $\begin{array}{c}\text { Values of } \\
\mathbf{2 0 0 4} \\
\text { CAP } \\
\text { Review }\end{array}$ & $\begin{array}{c}\text { Values of } \\
\mathbf{2 0 1 4} \\
\text { CAP } \\
\text { Review }\end{array}$ & $\begin{array}{c}\text { Acceptable } \\
\text { values }\end{array}$ \\
\hline Contribution & to & 218.114 & 195.251 & - \\
$\mathrm{X}^{2}$ & & & & \\
GFI & 0,918 & 0,951 & $>0,9$ \\
RMSEA & 0,056 & 0,052 & $0,05-0,08$ \\
AGFI & 0,892 & 0,902 & $\geq 0,9$ \\
\hline
\end{tabular}

To test the hypothesis that the factor loadings are the same across the two groups, we must add the chi-squares, since the two groups are independent. The total chi-square is the sum of the chi-squares of the two groups, (i.e. $218.114+$ $195.251=413.365)$ with 230 degrees of freedom. The LISREL showed that the overall chi-square of the difference of the two models is 420.586 with 17 degrees of freedom. The difference of the values of the two chi-squares is 7.221 with indicates that the hypothesis, of the equality of the factor loadings across the two groups cannot be rejected [108].

In order to compare the two SEM models with respect to the mean values of the latent variables, the Structural Means Model (SMM) was used. The SMM is another special type of SEM application that is used to test group mean differences in latent variables. The SMM model in this case examines the mean difference between the two CAP reviews (2004 and 2014) on the four latent variables: CAP Pillar I, CAP-Multiple Compliance, CAP-Pillar II and Local Economy.

The structured means model is testing the mean latent variable difference, which is indicated by the Mean Vector of Independent variables and is presented in Table 15. The results are interpreted based on the knowledge that the mean latent value on CAP Pillar I, CAP-Multiple Compliance, CAP-Pillar II and Local Economy are set to zero in the first group (CAP Reform 2004), so the values reported in Table 4 are indicate that the second group (CAP Reform 2014) was either greater than (positive values) or less than (negative values) the first group. Thus, the results presented in Table 15 for the four latent variables are the following (in brackets there are the standard errors):

\begin{tabular}{c|c|c|c}
\multicolumn{5}{c}{ Table 15 Mean Vector of Latent Variables } \\
\hline CAP Pillar & $\begin{array}{c}\text { CAP-Multiple } \\
\text { I }\end{array}$ & $\begin{array}{c}\text { CAP- } \\
\text { Compliance }\end{array}$ & $\begin{array}{c}\text { Local } \\
\text { Economy II }\end{array}$ \\
2.171 & 4.825 & 3.415 & 4.321 \\
$(0.122)$ & $(1.254)$ & $(0.521)$ & $(0.961)$ \\
\hline
\end{tabular}

For the CAP-Pillar I, the latent variable mean difference value of 2.171 indicates that the mean difference is greater for the second period of CAP reform, than the first period. This means that the second reform of the CAP seems to be better and to increase the general attitude towards Pillar I, 2014 compared to the previous one (CAP reform of 2004). For the latent variable CAP - Multiple Compliance, the mean value 4.825 , indicates that the mean difference is greater for the second period of CAP reform, than the first period. This means that the second reform of the CAP tends to increase the general attitude towards Multiple Compliance on 2014 compared to the previous one (CAP reform of 2004).

For the latent variable CAP-Pillar II, the mean value of 3.415 indicates that the mean difference is also greater for the second period of CAP reform, than the first period. This means that the second reform of the CAP increase the general attitude towards Pillar II compared to the previous one (CAP reform of 2004).

For the Local Economy, the mean value of 4.321 indicates that the mean difference is greater for the second period of CAP reform, than the first period. This means that the second reform of the CAP seems to have a positive effect on the local economy in general than the first reform.

The estimated group means are also presented with the variances and covariances of the four latent variables in Table 16. Overall, the second period of CAP reform (2014) seems to have positive effects on each one of the latent variables.

Since the comparison of the two SEM models showed that the models are good enough for both periods of CAP reform, the comparison of the coefficients of the two structural equations are tested 27/06/19 10:12. The purpose is to estimate the significance of the differences of the two periods with respect to the coefficients and testing whether the coefficients of the second period (CAP Reform of 2014) are higher than the first period (CAP Reform of 2004), as seems to be from the estimation of the two structural equations. Since the coefficients are hypothesized to be distributed normally, the tested hypothesis is that the $\xi_{i}, i=1,2,3$ coefficients are the same across the two models. Table 17 presents the results of the analysis.

From Table 6 it can be observed that all the coefficients have greater values in the second period (CAP 2014), than the first period (CAP 2004). Moreover, the coefficients $\xi_{1}$ and $\xi_{3}$, which refer to CAP Pillar I and CAP-Pillar II, seem to have significant change between the two CAP reforms. This means that in second CAP reform, the impact on local 
economy of these two variables has been improved in a significant level.

Table 16. Estimated Means and Covariance Matrices of the latent variables.

\begin{tabular}{|c|c|c|c|c|}
\hline & \multicolumn{4}{|c|}{ CAP Reform of $2004(N=140)$} \\
\hline & $\begin{array}{c}\text { CAP } \\
\text { Pillar I }\end{array}$ & $\begin{array}{c}\text { CAP- } \\
\text { Multiple } \\
\text { Compliance }\end{array}$ & $\begin{array}{c}\text { CAP- } \\
\text { Pillar II }\end{array}$ & $\begin{array}{c}\text { Local } \\
\text { Economy }\end{array}$ \\
\hline $\begin{array}{c}\text { CAP Pillar I } \\
\text { CAP- } \\
\text { Multiple } \\
\text { Compliance }\end{array}$ & $\begin{array}{l}58.45 \\
60.23\end{array}$ & 66.55 & & \\
\hline $\begin{array}{c}\text { CAP-Pillar II } \\
\text { Local }\end{array}$ & $\begin{array}{l}58.69 \\
65.47\end{array}$ & $\begin{array}{l}69.36 \\
67.77\end{array}$ & $\begin{array}{l}70.62 \\
59.63\end{array}$ & 69.55 \\
\hline $\begin{array}{c}\text { Economy } \\
\text { Means }\end{array}$ & 0 & 0 & 0 & 0 \\
\hline
\end{tabular}

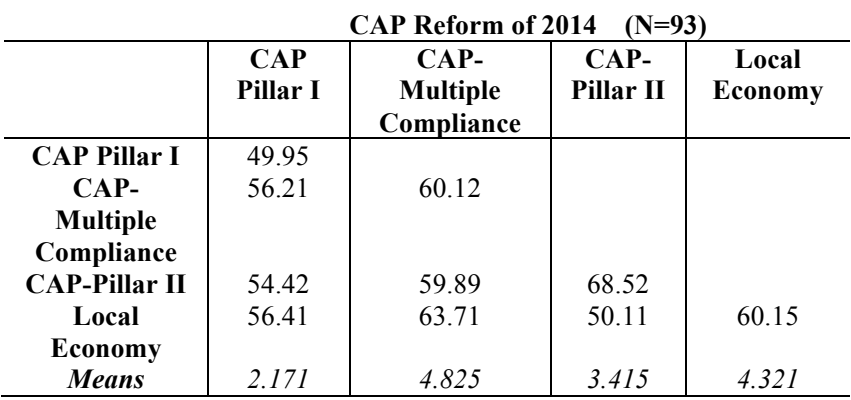

\section{Comparison of the coefficients of the structural equations}

Table 17. Tests for the equality, of the structural coefficients, for both periods of CAP reform.

\begin{tabular}{c|c|c|c|c}
\hline Coefficient & $\begin{array}{c}\text { Estimation } \\
\text { (CAP 2004) }\end{array}$ & $\begin{array}{c}\text { Estimation } \\
\text { (CAP 2014) }\end{array}$ & $\begin{array}{c}\text { Mean } \\
\text { Difference } \\
\text { (CAP 2014- } \\
\text { CAP 2004) }\end{array}$ & $\begin{array}{c}\text { T- } \\
\text { Value }\end{array}$ \\
\hline$\xi_{1}$ & $-0,850$ & $-0,317$ & $0,533^{*}$ & 4.523 \\
$\xi_{2}$ & $-0,870$ & $-0,784$ & 0,086 & 1.225 \\
$\xi_{3}$ & 0,704 & 0,911 & $0,207^{*}$ & 3.936 \\
\hline
\end{tabular}

" Significant at 5\% significance level

\section{Comparison of each one of the components of economy}

In order to draw useful results of the impact of the CAP reform of 2014 on the local economy, compared with the previous reform of 2004, a series of tests were held at each one of the 13 basic components of the local economy. In order to ensure the reliability of the specific components, a reliability analysis with Cronbach's $\alpha$ index was held for both periods of CAP reform. The results showed that in both periods there is high reliability (Cronbach's $\alpha>0.7$ ) of the 13 variables. Totally, 13 t-tests were extracted for the 13 variables which are the main components of the economy. These variables are presented in Table 18 .

Table 18. The components of the economy.

Land Value-Purchase.

Land Value- Hire.

Product processing.

Manufacturing Industry.

Product's transfer.

Manufacture of packaging materials.

Labor hands (harvesting, standardization, packaging)

Construction of storage facilities.

Purchase of agricultural machinery, accessories, etc.

Purchase of pesticides, fertilizers, supplies, etc.
Consumption in the local market.

Living standard.

Building activity in the area.

Cronbach's Alpha $=0.894$ (CAP reform 2004)

Cronbach's Alpha $=\mathbf{0 . 8 3 0}($ CAP reform 2014)

The hypothesis tested at all 13 variables (null hypothesis) is that there is no difference regarding the mean values of them, between the CAP reforms of 2004 and 2014. In order to decide whether the null hypothesis must be rejected or not, a series of t-test with independent samples was conducted for each one of the 13 variables. Moreover, Levene's Test for the equality of variance was used in order to decide on the homogeneity of the variances between the tested populations. Table 19 presents the sample means and standard deviations for each one of the variables for the two periods of CAP reform.

Table 19. Sample means and standard deviations of the variables regarding economy, for the two periods of CAP reform.

\begin{tabular}{l|l|r|r}
\hline & $\begin{array}{c}\text { CAP } \\
\text { Reform }\end{array}$ & Mean & $\begin{array}{c}\text { Std. } \\
\text { Deviation }\end{array}$ \\
\hline Land Value-Purchase. & 2004 & 3,02 & 0,939 \\
& 2014 & 3,52 & 0,824 \\
\hline Land Value- Hire. & 2004 & 2,85 & 1,044 \\
& 2014 & 3,14 & 0,950 \\
\hline Product processing. & 2004 & 2,37 & 0,848 \\
& 2014 & 2,66 & 0,712 \\
\hline Manufacturing Industry. & 2004 & 2,17 & 0,931 \\
\cline { 2 - 4 } & 2014 & 2,21 & 0,917 \\
\hline Product's transfer. & 2004 & 2,56 & 0,995 \\
& 2014 & 2,72 & 0,877 \\
\hline Manufacture of packaging & 2004 & 2,55 & 0,821 \\
materials. & 2014 & 2,58 & 0,792 \\
\hline Labour hands (harvesting, & 2004 & 2,59 & 0,987 \\
standardization, packaging) & 2014 & 2,97 & 0,877 \\
\hline Construction of storage & 2004 & 2,52 & 0,963 \\
facilities. & 2014 & 2,59 & 0,930 \\
\hline Purchase of agricultural & 2004 & 2,60 & 1,105 \\
machinery, accessories, etc. & 2014 & 2,85 & 1,021 \\
\hline Purchase of pesticides, & 2004 & 1,99 & 1,007 \\
fertilizers, supplies, etc. & 2014 & 2,57 & 0,921 \\
\hline Consumption in the local & 2004 & 2,30 & 0,779 \\
market. & 2014 & 2,33 & 0,816 \\
\hline Living standard. & 2004 & 2,31 & 0,886 \\
\hline Building activity in the area. & 2014 & 2,30 & 0,851 \\
\hline & 2004 & 2,11 & 0,926 \\
& & 2,24 & 0,769 \\
\hline
\end{tabular}

The analysis showed that in five (out of thirteen) components of the economy, the null hypothesis is rejected, i.e. there are significant differences at mean values of these variables between the two periods of CAP reform ( $p$ values $<0.05$ ). In all these five variables the mean values of the variables regarding the 2014 CAP reform are higher than the corresponding mean values for the 2004 CAP reform. This means that the 2014 CAP reform has a positive effect on these components of the economy. These variables are Land Value-Purchase, Land Value-Hire, Product processing, Labour hands (harvesting, standardization, packaging etc), 
Purchase of pesticides, fertilizers, supplies, etc., and are presented in Table 20.

Table 20. Variables with significant differences between CAP reform of 2004 and 2014.

\begin{tabular}{l|c|c}
\hline Variable & $\begin{array}{c}\text { Mean difference } \\
\text { (CAP 2004-CAP } \\
\text { 2014) }\end{array}$ & $\begin{array}{l}\text { T-Value } \\
\text { (df) }\end{array}$ \\
\hline Land Value-Purchase. & $-0,500$ & $-4,113$ \\
& & $(224)^{*}$ \\
Land Value- Hire. & $-0,290$ & $-2,126$ \\
& & $(225)^{*}$ \\
Product processing. & $-0,287$ & $-2,608$ \\
& & $(218)^{*}$ \\
Labour hands (harvesting, & $-0,373$ & $-2,882$ \\
standardization, packaging) & & $(221)^{*}$ \\
Purchase of pesticides, fertilizers, & $-0,579$ & $-4,389$ \\
supplies, etc. & & $(225)^{*}$ \\
\hline${ }^{*}$ Significant at 5\% significance level.
\end{tabular}

* Significant at 5\% significance level.

In the remaining eight variables (out of the 13 on economy) there are no significant differences between the two CAP reform periods ( $\mathrm{p}$-value $>0.05$ ). This means that the 2014 CAP reform has, on average, the same impact on these variables as the previous 2004 CAP reform. These variables are Manufacturing Industry, Product's transfer, Manufacture of packaging materials, Construction of storage facilities, Purchase of agricultural machinery, accessories, etc., Consumption in the local market, Living standard and Building activity in the area.

\section{Discussion and Conclusions}

Since its establishment, the implementation of CAP has always influenced and affected agriculture and the wider rural sector in a targeted and decisive way. This impact on agricultural and rural sectors, potentially and to a different extent each time, also influenced in many different ways the local economy. Such potential ways that can "transfer" the consequences of the CAP changes / reforms to the Local Economy can include:

- all kinds of inputs of agriculture, which are necessary in the production process of agriculture and livestock farming and which are obviously part of the commercial activity and hence the economy of the region;

- the transportation of the products produced;

- the processing, including the materials incorporated in it as well as the surplus value it entails;

- The trading and export of the produced products;

- The incorporation of work and thus the payment of wages and salaries in production and processing, so thus the payment of wages and salaries;

- In addition to the payment of EU subsidies should be mentioned also the subsistence costs for the survival of farmers and their families as part of the agricultural income generated by their agricultural holdings and which may, to a certain extent, contribute to the Local Economy of either an individual region or the areas of a region;

- the income of the staff employed in a region because of agriculture / stockbreeding (public and private agronomists and veterinarians, staff in banks, staff in cooperative organizations, and so on).
Of course, beyond this theoretical and general wording, it is necessary to follow scientifically the confirmation, exploration and quantification of each parameter that has an effect on the Local Economy and the development of the particular region, to assess on the one hand, whether each change (e.g. a reform) alters the impact for better or the worst, and on the other hand, in order for the resulting conclusions to be used in the next reforms at country level, as we must not forget that the decisions in the EU are the results of collective processes. Additionally, at agricultural holdings level, the use of scientific data can help to draw conclusions so that each of them is better adapted and made more modern, more efficient and, with emphasis on the importance of this word, more competitive.

As noted in the literature review unit, since the announcement of the 2003 CAP reform, the decoupling of subsidies introduced by CAP was expected to launch European, as well as Greek agriculture into a totally new and different situation as EU farmers would have become more competitive and more focused on the markets, while at the same time it would have had a positive impact on local economies since it was reported to provide the necessary income stability in rural areas [32]. However, negative impact on local economy were noted; such as, e.g. the reduction in the profits of commercial grain enterprises due to the reform of the CAP, or even their exit from the market [70] or the decline in productivity but also the avoidance of expensive cultivation work by the producers, resulting in a fall in quality levels and, more generally, the nonconfirmation of the expectations announced at the time of the reform [21]. Later, Crescenzi and Giua, expressed the view that regional development is favoured more in the more developed regions when the EU funds for the EU Regional Development Policy are supplemented by the expenses provide by CAP to these areas [87]. In Greece, it was found that CAP review consequences have an effect on the local economy [4]. Apart from those views, which are mentioned indicatively and which are differentiated according to the time at which they were formulated (i.e. before or after the implementation of the reformed CAP), scientists converge to what Mattas \& Loizou mentioned in 2017 that the CAP measures, in addition the immediate creation of a series of jobs also contribute to maintaining additional jobs, which would otherwise be lost in many regions if CAP did not exist[83]. It is similarly formulated and widely accepted that agriculture is a stabilizer because under the current crisis conditions, it is the only area that can continue to operate successfully [82].

It should be repeated here that the region as an administrative unit and as an area was chosen as a study area for the present scientific study as it is an area suitable for this purpose in terms of its extent, its population (both at the level of farmers, and at the level of the involved scientists) as well as the volume and diversity of its products. In this context, and in order to identify and document the changes in the Local Economy caused as an impact after each CAP reform, as well as to quantify the consequences of the CAP reforms on the local economy and on the course of development of the EMT region, the present scientific study, was organized and materialized as described in the previous chapters. Specifically, the data gathered with appropriate structured questionnaires, were formed after the processing of three factors, which concern the CAP and are correlated with the Local Economy (the CAP factors are: CAP - Pillar I, CAP - Cross-Compliance and CAP - Pillar II), both in 
relation to the 2004 reform, as well as the corresponding one of 2014. These three factors in fact represent, on the one hand, the three units which constitute the most relevant aspects of the applied CAP, and on the other hand, are a pragmatic approach on the part of the farmer, the stockbreeder and the scientist who cooperates with them, who do not only see CAP as a whole in front of them, but individually experience each of these three factors. Thus, the mathematical relationships described in the previous section gain an extra special value as they are not only indirectly estimated factors but also aspects of the CAP, that are individually perceived by each European producer. Briefly, the three CAP-related factors include "Pillar I", the EU's total subsidies given by the EU to farmers and stockbreeders, "Pillar II", the different financial frameworks and measures by which the EU strengthens the development projects through the CAP, actions and investments provided during each planned period, whereas the "CrossCompliance" includes the conditions that must be followed by the eligible farmers and stockbreeders in order to qualify for the subsidies. Within the "Cross-Compliance" framework, environmental issues that are now included in CAP, play a predominant role. Here, of course, one should mention that while the current version of the CAP has already been in force, as far as Pillar I is concerned, since 2014 onwards, the beginning of Pillar II's financial measures implementation follows later, because there is a need for an additional process of preparation but also of notice per measure. So, the image that the producers and the scientists working in the region's agricultural sector have in mind, is one of the measures that have begun implementation, as well as the image from the relevant information provided by the responsible Ministry in relation to the measures included in Pillar II of the specific reformed CAP who's financing could be described as a "bridge" from the previous period to the present one.

Some important aspects that have been adopted in the research process of this scientific study have an innovative character (at least in relation to other scientific studies which examine the impacts of CAP). These include the collection of data relating to a large percentage of the area and consequently the agricultural activity of the region by using appropriate questionnaires. This is accomplished by gathering data with questionnaires from scientists working in the region's agricultural sector and who do not represent a huge number in total, such as EMT's farmers and stockbreeders. As has been explained, each scientist cooperates with a large number of farmers/stockbreeders and can therefore convey a view that reflects the general picture he has formed from his work and through his cooperation with the many farmers with whom he cooperates. The second important aspect in this direction is the use of a qualitative questionnaire in order to form the quantitative questionnaire used to assess the consequences of CAP reforms on the Local Economy. It should be noted here that no such questionnaire was identified in any survey carried out before the first attempt at evaluating the 2003 CAP reform and thus it was decided to form one by conducting a previous qualitative survey through interviews. This approach applied in this scientific study is confirmed by its adoption as the equations that are shaped are comparable among themselves and reflect, as mentioned above, the three main components of CAP as perceived by those experiencing the consequences of the revised CAP forms. The third aspect is the duration of the study, spanning two successive reforms of the evolving CAP so that the changes and consequences of one reform can be correlated with that of the other, as well as addressing development of the region over a period of approximately 14 years. In addition, the most innovative and important aspect in which the study progressed and materialized is the combination of all the three aforementioned aspects. It is noteworthy that the adopted methodology addressed a major difficulty mentioned in the regional description; EMT farmers are not interested in developments taking place in CAP. Instead, their interest is limited solely to the EU subsidies they receive.

On the basis of the above, it can be argued that there would be scientific interest in cases such as the continuous monitoring of the consequences of CAP after each reform in the same or other regions of the country. Furthermore, a particular interest in adopting a corresponding scientific approach would also exist in cases such as, for example, the implementation of national options on the margins provided each time by CAP. It is worth noting that the margins provided for such national options are increasing over time, and according to the new CAP (expected to be implemented by 2020 - see literature review) there is the possibility of a complementary national agriculture policy being added alongside CAP. It should be mentioned here that in the forthcoming CAP reforms, the EU will offer even more choice to the Member States in terms of its implementation but also the possibility of developing complementing national actions alongside CAP in an ancillary base. It should not be overlooked that this possibility already enables some to envision a nationalization of the EU agricultural policy, something that Greece, for obvious reasons, disagrees with. Finally, future studies of this kind could also be carried for other regions of the country for comparison amongst the regions. A comparison between neighbouring regions would be of interest for an exploration of significant variations in the models and equations that would emerge in such cases.

From the processing of the study's data, a significant econometric relationship emerges between CAPs, as it is always in force after its reforms (those implemented in 2004 and 2014) and the Local EMT Economy. This relationship includes, as far as the CAP is concerned, the three factors mentioned above and indeed the formation of two similar econometric relationships with the same factors confirms the validity of the statistical analysis, done via Factor Analysis, Confirmatory Factor Analysis and the configuration of the specific Structural Equation Model. This ascertainment should be linked here to the study's data collection methodology, also based upon the data collected by the scientists working in the rural EMT Region section. In addition, the choice of questions and the processing of the data were based on the qualitative research carried out in the initial phase.

So, it is worth mentioning that all the above derive from and reflect a significant percentage of the region's agriculture that far exceeds $50 \%$ of the agricultural population of EMT. This was achieved by the response of the scientific staff working in the region's agriculture to the survey questionnaires. The importance of this point should be stressed, given the fact that the responses which formed the material on which the statistical analysis was applied, would have been impossible to have been gathered and processed to the same extent by the farmers and stockbreeders of the region. However, such a high percentage of scientific staff, by participating in the study, has in fact also transferred the corresponding views of a 
corresponding percentage of the farmers with whom it collaborates, evaluating it with the potential provided by its scientific background. Based therefore on the econometric relationships and the correlation of the three main components of CAP with the evolving regional development of the region, it can be said that this relationship is both substantive and also de facto scientifically documented.

It is important that the reform which was decided in 2003 and was put into effect in 2004 constituted the most powerful "turbulence" in the system of payments of EU subsidies, among all the CAP reforms launched by the EU because it introduced the decoupling of payments from the EU subsidies, from the production of the agricultural products and the payment of a decoupled single payment subsidy through the introduced SFP scheme (Single Farm Payment). The introduction of the SFP was a radical change and at the same time it shaped and constituted the next basis for the payment of CAP Pillar I subsidies to the next or subsequent reforms. Meanwhile, the next CAP reform (2014) continued to evolve on the basis of the data formed by the previous reform (2003), and this appears to continue (http://www.europa.eu).

It should be clarified that each impact (either positive or negative) of CAP reforms concerns an impact in line with the meaning of the concept of the Local Economy in the present study, of the entire Local Economy and is not limited only to the sectors closely related to agriculture. On the contrary, it also covers areas such as the level of living, the construction activity of the area and other more specific sectors of the EMT region in which the study was conducted. This particular relationship, and in particular the correlation between the impacts of CAP with the local economy, is of particular value as it reflects the role of CAP in relation to the development potential of the areas of the region.

The study of the first econometric relationship, which regards the reformed $2003 \mathrm{CAP}$, the implementation of which started in 2004, demonstrates the statistically significant relationship that exists with the econometric factors formed by the SEM which represent the EU subsidies included in Pillar I, the Pillar II financial measures also the environmental aspects of the CAP, which are included in the Cross-Compliance. The clear mathematical econometric relationship, with the implications caused in the local development of the region, constitutes a case of the Structural Equation Model, where the effect of Pillar I and of the Cross-Compliance has a negative effect, while only Pillar II has a positive impact on the Local Economy. This means that the implementation of Pillar I measures, as formed by the introduction of the Cross-Compliance, had a negative impact on the Local Economy. On the contrary, the implementation of the Pillar II financial measures has had a positive effect. Thus, from the survey carried out it can be argued that the previous way of calculating and paying the subsidies (prior to the reform and introduction of payments through the SFP which constitutes the main reform introduced by the reformed CAP of 2003) had a more positive impact on the local economy.

The most reasonable explanation to be drawn to this conclusion is that the previous CAP status (before 2004) strengthened and supported a version of a more productive and intensified agriculture, with the consequence that the more intensive farming application would involve larger volumes of production, thus, through the activity of the agricultural production sectors as well as the trading of products and all the sectors mentioned above it is concluded that the Local Economy of the region was favoured more. The fact that the specific reform of CAP, in relation to previous ones, had such a radical character that shaped a completely different "atmosphere" in the agricultural act, thereby changing many aspects of the production process. It should not be forgotten that this change was recorded in the answers to the questions concerning the impact on crops selected by the farmers, the practices they adopt, as well as the marked decrease in an interest in innovation and risktaking in new crops or new farming methods, the level of organization and planning of agricultural holdings, which had a negative development. In addition, Bhaskar and Beghin referred, among others, to the farmers' psychology, which was influenced by the developments [18].

It should be noted that the concept of environmental measures, i.e. of Cross-Compliance, which has been shown to have had a negative impact on the local economy, constituted and was seen as a framework of further commitments to the exercise of agriculture. This may be due to the fact that the adoption of environmental measures did not bring the expected benefits to the agricultural environment or to the applied agricultural practice. Besides, all the factors which involve constraints provoke the reaction of those involved in the agriculture production process. Moreover, it should be mentioned that, as noted in the research responses, its implementation in Greece is important and rather problematic, especially in the first years after that reform. Therefore, this may have been a possible reason that the expected benefits did not arise in the agricultural environment and in the applied agricultural practice. In either case, both explanations may exist by complimenting each other. A record should be made here and to the limited information regarding the EU subsidies (CAP-Pillar I) and the Cross-Compliance, which actually does not reach the Greek farmer in good time and for which, as it has been noted previously, the role of the Greek public sector is also limited, but also the interest of the farmers is only limited to the collection of EU subsidies and does not go into detail in order to seek more information about the CAP. Limited information certainly makes less likely the possibility to take action in order for the agricultural holdings to adapt to the resulting framework which therefore maximizes the negative impacts (see Region Description chapter).

The positive impact of the Pillar II financial frameworks provided to farmers gains particular value because it highlights the positive role of these frameworks for the entire local economy and especially at a time when in Greece in general there is an extreme tightness due to the prolonged and multiannual economic crisis. This situation functions in a suffocating way in terms of securing financial resources and wider funding not only for the production process but also for the trading of the agricultural products. Thus, this also highlights the need to maintain Pillar II's measures for a number of reasons, which have to do with and include the encouragement of the introduction of innovations and changes in agricultural holdings, in relation to their proven effectiveness here, but also because of the significant benefit that has been shown that they provide to the Local Economy. In addition, it is important that the financial measures on the one hand have contributed and still contribute to the introduction of innovations and modernization in spite of the existing problems, but also by the increase of the liquidity of the farmers included in these (with the financing of investments), but they also directly create a positive climate towards production as opposed to 
the climate caused by CAP reforms on the basis of the changes introduced to Pillar I, which does not support the production of products but provides subsidies through SFP as a whole, social type of aid to farmers that meet the relevant conditions.

In the same direction, a general reflection is also ascertained concerning the degree of confirmation of the expectations which had been expressed during the announcement of specific reforms, on issues such as the increase of the size and the expanse of agricultural holdings, as well as "securing a bargaining advantage for farmers", but also for a better adaptation of the agricultural holdings to the free market and the competition conditions as it had been announced at the introduction of the specific CAP reform. Based thus on the econometric relationship that emerged it can be argued that the radical breakthrough in the European agriculture, which was brought about by the 2003 reform, with the main factor of the decoupled subsidies, had a negative effect on the Local Economy in the EMT Region as the intensified nature of the agricultural production was limited and the decoupled single payment was actually paid, as mentioned, as an extra-agricultural aid, which apparently did not correlate with the agricultural production, so many agricultural holdings reportedly faced problems of a financial nature of their farming activities, in relation to the regime which existed before the reform of 2003

Regarding 2014, the econometric relationship which came as a result, includes the same factors but also the coefficient remains the same as the mathematical relationship with regard to the 2003 reform of the CAP. Thus, Pillar I has a negative sign with a smaller absolute value, that is, it actually takes a clearly more positive value. The Cross-Compliance still has a negative value with a lower absolute value, i.e., in essence, it also has a more positive value, although the change from 2003 to 2014 is not as great as in the case of the Pillar I factor. Finally, the value of the Pillar II coefficient has increased its already positive value since the 2003 reform, which came into force in 2004. Moreover, the statistical analysis which took place and is described in the relevant unit and relates to the comparison between the factors of the two econometric equations, confirms that all 2014 factors have more positive values, and therefore have a more positive contribution to the Local Economy factor than the previous reform.

The above ascertainment can be explained with the internal convergence applied to the price of allowances, the 'turbulence' caused by the previous reform, up to a point so that the situation was normalized as the money from the EU subsidies did not get collected by those who were assigned the rights during the reference period 2000-2003, but the farmers active in 2014. In this way, the subsidies received by farmers who had not been fortunate to have significant rights from the reference period, has been improved. This situation which was formed after the new reform has given to the farmers and the agricultural holdings the ability to cope better with the new conditions and so this CAP reform has had a more positive impact on the Local Economy and on the local development in the region. An alternative explanation that could be cited is the adaptation, albeit with a considerable time delay, to the conditions created by the radical reform of 2003, e.g. the smoother implementation of the Cross-Compliance, the application of which can also provide benefits to agriculture beyond the commitments it entails. In addition, however, it can be claimed at the same time that both versions may potentially be in force synergistically.
The fact is, however, that the 2014 reform reduced and mitigated the differences among the value of the farmers' rights, which were held by farmers since the previous reform. While at the same time, it also contributed to the reduction of differences between the EU Member States. While Pillar II's financial measures continue reinforcing actions, investments and projects in the agricultural sector. Additionally, Cross-Compliance continued to include the conditions for receiving subsidies, including the environmental aspect of CAP. In the case of the CrossCompliance, the producers have adapted to its requirements, but it probably has also been properly implemented in the region under IACS - Integrated Management and Control System EU subsidies. Based all of this, the impact of 2014 CAP reform implementation on the Local Economy of the areas of the EMT Region is more positive than the previous reform. This is also substantiated by the statistical comparison of the two equations formed for 2004 and 2014.

Given the above conclusions, it is documented that the CAP as a whole, and in particular the changes, affect crop allocation, agricultural production and the agricultural economy, in general. Moreover, these effects are further extended over the local economy in rural areas. It can be accepted that the effects on purely agricultural issues are more direct and clearer and may be studied more easily, but beyond this, CAP effects extend throughout the local economy on rural areas. Overall, however, it can be concluded that the 2004 reform had a negative impact on the Local Economy of the Region, both by changing the method of calculating and paying the subsidies despite the fact that the eligible farmers received decoupled substantial amounts of money from production, as well as with the implementation of the Cross-Compliance as a precondition for the payment of EU subsidies. Then, the next reform of CAP, which was implemented after 10 years, has had a more positive effect on the Local Economy and the local development of the region, both on the basis of the differentiated way of calculating and paying the subsidies and with the implementation of the Cross-Compliance, which was maintained as a condition for receiving the EU subsidies. In both reforms, Pillar II's rural development financial measures seem to have a positive effect, which in the recent reform has noted a further increase.

In general, it can be concluded from the above that the conditions which are conducive to the Local Economy are the conditions which include the granting of more money from the EU subsidies to those who are currently producing instead of receiving the decoupled subsidies on the basis of remote, reference periods. Similarly, the financial measures affecting farmers and the agricultural sector in general play an extremely important role as they not only contribute to the modernization of the holdings and their competitiveness, but also to the development of the Local Economy. It is therefore reasonable to conclude that the rectifications of the EU budgets in CAP Pillar II should always, for developmental reasons in both agriculture and the economy as a whole, ensure sufficient money for these measures and reduce the bureaucracy and other adverse effects that public administration may have on these measures. It should be added here that, on the basis of the above, it is reasonable to conclude that the Local Economy of the particular Region is more positively affected when the CAP money is provided as a subsidy to those who participate in the agricultural production process and produce and not when they are provided as a form of social subsidy to those living in the 
countryside even to former farmers, who have restricted their productive assistance to agriculture nowadays.

Moreover, in the present study, in addition to the overall impact on Local Economy, the differences between 13 sectors of the Local Economy which were affected by the CAP reforms which were implemented in 2004 and 2014, were analyzed in more detail between these two periods. These sectors of the Local Economy were highlighted by the qualitative research that originally took place and included:

$\begin{aligned} & \text { i. } \text { Land value in terms of purchase, } \\ & \text { ii. } \text { Land value in terms of rental, } \\ & \text { iii. The processing of agricultural products, } \\ & \text { iv. The manufacturing industry, } \\ & \text { v. The product transportations, } \\ & \text { vi. The manufacture (and use) of packaging } \\ & \text { materials, } \\ & \text { vii. Manual labour (as an integration of } \\ & \text { agricultural work in harvest, } \\ & \text { viii. The construction of storage facilities, } \\ & \text { ix. The purchase of agricultural machinery, } \\ & \text { accessories, etc., } \\ & \text { x. The purchase of agricultural inputs } \\ & \text { (pesticides, fertilizers, supplies, etc.) } \\ & \text { xi. The consumption on the local market, } \\ & \text { xii. The standard of living } \& \\ & \text { xiii. The construction activity in the region. }\end{aligned}$

All these sectors of the local economy participated in the modelling of the Building Model equations cited above as they participated in the statistical analysis of the data with all the statistical "tools" and methods mentioned but were also examined one by one to better interpret the conclusions given by the two econometric equations (2004 \& 2014).

The analysis showed that in five of these components of the economy, there are significant differences at mean values of these variables between the two periods of CAP reform. In all these five variables the mean values of the variables regarding CAP reform of 2014 are higher than the corresponding mean values of the CAP reform of 2003. This means that except the total CAP reform of 2014, these components of Local Economy have been positively affected by changes arising from reform. These variables are: Land Value-Purchase, Land Value-Hire, Product processing, Labour hands (harvesting, standardization, packaging etc). Purchase of inputs (pesticides, fertilizers, supplies, etc.). Of the remaining eight variables of the economy, there are no significant differences between the two CAP reform periods. This means that the CAP reform of 2014 has, on average, the same impact on these variables as the previous CAP reform of 2003. These variables are: Manufacturing Industry, Product's transfer, Manufacture of packaging materials, Construction of storage facilities, Purchase of agricultural machinery, accessories, etc., Consumption in the local market, Living standard, and Building activity in the area.

Concluding, it should be noted that the recent CAP reform has had a positive influence on the value of land both in terms of purchasing and in terms of renting plots of land. This can be attributed to the fact that the previous reform has limited the intensive nature of farming and production in agriculture, with the result that the demand for agricultural land and hence the value of land to be limited to the need to find land for the activation of the rights held by each farmer. Obviously, this cause does not help to find the most productive, fertile and thus expensive farmland, but simply to find the land with the cheapest rents. So, the value of land fell, and it recovered and regained an increase when agriculture began to return to a smoother and intense pace with the assistance of the next reform, and this is why the statistically significant increase in these sectors was also recorded.

The return of agriculture to a more intense pace seems to explain the statistically significant positive change in the other sectors that were differentiated, that is the processing industry, the labour hands that are needed in the various sectors of the agricultural production such as harvesting, standardization and packaging, etc.) and also the increase in inputs incorporated in the production such as pesticides, fertilizers and other supplies.

In the remaining areas where there was no positive change, three cases could be distinguished. Those requiring large amounts of money, such as the creation of new units within the Manufacturing Industry and Construction of storage facilities, or the availability of significant sums by farmers for the purchase of equipment which not only has a high price but also for which several years are required until its depreciation such as the purchase of agricultural machinery, accessories, etc. Those that do not require significant amounts of money and would reasonably be expected to have a positive development that was not captured by the statistical processing of items such as the Product's transportation and the Manufacture of packaging materials. From these categories, in the first one, it is perhaps reasonable that a positive impact has not yet been recorded at the present time in the first case, as the need for large sums of money and the difficulties of financial strain and bureaucracy (amongst others) have left no room for positive differentiation to be formed. For the second case, a marginal positive change is recorded but this has not been proven as statistically significant and therefore further investigation may be required in these cases.

The third case includes the Consumption in the local market, the Living standard and the Building activity in the area. In this case, it should be noted that these are sectors that are affected by the long-term crisis in Greece and thus it would not have been easy to record a positive development in them as either the extent of the economic crisis should have been limited or there should have been further development of the agriculture and the farming sector more broadly. It is worth arguing that there is probably a positive development in these sectors, but this is not recorded due to the wider financial conditions that have prevailed across the country for many years. However, it is important and must be recorded that none of the thirteen sectors examined has seen a negative change from 2004 to 2014 .

Based on all the above, it should be stated that the 2014 CAP reform, has had a more positive impact on the region's economy. This effect is considered to be more positive in relation to the 2004 reform, which had caused negative consequences on all sectors apart from Pillar II, which relates to the rural development and includes a significant number of financial measures. In the 2014 reform, Pillar I (EU subsidies) and the Cross-Compliance (environmental measures, etc.) had a negative but more positive effect than the one caused by the 2004 reform. Overall, the impact of the CAP as it is in force, disseminates in all sectors of the economy and affects the region's development, but the main areas in which positive developments have been recorded (among those examined) are Land Value-Purchase, Land Value-Hire, Product processing, Labour hands (harvesting, standardization, packaging etc.), Purchase of inputs 
(pesticides, fertilizers, supplies, etc.), which are closely related to agriculture. The effects which take place are always examined under the current economic conditions, which include the multi-annual economic crisis, which plagues the country and causes, among other things, financial constraints, over-taxation and possibly "concealing" some positive effects that may have been recorded if there was no crisis. The recording of the impacts at the local level can be a guide, not only in the case of agricultural policy, but also for other studies on the wider development potential of each region in different sectors.

Overall, the impact of CAP as it applies diffuses in all sectors of the economy and affects the region's course of development. It is noted however, a simultaneously rise in all sectors of the economy as a result of the impact of the 2014 CAP reform as other sectors of the economy start to show improvement, while some other sectors follow later on. However, the main areas in which positive developments have been recorded (among those examined) are Land Value-Purchase, Land Value-Hire, Product Processing, Labour Hands, Purchasing of inputs (pesticides, fertilizers, etc.), which are closely related to agriculture. The effects that are being exercised are always examined under the current economic conditions, which include the multiannual economic crisis, which plagues the country and causes, among other things, financial constraints, overtaxation and possibly concealing some positive effects, which may have been recorded if there was no crisis. The recording of the impacts at the local level can be a guide, not only in the case of agricultural policy, but also for other studies on the wider development potential of each region in different sectors.

Concluding, it should be noted that since the previous reform (2004) of the CAP did not ultimately enhance the increase in production intensification, then the scientific view can be expressed that Greek agriculture and, more specifically, the agriculture in EMT has a far negative impact on the local economy when it is left out of the production, and even as the degree of intensification of the way of production decreases. From here it follows that anything that avoids the intensity of production does not contribute to causing a positive impact of CAP on the local economy. Therefore, emphasis should always be placed on production, or at least ensure that it does not act as a deterrent against it, always under the condition of being subject to the compliance with the environmental requirements set by $\mathrm{CAP}$ and which are included in the Cross-Compliance.

With regard to the available financial "tools" provided to agriculture and the wider rural development under Pillar II, this scientific study shows not only their positive impact on agriculture and the rural sector but also on the local economy of the areas of the region as well as the growing impact from one reform 2003 to the current and applied reform. This conclusion should be added to the benefits of the financial tools and of Pillar II in agriculture, as in this way enhances modernization, both at agricultural holdings level as well as at local, regional and/or national level agriculture, improving competitiveness of the agricultural sector as well as introducing elements of modernization and innovation.

Regarding the applied Cross-Compliance, it can be said from the present scientific paper that, without any significant changes being made to it, its implementation has become normalized over time, and thus the negative impact it initially caused on the local development reduces, without more conclusions being able to be drawn at this point. It is worth noting that the Cross-Compliance, apart from a central EU option in the agricultural sector, constitutes also a decisive step in the sustainable and integrated nature of the European agriculture.

Overall, it should be noted that the more positive impact of CAP reforms on the Local Economy indirectly affects also the behaviour of farmers as each of them, together with their families, understandably wishes to live in a more prosperous area with better quality of life, from where young people will not have the tendency to flee. Thus it emerges that the positive impact of CAP on the Local Economy and the development course of the EMT implies that, in turn, the Improved Local Economy is pushing for the improvement of factors such as the age distribution of the population in these areas (due to the presence of young people in the area); in turn it contributes to better performance, for example, of Pillar II, resulting in a further increase in the positive effect exercised on the Local Economy and the development of the region. This image is important as it refers to the image of an autocatalytic reaction (in scientific terms from the field of Chemistry) which in itself accelerates its implementation. This conclusion, together with the conclusion that subsidies have an even more positive effect on the Local Economy when addressed to the actual producers and not to the holders of old rights, constitute two very important conclusions for the course of the Local Development of the Region. With the same reasoning it can be documented that, on the contrary, whatever negatively affects the Local Economy, it negatively affects every farmer, and this is again transferred as a negative impact on the economy of the region.

As a conclusion, it should also be noted the important observation that even the positions of the country's representatives (at all levels) in the EU institutions dealing with the CAP reform must be taken into account and used in the placements and proposals that they formulate or to the ones which accept the impact of all these on both farming and stockbreeding, as well as on the wider Local Economy in all regions of the country where data exists, such as those provided in the current study. In any case, it is significant to ensure a positive impact on the Local Economy as well as in sectors such as the absorption of labour, that is, of employment or, conversely, the reduction of the existing unemployment, which, due to the prolonged and chronic economic crisis, is at extremely high levels. Here, therefore, a wider reflection arises, as it should now be sought during the discussion of CAP reforms, certainly what serves the needs and prospects of the Greek agriculture and livestock as long as it can be appreciated by this or any other scientific approach and what is secondary to the Local Economy of the areas of the Greek region. Typically, the benefits of labour absorption or the resulting reduction in unemployment have multiplicative benefits in every sector of the economy, both under normal economic conditions and even more in crisis conditions as they have a wider multiplicative character in the whole economy.

This scientific study aims to analyze and document the views of the producers through the scientific potential of EMT. However, as stated previously, the interest of the Greek farmer in the CAP in advance (before it starts being implemented), is extremely limited and is limited exclusively to the subsidies paid. This finding is worrying, and efforts should be made to ensure that the Greek farmer seeks more information on his own accord about CAP and about the developments and reforms related to it. 
Briefly, therefore, it can be repeated that with the current scientific study, it was found that:

- The CAP as it developed after the two ongoing reforms had an effect on the Local Economy and the course of development of the areas of EMT;

- $\quad$ The impact of implementing CAP Pillar I (payment of SFP subsidies and decoupling) and the impact of implementing Cross-Compliance introduced by the 2004 CAP, was negative on the Local Economy. However, a positive effect on Local Economy have occurred as a result of the financial measures included in CAP Pillar II;

- The situation is the same for the CAP that was applied after the 2014 reform, pointing out that the impact of both Pillar I and of the CrossCompliance was less negative, whereas the impact of CAP Pillar II was even more positive.

- Overall, the reform of the 2014 CAP has had a more positive impact on the Local Economy in the EMT region than the previous reform (which was launched in 2004).

- The subsidies payment method in the SFP system, had since 2004 a negative impact on the Local Economy and the course of development in EMT, which was moderated with the implementation of the 2014 reform. The situation for the CrossCompliance is similar too. Whereas, the CAP Pillar II financial tools show that they are increasing the already positive impact of the CAP on the Local Economy and the development of the region by implementing these two successive reforms.

- From the sub-sectors of the Local Economy, the analysis showed that in five (5) of the 13 sectors examined, there was a statistically significant improvement from the implementation of the 2004 reform to the implementation of the 2014 reform, and these are Land Value-Purchase, Land ValueHire, Product processing, Labour harvesting, Purchasing of inputs (pesticides, fertilizers, supplies, etc.). Whereas none of the other 8 sectors showed an unfavourable development since the first reform which was examined (implementation since 2004) to the second (implementation since 2014).

This is an Open Access article distributed under the terms of the Creative Commons Attribution License

\section{References}

[1] M. Petrick, "The Co-evolution of Semantics and Policy Paradigms: 50 Years of Europe's Common Agricultural Policy," Intereconomics, vol. 43, no. 4, pp. 246-252, Jul. 2008.

[2] L. George, "REPORT on the future of the Common Agricultural Policy after 2013 (2009/2236(INI))." EUROPEAN PARLIAMENT, 21-Jun-2010.

[3] "The common agricultural policy at a glance," European Commision. [Online]. Available: https://ec.europa.eu/info/foodfarming-fisheries/key-policies/common-agricultural-policy/capglance_en. [Accessed: 11-Oct-2018].

[4] T. Markopoulos, S. Papadopoulos, C. Karelakis, K. Galanopoulos, and K. Mattas, "The Effects of the Reformed C.A.P. to Cereal Crops:," Int. J. Food Beverage Manuf. Bus. Models, vol. 2, no. 2, pp. 1-12, Jul. 2017.

[5] M. Konstandinos and L. Efstratios, "Agriculture: a powerful tool of rural development in the current economic crisis," Mar-2013.

[6] M. Tracy and M. Tracy, Government and agriculture in Western Europe, 1880-1988, 3rd ed. New York: Harvester Wheatsheaf, 1989.

[7] K. Van der Heijden, Ed., International food safety handbook: science, international regulation, and control. New York: Marcel Dekker, 1999.

[8] M. N et al., "Sustainable agriculture in a developed countryside: a ten year strategy for the agricultural development of Greece," Greek Minist. Agric., 2002.

[9] N. N. Maraveyas and Y. El. Doukas, "Traceability and the new CAP," no. 698-2016-47844, p. 8, 2009

[10] "Hellenic Ministry of Rural Development and Food," Hellenic Ministry of Rural Development and Food. [Online]. Available: http://www.minagric.gr/index.php/en/. [Accessed: 11-Oct-2018].

[11] A. F. Amores and I. Contreras, "New approach for the assignment of new European agricultural subsidies using scores from data envelopment analysis: Application to olive-growing farms in Andalusia (Spain)," Eur. J. Oper. Res., vol. 193, no. 3, pp. 718-729, Mar. 2009.

[12] C. Charlier and E. Valceschini, "Food Safety, Market Power and Private Standards: An Analysis of the Emerging Strategies of Food Operators," Int. J. Food Syst. Dyn., vol. 1, no. 2, pp. 1-8, 2010.

[13] D. Ahner and M. Scheele, "The Common Agricultural Policy: An overview from where we come, Where we are, Tasks ahead.," presented at the uropean Agricultural Policy in Transformation, Wageningen University, 2000.
[14] B. Kupker, S. Huttel, W. Kleinhanss, and F. Offermann, "Assessing impacts of CAP reform in France and Germany," Ger. J. Agric. Econ., vol. 55, no. 5-6, pp. 1-11, 2006.

[15] E. Schmid and F. Sinabell, "On the choice of farm management practices after the reform of the Common Agricultural Policy in 2003," J. Environ. Manage, vol. 82, no. 3, pp. 332-340, Feb. 2007.

[16] European Commission, "Study inventory of certification schemes for agricultural products and foodstuffs." 2010.

[17] JOHAN F.M. SWINNEN, "A FISCHLER REFORM OF THE COMMON AGRICULTURAL POLICY?” S EPTEMBER-2001.

[18] A. Bhaskar and J. C. Beghin, "How Coupled Are Decoupled Farm Payments? A Review of the Evidence," J. Agric. Resour. Econ., vol. 34, no. 1, pp. 130-153, 2009.

[19] A. Lindgreen and M. Hingley, "The impact of food safety and animal welfare policies on supply chain management: The case of the Tesco meat supply chain," Br. Food J., vol. 105, no. 6, pp. 328-349, Jul. 2003.

[20] K. Mattas, C. Fotopoulos, V. Tzouvelekas, S. Loizou, and K. Polymeros, "The dynamics of crop sectors in regional development: The case of tobacco," Int. Adv. Econ. Res., vol. 5, no. 2, pp. 255-268, May 1999.

[21] T. Markopoulos, "The reform of the common agricultural policy and its effects on agricultural production with particular emphasis on the cultivation of cereals," DUTH, Greece, 2016.

[22] R. J. F. Burton and G. A. Wilson, "Injecting social psychology theory into conceptualisations of agricultural agency: Towards a post-productivist farmer self-identity?," J. Rural Stud., vol. 22, no. 1, pp. 95-115, Jan. 2006.

[23] S. Huettel and A. Margarian, "Structural change in the West German agricultural sector," Agric. Econ., vol. 40, pp. 759-772, Nov. 2009.

[24] T. MARKOPOULOS, C. KARELAKIS, K. GALANOPOULOS, and K. MATTAS, "Did The 2004 Cap Reform Affect Production Practices Of Cereals? Insights From The Agricultural Input Suppliers," Sci. Bull. - Econ. Sci., vol. 14, no. 2, pp. 71-83, 2015.

[25] N. Maravegias and M. Tsinisizelis, New European Union, Organisation and Politics, 50 years. Themelio, 2007.

[26] L. B. Jacobsen, "Do support payments for organic farming achieve environmental goals efficiently?," in Organic agriculture: sustainability, markets and policies. OECD workshop on organic agriculture, Washington, D.C., USA, 23-26 September 2002, O. Oecd, Ed. Wallingford: CABI, 2003, pp. 345-364. 
[27] I. Hodge and P. Midmore, "Models of Rural Development and Approaches To Analysis Evaluation And Decision-Making," Économie Rurale, no. 307, pp. 23-38, Dec. 2008.

[28] M. Rizov, "Rural development and welfare implications of CAP reforms," J. Policy Model., vol. 26, no. 2, pp. 209-222, Feb. 2004.

[29] M. Rizov, "Rural development perspectives in enlarging Europe: The implications of CAP reforms and agricultural transition in accession countries," Eur. Plan. Stud., vol. 14, no. 2, pp. 219 238, Feb. 2006.

[30] K. Happe, Agricultural policies and farm structures: agent-based modelling and application to EU-policy reform. Halle (Saale): Inst. für Agrarentwicklung in Mittel- und Osteuropa, 2004.

[31] E. Erjavec, S. Kavčič, D. Regoršek, L. Bartová, and AGMEMOD Partnership, Impact analysis of the CAP reform on the main agricultural commodities: report I: AGMEMOD - summary report. Luxembourg: Office for Official Publications of the European Communities : European Commission : Joint Research Centre: Institute for Prospective Technological Studies IPTS, 2008.

[32] Kanellopoulos P., "European Union's Loyalty," 2003.

[33] Mousis N., "European Union, loyal, economy, policy," 2008.

[34] J. F. M. Swinnen and Centre for European Policy Studies, Eds., The perfect storm: the political economy of the Fischler reforms of the Common Agricultural Policy. Brussels: Centre for European Policy Studies, 2008.

[35] Stefan Tangermann, "Agricultural Policies in OECD Countries 10 Years After the Uruguay Round: How Much Progress?"

[36] A. Swinbank and R. B. Tranter, "Decoupling EU Farm Support: Does the New Single Payment Scheme Fit within the Green Box?," Estey Cent. J. Int. Law Trade Policy, vol. 6, no. 1, pp. 1$15,2005$.

[37] G. Philippidis, "The economic cost of the CAP revisited," Agric. Econ., vol. 25, no. 2-3, pp. 375-385, Sep. 2001.

[38] K. Happe, A. Balmann, K. Kellermann, and C. Sahrbacher, "The Use of Agent-Based Modelling to Establish a Link between Agricultural Policy Reform and Structural Change," no. 7332016-50658, p. 27, 2005.

[39] E. Feinerman and M. H. C. Komen, "Agri-environmental Instruments for an Integrated Rural Policy: An Economic Analysis," J. Agric. Econ., vol. 54, no. 1, pp. 1-20, Mar. 2003.

[40] P. Conforti, F. de Filippis, and L. Salvatici, "The Mid-Term Review Of The Common Agricultural Policy: Assessing The Effects Of The Commission Proposals," National Institute of Agricultural Economics, Italy - INEA, Osservatorio Sulle Politiche Agricole dell'UE, Working Papers 14802, 2002.

[41] K. B. Matthews, K. Buchan, D. G. Miller, and W. Towers, "Reforming the CAP-With area-based payments, who wins and who loses?," Land Use Policy, vol. 31, pp. 209-222, Mar. 2013.

[42] S. Mary, "Assessing the Impacts of Pillar 1 and 2 Subsidies on TFP in French Crop Farms: Assessing the Impacts of Pillar 1 and 2,” J. Agric. Econ., vol. 64, no. 1, pp. 133-144, Feb. 2013.

[43] Copus, Andrew K et al., "Study on Employment in Rural Areas," May 2006.

[44] PAOLO SCKOKAI and DANIELE MORO, "MODELLING THE CAP ARABLE CROP REGIME UNDER UNCERTAINTY," DI ECONOMIA AGRO-ALIMENTARE UNIVERSITÀ CATTOLICA, 29100 PIACE ZA N - ITALY, O DI ECONOMIA AGRO-ALIMENTARE UNIVERSITÀ CATTOLICA, 29100 PIACENZA - ITALY, May 2002.

[45] M. Lobley and A. Butler, "The impact of CAP reform on farmers' plans for the future: Some evidence from South West England," Food Policy, vol. 35, no. 4, pp. 341-348, Aug. 2010.

[46] D. Ballas, G. P. Clarke, and E. Wiemers, "Spatial microsimulation for rural policy analysis in Ireland: The implications of CAP reforms for the national spatial strategy," $J$. Rural Stud., vol. 22, no. 3, pp. 367-378, Jul. 2006.

[47] Erwin Schmid and Franz Sinabell, "Implications of the CAP Reform 2003 for Rural Development in Austria,” Aug. 2004.

[48] Erwin Schmid and Franz Sinabell, "Organic farming and the new CAP - results for the Austrian agricultural sector," Copenhagen, Denmark, 2005, p. 13.

[49] Erwin Schmid, Markus F. Hofreither, and Franz Sinabell, "Impacts of CAP Instruments on the Distribution of Farm Incomes - Results for Austria," University of Natural Resources and Applied Life Sciences Vienna, University of Natural Resources and Applied Life Sciences Vienna ,Austrian Institute of Economic Research, Jänner 2006.
[50] P. Lehoux and S. Blume, "Technology Assessment and the Sociopolitics of Health Technologies," J. Health Polit. Policy Law, vol. 25, no. 6, pp. 1083-1120, Dec. 2000.

[51] SLI, "Utvärdering av ett investeringsstöd till livsmedelsindustrin.”2001.

[52] Rasha Gustavsson, Helena Johansson och, and Lennart Persson, "Landsbygdsutveckling- en analys av projekt för ökad sysselsättning," Livsmedelsekonomiska institutet, 2004.

[53] Joakim Gullstrand, "Regional inkomstutveckling och ekonomisk koncentration - med fokus på jordbruket," Livsmedelsekonomiska institutet, 2004.

[54] J. Morison, R. Hine, and J. Pretty, "Survey and Analysis of Labour on Organic Farms in the UK and Republic of Ireland," Int. J. Agric. Sustain., vol. 3, no. 1, pp. 24-43, Jan. 2005.

[55] Hasler, B., Jensen, J.D., Madsen, B., Andersen, M., Huusom, H., and Jacobsen, B.L., "Scenarios for rural areas development -an integrated modelling approach.," 2002.

[56] K. Pietola, "Timing and type of exit from farming: farmers' early retirement programmes in Finland," Eur. Rev. Agric. Econ., vol. 30, no. 1, pp. 99-116, Mar. 2003.

[57] M. Vare, "Spousal Effect and Timing of Retirement," J. Agric. Econ., vol. 57, no. 1, pp. 65-80, Mar. 2006.

[58] W. Britz, T. Heckelei, and I. Perez Dominguez, "Effects of decoupling on land use: an EU wide, regionally differentiated analysis. Landnutzungseffekts von Entkopplung: Eine EU-weite, regional differenzierte Analyse," Ger. J. Agric. Econ., no. 6702016-45689, p. 12, 2006.

[59] C. Benjamin, C. Gueguen, and M. Houee, "World Cereals Markets Under Alternative Common Agricultural Policy Reforms," International Association of Agricultural Economists, 2003 Annual Meeting, August 16-22, 2003, Durban, South Africa 25913, 2003.

[60] Häring, A.M., Bichler, B., and Dabbert, S., "The impact of organic production methods on farm structure in the EU: A descriptive analysis based on farm survey data for 2000.," Sep. 2003.

[61] J. Abildtrup, A. Dubgaard, and K. S. Andersen, "CASE STUDY: GREEN ROADS TO GROWTH Support to organic farming and bio-energy as rural development drivers." INSTITUTE OF FOOD AND RESOURCE ECONOMICS THE ROYAL VETERINARY AND AGRICULTURAL UNIVERSITY, 2006.

[62] F. Offermann and H. Nieberg, Economic performance of organic farms in Europe. Stuttgart-Hohenheim: Inst. für Landwirtschaftliche Betriebslehre, 2000.

[63] A. Gohin, "Assessing CAP Reform: Sensitivity of Modelling Decoupled Policies," J. Agric. Econ., vol. 57, no. 3, pp. 415-440, Sep. 2006.

[64] M. van Leeuwen and T. Fellmann, Potential impacts on agricultural commodity markets of an EU enlargement to Turkey: extension of the AGMEMOD model towards Turkey and accession scenario. Seville: European Commission, Joint Research Centre, Institute for Prospective Technological Studies, 2011.

[65] P. Howley, J. Breen, and C. O. Donoghue, "Does the single farm payment affect farmers' behaviour? A macro and micro analysis," Int. J. Agric. Manag., vol. 2, no. 1, p. 57, 2012.

[66] L. Latruffe, A. Dupuy, and Y. Desjeux, "What would farmers' strategies be in a no-CAP situation? An illustration from two regions in France," J. Rural Stud., vol. 32, pp. 10-25, Oct. 2013.

[67] Judez, Lucinio, de Andres, Rosario, Ibanez, M., De Miguel, J.M., Miguel, J.L., and Urzainqui, Elvira, "Impact Of The Cap Reform On The Spanish Agricultural Sector," Nov. 2008.

[68] I. J. Lorite and M. Arriaza Balmón, "Effects of the decoupling of the subsidies on agricultural water productivity," European Association of Agricultural Economists, 2008 International Congress, August 26-29, 2008, Ghent, Belgium 44017, 2008.

[69] Azucena GRACIA, Tiziana de MAGISTRIS, and José María CASADO, "THE EFFECT OF THE NEW SINGLE FARM PAYMENT IN IRRIGATED AGRICULTURE: THE CASE OF SPAIN," Centro de Investigación y Tecnología Agroalimentaria de Aragón (CITA) Avda Montanana 930, 50059 Zaragoza, Spain, Feb. 2008.

[70] M. Crescimanno, V. De Stefano, and A. Galati, "Possible Future Scenarios For Sicilian Cereal Cropping In The Light Of Current Trends In Agricultural Policy Of The European Union," European Association of Agricultural Economists, 109th Seminar, November 20-21, 2008, Viterbo, Italy 44804, Nov. 2008. 
[71] P. Ciaian, d'Artis Kancs, and S. G. y Paloma, "Income Distributional Effects of CAP Subsidies: Micro Evidence from the EU," Outlook Agric., vol. 44, no. 1, pp. 19-28, Mar. 2015.

[72] S. Kilian, J. Anton, N. Roder, and K. Salhofer, "Impacts Of 2003 Cap Reform On Land Prices: From Theory To Empirical Results," European Association of Agricultural Economists, 109th Seminar, November 20-21, 2008, Viterbo, Italy 44808, Nov. 2008.

[73] D. Psaltopoulos, E. Balamou, and K. J. Thomson, "Rural?Urban Impacts of CAP Measures in Greece: An Inter-regional SAM Approach," J. Agric. Econ., vol. 57, no. 3, pp. 441-458, Sep. 2006.

[74] E. Giannakis and S. Efstratoglou, "An input-output approach in assessing the CAP reform impact of extensive versus intensive farming systems on rural development: The case of Greece," Agric. Econ. Rev., vol. 12, no. 1, 2011.

[75] S. Severini and A. Tantari, "How direct payments and their reform have affected farm income inequality in Italy?," Italian Association of Agricultural and Applied Economics (AIEAA), 2012 First Congress, June 4-5, 2012, Trento, Italy 124099, 2012.

[76] A. Gocht et al., "EU-wide Economic and Environmental Impacts of CAP Greening with High Spatial and Farm-type Detail," $J$. Agric. Econ., vol. 68, no. 3, pp. 651-681, Sep. 2017.

[77] J. Blomquist and M. Nordin, "Do the CAP subsidies increase employment in Sweden? estimating the effects of government transfers using an exogenous change in the CAP," Reg. Sci. Urban Econ., vol. 63, pp. 13-24, Mar. 2017.

[78] A. Vastola et al., "A comparative multidimensional evaluation of conservation agriculture systems: A case study from a Mediterranean area of Southern Italy," Land Use Policy, vol. 68, pp. 326-333, Nov. 2017.

[79] D. Bertoni, G. Aletti, G. Ferrandi, A. Micheletti, D. Cavicchioli, and R. Pretolani, "Farmland Use Transitions After the CAP Greening: a Preliminary Analysis Using Markov Chains Approach," Land Use Policy, vol. 79, pp. 789-800, Dec. 2018.

[80] V. J. Pereira and D. Martinho, "Insights from over 30 years of common agricultural policy in Portugal," Outlook Agric., vol. 46, no. 3, pp. 223-229, Sep. 2017.

[81] E. Kelly et al., "Sustainability indicators for improved assessment of the effects of agricultural policy across the EU: Is FADN the answer?," Ecol. Indic., vol. 89, pp. 903-911, Jun. 2018.

[82] K. Mattas and E. Tsakiridou, "Shedding fresh light on food industry's role: the recession's aftermath," Trends Food Sci. Technol., vol. 21, no. 4, pp. 212-216, Apr. 2010.

[83] K. Mattas and E. Loizou, "The CAP as a Job Stabiliser," EuroChoices, vol. 16, no. 3, pp. 23-26, Dec. 2017.

[84] G. Tsantopoulos, C. Karelakis, E. Zafeiriou, and D. Tsoulakaki, "Mapping the Rural Problem and Development: What do Greek Landowners Think?," Procedia Econ. Finance, vol. 9, pp. 208 $218,2014$.

[85] M. Vrahnakis, S. Nasiakou, Y. Kazoglou, and G. Blanas, "A conceptual business model for an agroforestry consulting company," Agrofor. Syst., vol. 90, no. 2, pp. 219-236, Apr. 2016.

[86] “Overview of CAP Reform 2014-2020," DG Agriculture and Rural Development, Unit for Agricultural Policy Analysis and Perspectives., 2013.

[87] R. Crescenzi and M. Giua, "The EU Cohesion Policy in Context: Regional Growth and the Influence of Agricultural and Rural Development Policies," SSRN Electron. J., 2014.

[88] G. Alons and P. Zwaan, "New Wine in Different Bottles: Negotiating and Selling the CAP post-2013 Reform: New wine in different bottles," Sociol. Rural., vol. 56, no. 3, pp. 349-370, Jul. 2016.

[89] J. Vapa-Tankosic and M. Stojsavljevic, "EU common agricultural policy and pre-accession assistance measures for rural development," Ekon. Poljopr., vol. 61, no. 1, pp. 195-210, 2014.
[90] C. Nazzaro and G. Marotta, "The Common Agricultural Policy 2014-2020: scenarios for the European agricultural and rural systems," Agric. Food Econ., vol. 4, no. 1, Dec. 2016.

[91] A. Bisaga And S. Sokołowska, "The Role Of Instruments Of The Common Agricultural Policy To Ensure Stability Of Commercial Agricultural Holdings And Development Of Rural Areas A Case Study Of Opole Province," Ekon. Śr., vol. 64, no. 1, pp. 110-120, 2018.

[92] B. Piotr, B.-B. Aneta, and D. James W, "Price volatility of Polish agricultural commodities in the view of the Common Agricultural Policy," Agric. Econ. Zemédélská Ekon., vol. 64, no. No. 5, pp. 216-226, May 2018.

[93] T. Kuhmonen, "Systems view of future of wicked problems to be addressed by the Common Agricultural Policy," Land Use Policy, vol. 77, pp. 683-695, Sep. 2018.

[94] B. Rudloff and M. Brüntrup, "Fair play: the recent common agricultural policy and its limited effect on development. (SWP Comment, 21/2018).," Berl. Stift. Wiss. Polit. -SWP-Dtsch. Inst. Für Int. Polit. Sicherh., 2018.

[95] G. Lampiris, C. Karelakis, and E. Loizou, "Evaluation of the impacts of CAP policy measures on a local economy: The case of a Greek region," Land Use Policy, vol. 77, pp. 745-751, Sep. 2018.

[96] D. Skuras, E. Dimara, and S. Stathopoulou, "Capital subsidies and job creation in rural areas: A Greek case study," Int. J. Manpow., vol. 24, no. 8, pp. 947-963, Dec. 2003.

[97] N. C. Baltas, "The Welfare Effects of the Berlin Cap Agreement on Greek Agriculture.," Glob. Econ. GROWTH Crit. Eval., vol. Ch17, pp. 241-256, 2002.

[98] Ferdinand Fasterding and Daniela Rixen, "Analyse der Beschäftigungsmöglichkeiten im Agrarsektor Deutschlands und Beschäftigungseffekte agrarpolitischer Maßnahmen," May 2005.

[99] Andrew Copus et al., "Study on Employment in Rural Areas Final Deliverable," May 2006.

[100] Alessandro Corsi and Cristina Salvioni, "Effects of the CAP Reform on Off-Farm Labour Participation," University of Torino, Italy, and CHILD , University of Chieti-Pescara, Italy, Aug. 2012.

[101] A. F. Tulla, A. Vera, A. Badía, C. GUIRADO, and N. Valldeperas, "Rural And Regional Development Policies In Europe : Social Farming In The Common Strategic Framework ( Horizon 2020 ),, 2014.

[102] G. Medina and C. Potter, "The nature and developments of the Common Agricultural Policy: lessons for European integration from the UK perspective," J. Eur. Integr., vol. 39, no. 4, pp. 373388, Jun. 2017.

[103] G. J. P. van Breukelen and M. J. J. M. Candel, "Calculating sample sizes for cluster randomized trials: We can keep it simple and efficient!," J. Clin. Epidemiol., vol. 65, no. 11, pp. 12121218, Nov. 2012.

[104] Markopoulos, T., Fotidis, I., Kotsopoulos, T., Nikita Martzopoulou, Ch., and Martzopoulos G., "«Comparison of three Alternative Scenarios, for the Utilization of low Enthalpy Geothermal Field in Eratino-Kavala, Greece».," 2009.

[105] Directorate-General for Research and Innovation, "Gendered Innovations. How Gender Analysis Contributed to Research," European Commission, Brussels.

[106] S. Papadopoulos and T. Markopoulos, "Factors Affecting the Implementation of Integrated Agriculture in Greece," Procedia Econ. Finance, vol. 33, pp. 269-276, 2015.

[107] R. E. Schumacker and R. G. Lomax, A beginner's guide to structural equation modeling, 3rd ed. New York: Routledge, 2010.

[108] K. G. Jöreskog, U. H. Olsson, and F. Y. Wallentin, Multivariate Analysis with LISREL. Cham: Springer International Publishing, 2016.

[109] “The Common Agricultural Policy (CAP)." European Parliament. 


\section{Appendix}

Table A.1: Table A.1: The main changes proposed in the Proposal for a Regulation on Strategic Plans for the forthcoming revision of the CAP 2021-2027 [109]

\begin{tabular}{|c|c|}
\hline REGULATION & CHANGE-CHALLENGE \\
\hline $\begin{array}{l}\text { Explanatory } \\
\text { Memorandum }\end{array}$ & $\begin{array}{l}\text { Member States are obliged to allocate } \mathbf{3 0} \% \text { of Pillar I payments for the allocation of additional } \\
\text { payments under four voluntary schemes for farmers: } \\
\text { - } \quad \text { organic agriculture, } \\
\text { - } \quad \text { permanent pastures, } \\
\text { - } \quad \text { areas with natural constraints and } \\
\text { linear elements of the landscape }\end{array}$ \\
\hline $\begin{array}{l}\text { Explanatory } \\
\text { Memorandum }\end{array}$ & $\begin{array}{l}\text { Member States should pay particular attention to: } \\
\text { - } \quad \text { specific environmental and climate objectives, } \\
\text { - } \quad \text { renewal of the generations and } \\
\text { modernization of policy implementation, with emphasis on better use of the know-how. } \\
\text { advice and new (digital) technologies }\end{array}$ \\
\hline $\begin{array}{l}\text { ARTICLE } 4 \\
\text { Definitions which will } \\
\text { be formulated in the } \\
\text { CAP strategic plans }\end{array}$ & $\begin{array}{l}\text { Definitions: } \\
\text { - of the rural activity, } \\
\text { - of the rural area, } \\
\text { - of the eligible hectares, } \\
\text { - of the real farmer and } \\
\text { of the young farmer }\end{array}$ \\
\hline $\begin{array}{l}\text { ARTICLE } 14 \\
\text { Types of intervention } \\
\text { in the form of direct } \\
\text { subsidies }\end{array}$ & $\begin{array}{l}\text { The decoupled direct subsidies are as follows: } \\
\text { a) basic income support for sustainability, } \\
\text { b) complementary support for the distributional income for sustainability, } \\
\text { c) supplementary income support for young farmers, } \\
\text { d) climate and environmental programs. } \\
\text { The associated direct subsidies are as follows: } \\
\text { a) coupled income support, } \\
\text { b) specific subsidy for the cultivation of cotton. }\end{array}$ \\
\hline $\begin{array}{l}\text { ARTICLE } 15 \\
\text { Reduction of subsidies }\end{array}$ & $\begin{array}{l}\text { Member States shall reduce the amount of direct subsidies granted to a farmer for a given calendar } \\
\text { year in excess of } \mathbf{6 0 , 0 0 0} \text { EUR as follows: } \\
\text { a) by at least } 25 \% \text { for the part between } 60,000 \text { EUR and } 75,000 \text { EUR } \\
\text { b) by at least } 50 \% \text { for the part between } 75,000 \text { EUR and } 90,000 \text { EUR } \\
\text { c) by at least } 75 \% \text { for the part between } 90,000 \text { and } 100,000 \text { EUR } \\
\text { d) by } 100 \% \text { for the amount exceeding } 100,000 \text { EUR. }\end{array}$ \\
\hline $\begin{array}{l}\text { ARTICLE } 18 \\
\text { Subsidy amount per } \\
\text { hectare }\end{array}$ & $\begin{array}{l}\text { Member States may decide to vary the amount of the basic income support per hectare among the } \\
\text { different groups of regions which are facing similar socio-economic or agronomic conditions. }\end{array}$ \\
\hline $\begin{array}{l}\text { ARTICLE } 19 \\
\text { Subsidy entitlements }\end{array}$ & $\begin{array}{l}\text { Member States that have implemented the basic subsidy scheme, may decide to grant the basic } \\
\text { income support under the payment entitlements. } \\
\text { When Member States which have implemented the basic subsidies scheme, decide not to grant basic } \\
\text { income support under payment entitlements, the payment entitlements granted expire on } 31 \\
\text { December } 2020 \text {. }\end{array}$ \\
\hline $\begin{array}{l}\text { ARTICLE } 20 \\
\text { Value of subsidy } \\
\text { entitlements and } \\
\text { convergence }\end{array}$ & $\begin{array}{l}\text { Member States determine the unit value of the subsidy entitlements before convergence by } \\
\text { adjusting the value of the subsidy entitlements in proportion to their value for the } 2020 \text { claim year and } \\
\text { the related subsidies for the agricultural practices beneficial for the climate and the environment } \\
\text { foreseen for the } 2020 \text { application year. } \\
\text { Member States may decide to vary the value of the subsidy entitlements. } \\
\text { Member States shall, until the application year } 2026 \text { at the latest, set a ceiling on the value of the } \\
\text { subsidy entitlements for the Member State or for each group of territories. } \\
\text { When the value of the subsidy entitlements is not a uniformed one inside a Member State or within of } \\
\text { each group of territories, the Member States shall ensure that the value of the subsidy } \\
\text { entitlements converges to a single unit price by } 2026 \text { at the latest. } \\
\text { Member States shall ensure that, until } 2026 \text { at the latest, all subsidy entitlements have a value of at } \\
\text { least } 75 \% \text { of the average unit base amount for the basic income support for the application year } \\
2026 \text {. } \\
\text { Member States shall finance the increases in the value of the subsidy entitlements required for } \\
\text { compliance. } \\
\text { Member States may decide to apply the reduction on the whole or to a part of the } \\
\text { subsidy entitlements. } \\
\text { The reductions are based on objective and non-discriminatory criteria. These criteria may } \\
\text { include the fixing of a maximum reduction which may not be less than } 30 \% \text {. }\end{array}$ \\
\hline
\end{tabular}


ARTICLE 20

Reserve subsidy entitlements

\section{ARTICLE 25}

Single subsidy for small farmers

ARTICLE 26

Supplementary support for the distribution of income for sustainability

\section{ARTICLE 28}

Climate and environmental programs

\section{ARTICLE 60 \\ Intervention Types}

\section{ARTICLE 70}

Risk management tools

Each Member State that decides to grant the basic income support under the payment of subsidy entitlements manages a national reserve.

Member States shall determine the value of the new subsidy entitlements allocated from the reserve at the national average value of the subsidy entitlements in the allocation year or at the average value of the subsidy entitlements for each group of territories.

Member States can support small farmers, as defined by the Member States with a one-off lump sum.

Member States shall ensure that support is redistributed from larger to smaller or medium-sized agricultural holdings in the form of an annual decoupled subsidy per chosen hectare to eligible farmers under basic income support.

Member States provide support for voluntary climate and environmental programs ("ecological programs").

Member States shall draw up a list of agricultural practices which are beneficial to the climate and the environment.

Member States choose one or more of the following types of intervention in their strategic plans for the CAP:

a) the establishment and / or renewal of mutual funds by the producers' organizations.

b) harvest and production insurance which helps to ensure the producers' income in the event of damage resulting from natural disasters, adverse climate conditions, diseases or pests, while at the same time ensuring that the necessary precautionary measures are taken by the beneficiaries. Member States may grant:

a) financial contributions to insurance premiums,

(b) financial contributions to mutual funds.

Member States may decide to transfer:

a) up to $15 \%$ of the allocation of the Member State for direct subsidies, after deducting the allocations for cotton, for the calendar years 2021 to 2026 in the EAFRD allocation of the

ARTICLE 90

Flexibility between allocations of direct subsidies and EAFRD allocations
Member State for the financial years 2022 to 2027; or

b) up to $15 \%$ of the EAFRD Member State allocations in the financial years $2022-2027$ in the allocation of direct subsidies for the calendar years 2021 to 2026.

The rate of transfer from the Member State's allocation for direct subsidies to the EAFRD allocation, which is mentioned in the first subparagraph, may be increased by:

a) up to 15 percentage points, provided that Member States use the corresponding increase for the EAFRD-funded interventions and manage the specific environmental and climate objectives,

b) up to 2 percentage points, provided that Member States use the corresponding increase to Article 86 (b) paragraph 4 of this Regulation (NEW FARMERS).

Table A.2: Factor analysis results

\begin{tabular}{|c|c|c|c|}
\hline $\begin{array}{c}\text { N. of factor } \\
\text { analysis }\end{array}$ & $\begin{array}{l}\text { Factor } \\
\text { Code }\end{array}$ & Factor & Cronbach's $a$ \\
\hline \multirow[t]{2}{*}{1} & M1 & Product Production & 0.801 \\
\hline & M2 & Output Reduction & - \\
\hline 2 & M3 & Differentiation & 0.609 \\
\hline \multirow[t]{2}{*}{3} & M4 & Human Resources & 0.802 \\
\hline & M5 & Farms & 0.795 \\
\hline \multirow[t]{3}{*}{4} & M6 & Application Accuracy & 0.843 \\
\hline & M7 & Financial Consequences & 0.749 \\
\hline & M8 & Impact & 0.589 \\
\hline \multirow[t]{2}{*}{5} & M9 & Farm Income from winter cereals & 0.893 \\
\hline & M10 & Farm Income from summer cereals & 0.747 \\
\hline \multirow[t]{4}{*}{6} & M12 & Market Bodies & 0.919 \\
\hline & M13 & Marketing Practices & 0.646 \\
\hline & M14 & Marketing Problems & - \\
\hline & M15 & Climate Impact & - \\
\hline
\end{tabular}


Th. Markopoulos/Journal of Engineering Science and Technology Review 12 (2) (2019) 185 - 223

\begin{tabular}{|l|l|l|r|}
\hline \multirow{3}{*}{7} & M45 & Areas in dependence on Agriculture & 0.898 \\
\cline { 2 - 4 } & M46 & Boarder Sectors & 0.827 \\
\cline { 2 - 4 } & M47 & Land Value & 0.777 \\
\hline
\end{tabular}

This factor consists of only one item, so Cronbach's a cannot be extracted. 